\title{
Oxidation of Stressed Polymers as Studied by Chemiluminescence
}

\author{
Karin Jacobson
}

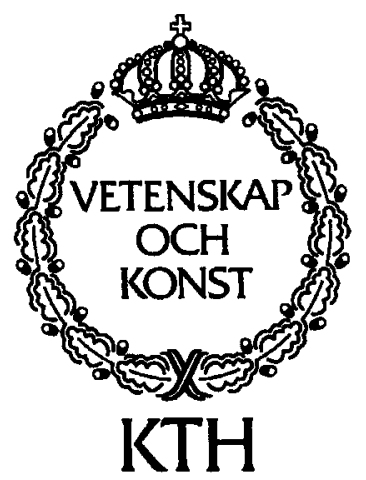

\section{Department of Polymer Technology Royal Institute of Technology Stockholm 1999}

\begin{abstract}
Akademisk avhandling
som med tillstånd av Kungliga Tekniska Högskolan framlägges för offentlig granskning för avläggande av doktorsexamen fredagen den 17 september 1999, kl. 10.00 i Kollegiesalen, Administrationsbygganden, Vallhallavägen 79, KTH, Stockholm. Avhandlingen försvaras på engelska.
\end{abstract}




\title{
Oxidation of Stressed Polymers as Studied by Chemiluminescence
}

\author{
Karin Jacobson \\ Department of Polymer Technology, Royal Institute of Technology, \\ Stockholm, Sweden
}

\begin{abstract}
Since the use of chemiluminescence (CL) is known to be a very sensitive technique for studying oxidation of polymers, its potential as a tool for studying the oxidation of stressed polymers is thoroughly investigated in this thesis. A number of earlier reports on stress induced chemiluminescence (SCL) show that SCL has potential for elucidating polymer stress reactions. However, the conclusions as to the origin of the light and the effect of stress drawn in these reports are quite ambiguous.

The papers summarised in this thesis can be divided into two parts. Papers I, II, II and IV deal with the construction of a specially designed SCL instrument and the origin of the luminescence emitted from some polymers during tensile testing. This luminescence was shown to have different sources reflected in the names: chemiluminescence, thermoluminescence, triboluminescence. It could also be a superposition of two or all three phenomena. The chemiluminescence was shown to originate mainly from hydroperoxide decomposition due to stress-induced adiabatic heating, which after necking is localised in the travelling neck shoulders. This CL was thus not an effect of direct stress. However, some CL was also found to be due to radical formation at fracture, i.e. directly caused by stress. The thermoluminescence proved to be a result of radiation from fluorescent light tubes and was negligible if the specimens were kept in the dark prior to a measurement. The triboluminescence was found to be emitted from irradiated specimens in which stress helped to recombine separated charges.
\end{abstract}

Papers V and VI deal with how sub-yield stresses influence the oxidative degradation of polymers. In order to attain significant oxidation within a reasonable time, the process was accelerated by an elevated temperature. The materials studied were injection moulded parts of polyamide, polypropylene and high density polyethylene. Polyamide was also studied as film, in which there is no restricted oxygen diffusion. It was shown that stress did not change the course of oxidation in any of the materials.

In addition to these papers, which all deal with stress chemiluminescence, parts of two papers [VII and VIII], which discuss other specific features of the chemiluminescence technique are also included in the thesis.

Keywords: Stress, chemiluminescence, oxidative degradation, load, oxidation, thermoluminescence, triboluminescence, polyamide, PA6, PA66, polyethylene, HDPE, polypropylene, $\mathrm{PP}$, hydroperoxides, charge recombination. 


\section{LIST OF PAPERS}

This thesis is a summary of the following papers:

I Jacobson, K., Färnert, G., Stenberg, B., Terselius, B. \& Reitberger, T., Stress-Induced Chemiluminescence Instrument for the Study of Oxidation of Polymers Subjected to Stress, Polymer Testing, 1999, 18, 523.

II Jacobson, K., Stenberg, B., Terselius, B. \& Reitberger, T., StressInduced Chemiluminescence from Injection Moulded Polyamide 66 and Polypropylene, Polym. Deg. Stab., 1999, 64, 17.

III Jacobson, K., Stenberg, B., Terselius, B. \& Reitberger, T., Fracture of some Polymers as Studied with Stress Chemiluminescence (SCL), submitted to Polymer International, 1999.

IV Jacobson, K., Stenberg, B., Terselius, B. \& Reitberger, T., The Influence of Thermoluminescence on Stress-Induced Chemiluminescence Measurements of Injection Moulded Polyamide 66 and Polypropylene, Polym. Deg. Stab., 1999, 65, 107.

V Jacobson, K., Stenberg, B., Terselius, B. \& Reitberger, T., Oxidation of Stressed Polyamide 6 Film as Measured by StressChemiluminescence (SCL), Polym. Deg. Stab., 1999, 65, 449.

VI Jacobson, K., Stenberg, B., Terselius, B. \& Reitberger, T., Oxidation of Stressed Injection Moulded Polyolefins and Polyamide 6 as Measured by Chemiluminescence, submitted to Polym. Deg. Stab., 1999.

It also contains parts of the following papers:

VII Jacobson, K., Eriksson, P., Stenberg, B. \& Reitberger, T., Influence of Moisture on the Oxidation of Polyamide 6 Film as Measured by Chemiluminescence, in manuscript.

VIII Ahlblad G., Jacobson K. \& Stenberg B., Accelerated ageing of nitrilebutadiene rubber studied by chemiluminescence, Plast. Rubber Comp., Proc. \& Appl., 1996, 25, 464. 


\section{INTRODUCTION}

The life time of polymeric materials is limited. A number of factors are responsible for the detoriation of material properties, such as oxidative degradation, thermal degradation, UV irradiation and mechanical load. Since a large number of polymeric products are used in load-bearing constructions placed out doors in different types of climates, all these factors can limit their service life. It is often necessary for designers of polymeric products to estimate the service life of a material in its particular function and environment.

Different degradation mechanisms are known to work synergistically; e.g. UV irradiation is known to accelerate both oxidative and mechanical degradation. There is also a prevailing theory that stress accelerates oxidative degradation.

\subsection{Purpose of Study}

The major aim of this study has been to increase our knowledge of how stress influences the oxidation of polymers. Another important aim has been to understand the mechanisms that cause luminescence from stressed polymers. Many observations of this latter phenomenon has been reported in the literature.

The chemiluminescence (CL) technique has been used as the major analytical tool since it is known to be one of the most sensitive techniques for studying low levels of oxidative degradation of polymers. A special instrument for stress-induced chemiluminescence (SCL) measurements had to be developed for the study since no such instrument was commercially available.

The papers included in this study can be divided into two main parts:

- The use of SCL technique to study luminescence emitted during tensile testing of injection moulded specimens [papers I, II, III, and IV]

- Oxidative degradation under constant load [papers V and VI]

In addition to these papers, which all deal with stress chemiluminescence, two papers [papers VII and VIII], which discuss other specific features of the chemiluminescence technique are also included in the study.

\subsection{Materials}

\subsubsection{Polyamides}

The development of polyamides originates from W. H. Carothers' experiments on condensation polymerisation in 1928 [Carothers, 1928]. Polyamides are characterised by the -CONH- structural unit and are frequently refered to as Nylons. The word Nylon is sometimes claimed to originate from Carothers' comment after producing the first polyamide fibre "Now You Lousy Old Nippons". Linear polyamides are formed by a condensation reaction of bifunctional monomers. Polymers from aminoacids are called $\mathrm{AB}$ types of which polyamide 6 (PA6 or 
polycaprolactam) is of great commercial importance. Polymers formed from a condensation reaction between a diamin and a diacid are called AABB types. Polyamide 66 (PA66) made from hexamethylenediamine and adipic acid is the most important polyamide of this type. In the experiments reported on in this study both PA6 and PA66 were used.

The production, properties and applications of PA6 and PA66 are very similar. However, there is a difference in upper use temperature due to the difference in melting point between PA6 $\left(225^{\circ} \mathrm{C}\right)$ and PA66 $\left(265^{\circ} \mathrm{C}\right)$. Higher nylons (PA610, PA612, PA11 and PA12) have significantly lower stiffness and heat resistance than PA6 and PA66 but have instead improved chemical resistance and lower moisture absorption.

Polyamides are mainly used as fibres in textile goods and as engineering plastics in a large variety of applications, e.g. bearings, gears and hinges. Both as plastics and as fibres polyamides are characterised by a combination of high strength, elasticity, toughness and abrasion resistance. Good mechanical properties are maintained up to $150^{\circ} \mathrm{C}$. The solvent resistance is good, but polyamides are hygroscopic and degrade by hydrolysis at elevated temperatures. Moisture strongly affects the glass transition temperature $\left(\mathrm{T}_{\mathrm{g}}\right)$ of polyamides and acts as a plasticiser increasing the flexibility and toughness. The density of polyamides is generally $1.14 \mathrm{~g} / \mathrm{cm}^{3}$.

[Billmeyer, 1984]

\section{2. 2 Polypropylene (PP)}

The discovery of co-ordination polymerisation by Ziegler [Ziegler 1955] and Natta [Natta 1955] made production of polypropylene possible in 1957. Commercial exploitation was very rapid, with the material becoming widely used as fibres, film, and injection mouldings. Today polypropylene is one of the four largest volume plastic materials in use.

Due to the pendant methyl group in the repeating unit of polypropylene

$-\left[\mathrm{CH}_{2-}\right.$ $\mathrm{CH}\left(\mathrm{CH}_{3}\right)$ ]- the polymer can be made in isotactic, sydiotactic and atactic form. The crystallisability of isotactic polypropylene makes it the only form with properties of any commercial interest worth mentioning. Isotactic polypropylene is an essentially linear polymer with high crystallinity. The sterical hindrance of the methyl group makes the polymer crystallise in the form of helices. This crystal structure is the reason for the low density $\left(0.90-0.91 \mathrm{~g} / \mathrm{cm}^{3}\right)$. The methyl groups also stiffen the backbone, thus increasing the crystalline melting point $\left(\sim 165^{\circ} \mathrm{C}\right)$ and the glass transition temperature $\left(\sim-10^{\circ} \mathrm{C}\right)$. As a result polypropylene, as compared with high density polyethylene (HDPE) which does not have pendant methyl groups, has a higher softening point, room temperature modulus, and hardness. The methyl groups in polypropylene also increase the chemical reactivity as compared with HDPE. The presence of tertiary hydrogen reduces its oxidative stability and facilitates chain scission during thermal and high energy treatments.

[Billmeyer, 1984; Brydson, 1995; Klason and Kubat, 1995] 


\subsubsection{High Density Polyethylene (HDPE)}

Co-ordination polymerisation, as discussed above for polyproylene, also made the production of the linear material HDPE possible in 1957. Polyethylene is the plastic material produced in the largest quantity today, and HDPE accounts for about $40 \%$ of the total polyethylene production. HDPE has higher stiffness and heat resistance than low density polyethylene (LDPE) and has replaced LDPE in applications where these properties are important.

HDPE is highly crystalline (over 90\%) with a melting point of $140^{\circ} \mathrm{C}$ and a density in the range of $0.95-0.97 \mathrm{~g} / \mathrm{cm}^{3}$ as compared with $0.91-0.94 \mathrm{~g} / \mathrm{cm}^{3}$ for LDPE. The main attractive features of the material, in addition to its low price, are good chemical resistance, excellent electrical insulation properties, easy processing, toughness and flexibility. HDPE is mainly used as material for bottles, containers, pipes, wire and cable insulation. It can also appear in the form of film and sheets.

[Billmeyer, 1984; Brydson, 1995]

\section{3 Polymer Degradation}

The degradation of polymeric materials often limits their service life. To improve their durability the mechanisms responsible for their degradation must be understood. Degradation occurs as the result of an environment-dependent chemical or physical attack. The mechanism can be very complex since it may involve a number of chemical and physical reactions. In out door applications polymers can for example be exposed to UV light, elevated temperatures and chemical attacks from air pollutants as well as mechanical stress. The understanding of the degradation mechanisms is further complicated by factors such as morphology, diffusion processes and interactions of additives. Degradation can be desirable in special applications such as in biomedical, hygienic and packaging products [Albertsson and Huang, 1995; Hakkarinen, 1996; Palmgren, 1997]. However, in most applications degradation is an undesirable process [Scott, 1965; White and Turnbull, 1994; Clough et al, 1996].

\subsubsection{Oxidative Degradation}

Of all degradation mechanisms oxidation is one of the most important. The first report on oxidative degradation of polymers was made by Hoffman in 1861 [Hoffman, 1861]. He found that the perishing of natural rubber involves absorption of oxygen. Since then oxidative degradation has been extensively studied and a number of text books cover the topic [Scott, 1965; Reich and Stivala, 1969; Rànby and Rabek, 1975; Jellinek, 1978; Allen, 1983; Scott, 1993; Clough et al, 1996].

\section{Autoxidation}

The strict definition of autoxidation is auto-initiated oxidation by molecular oxygen, but the word is commonly used to describe the reaction of oxygen with organic materials by a free radical process [Scott, 1965]. Oxidation of hydrocarbon polymers is often characterised by a period with a low oxidation rate, which is fairly equal to the service life of the material. This period can be shortened by addition of initiators, e.g. peroxides, and prolonged by addition of antioxidants and stabilisers [Al-Malaika, 1993]. The rate of oxidation will normally increase after the first initial 
period due to the build-up of hydroperoxide concentration, and eventually decrease again, often to a constant level; see Figure 1.1.

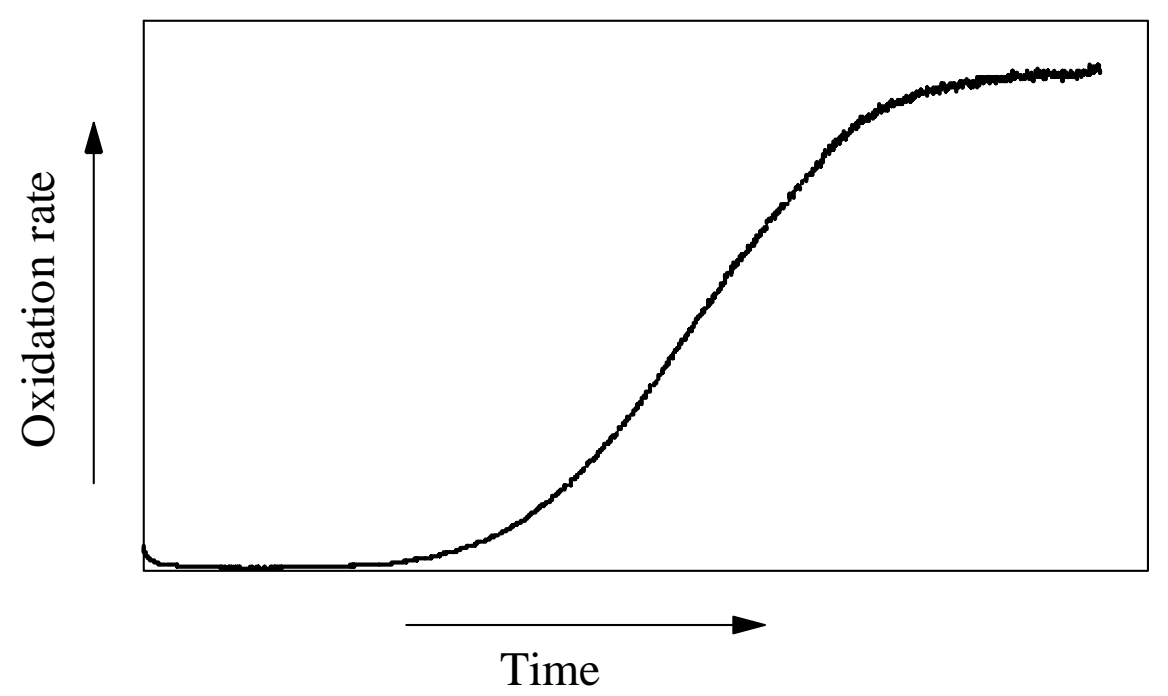

Figure 1.1 A typical curveof the rate of polyproylene oxidation.

The oxidation rate of hydrocarbons is usually very low at ambient temperatures in the dark. The free radical chain reaction is often initiated thermally, photochemically, mechanically or by high energy radiation. Presence of chemical impurities, cross-links, functional groups and unsaturations increases the rate of degradation. Thus factors that determine the susceptibility to oxidative degradation is the polymer structure and the content of impurities.

During processing, e.g. injection moulding or extrusion, polymers are not only subjected to high temperatures but also to shearing forces causing thermal and mechanical degradation and formation of macroradicals [Scott, 1995]. The radicals produced during processing will react with dissolved or atmospheric oxygen. The material can thus contain oxidation products, e.g. peroxides and carbonyls, right from the start of their service life [Chakraborty and Scott, 1977].

In the 1940s the basic autoxidation scheme (BAS) was developed. It is based on a free radical chain reaction developed from extensive studies of low molecular hydrocarbons [Bolland and Gee, 1946; Bolland, 1949; Bateman, 1954]. The scheme has been modified to describe polymer oxidation [Scott, 1965] and has been used to characterise polymer degradation under different environmental conditions [Reich and Stivala, 1969; Rånby and Rabek, 1975; Kamiya and Niki, 1978; Al-Malaika, 1993; Gillen et al, 1995]. The scheme is, however, based on liquid solutions with homogeneous kinetics. The degradation of solid polymers is influenced by the restricted mobility of radicals, morphological variations and the enhanced sensitivity of oxidation products on further oxidation and becomes heterogeneous in character [Buchachenko, 1976; Billingham, 1989; Ahlblad, 1998]. 
Three different steps can be distinguished in the autoxidation scheme: initiation, propagation, and termination:

\begin{tabular}{|c|c|c|c|}
\hline Initiation & $\begin{array}{l}\text { Polymer } \\
\text { ROOH } \\
2 \mathrm{ROOH}\end{array}$ & $\begin{array}{l}\rightarrow \\
\rightarrow\end{array}$ & $\begin{array}{l}\mathrm{R} \cdot \\
\mathrm{RO} \cdot+\cdot \mathrm{OH} \\
\mathrm{RO} \cdot+\mathrm{RO}_{2} \cdot+\mathrm{H}_{2} \mathrm{O}\end{array}$ \\
\hline Propagation & $\begin{array}{l}\mathrm{R} \cdot+\mathrm{O}_{2} \\
\mathrm{RO}_{2} \cdot+\mathrm{RH}\end{array}$ & $\rightarrow$ & $\begin{array}{l}\mathrm{RO}_{2} \cdot \\
\mathrm{ROOH}+\mathrm{R}\end{array}$ \\
\hline Termination & $\begin{array}{l}\mathrm{R} \cdot+\mathrm{R} \cdot \\
\mathrm{R} \cdot+\mathrm{RO}_{2} \\
\mathrm{RO}_{2}+\mathrm{RO}_{2} \cdot\end{array}$ & $\begin{array}{l}\rightarrow \\
\rightarrow\end{array}$ & $\begin{array}{l}\text { Products } \\
\text { Products } \\
\text { Products }+\mathrm{O}_{2}\end{array}$ \\
\hline
\end{tabular}

\section{Initiation}

Autoxidation is initiated by the production of radicals. Radicals are formed when chemical bonds are broken. The scission requires energy from, for example, heat, UV light, stress, or high energy radiation. Weak links, i.e. bonds with lower bond dissociation energy than normal, will be those most susceptible to scission.

$$
\text { Polymer } \quad \rightarrow \quad \text { R. }
$$

The radicals formed will react either with other radicals or more probably with oxygen due to its higher concentration and availability. The reaction with oxygen results in the production of polymer peroxides, mainly hydroperoxides. The peroxides will decompose when heated or irradiated, yielding free radicals which can initiate autoxidation. The decomposition can proceed homolytically (reaction IIa) or bimolecularly (reaction III). The dominating reaction pathway depends on hydroperoxide concentration and reaction temperature [Bateman et al, 1952 \& 1953; Reich and Stivala, 1969; Al-Malaika, 1993]. A number of authors have also found the closeness to adjacent hydroperoxides to be decisive [Chien and Jabloner, 1968; Zlotova and Denisov, 1971; Gijsman et al, 1993; Kron, 1996].

$$
\begin{array}{lll}
\mathrm{ROOH} & \rightarrow & \mathrm{RO}+\cdot \mathrm{OH} \\
2 \mathrm{ROOH} & \rightarrow & \mathrm{RO}+\mathrm{RO}_{2} \cdot+\mathrm{H}_{2} \mathrm{O}
\end{array}
$$

Hydroperoxide decomposition has also been found to be catalysed by transition metal impurities, usually metal catalyst residues left from production (reaction IIb and IIc) [Kamiya, 1966; Hiatt et al, 1968; Reich et al, 1971, Carlsson and Wiles, 1976].

$$
\begin{array}{lr}
\mathrm{ROOH}+\mathrm{M}^{\mathrm{n}+} \rightarrow & \mathrm{RO}+\mathrm{M}^{(\mathrm{n}+1)+}+\mathrm{OH}^{-} \\
\mathrm{ROOH}+\mathrm{M}^{(\mathrm{n}+1)+} \rightarrow & \mathrm{RO}_{2}+\mathrm{M}^{\mathrm{n}+}+\mathrm{H}^{+}
\end{array}
$$




\section{Introduction-}

In addition, hydroperoxides and carbonyls are known to act as UV cromphores, initiating photo-oxidation

\section{Propagation}

The initiation step is followed by a propagation cycle, which proceeds by consumption of oxygen by the material. The cycle of radical chain reactions is outlined in Figure 1.2.

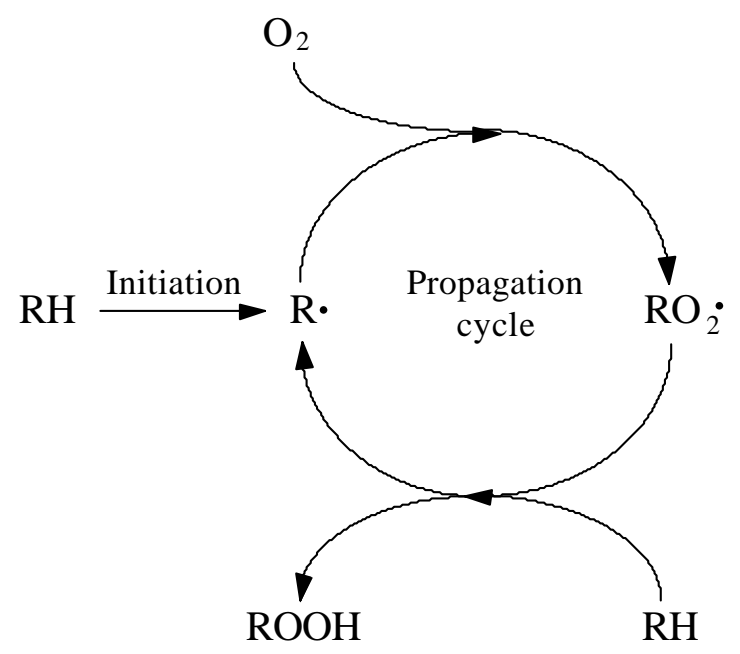

Figure 1.2. The autoxidation cycle.

The reaction between an alkyl radical and oxygen is usually very rapid since oxygen is a diradical, which makes the reaction essentially a radical coupling Reich and Stivala, 1969]. The reaction is almost independent of temperature but depends on the oxygen pressure and on the radical structure [Miller and Mayo, 1956; Hendry and Russell, 1964].

$$
\mathrm{R} \cdot+\mathrm{O}_{2} \quad \rightarrow \quad \mathrm{RO}_{2}
$$

The produced peroxyl radical can abstract a hydrogen atom from the polymer producing a hydroperoxide and a new macro radical, which can start another propagation cycle until all oxygen is consumed.

$$
\mathrm{RO}_{2}+\mathrm{RH} \quad \rightarrow \quad \mathrm{ROOH}+\mathrm{R} .
$$

The abstraction may be either intramolecular by abstraction of a hydrogen atom from the same polymer chain or intermolecular by abstraction from an adjacent molecule [Rust, 1957; Van Sickle et al, 1972 \& 1973]. Hydrogen abstraction, reaction $\mathrm{V}$, requires more energy than reaction IV and is thus the rate-determining step in the autoxidation cycle [Kamiya and Niki, 1978]. The rate of reaction V depends on the bond dissociation energy of the abstracted hydrogen and steric and polar effects [Ingold, 1967]. Tertiary hydrogens are more easily abstracted than secondary and primary hydrogens, and thus polymers with many tertiary hydrogens, e.g. polypropylene, are more susceptible to oxidative degradation than, for example, polyethylene [Al-Malaika, 1993]. Since reaction V has a higher 
activation energy that reaction IV it is also more dependent on temperature. Increasing the rate of reaction $\mathrm{V}$ will increase the number of propagation cycles before termination (kinetic chain length) and the yield of hydroperoxides [Kamiya and Niki, 1978]. An increasing amount of hydroperoxides will lead to an increasing amount of initiating species. At a critical hydroperoxide concentration the overall rate of oxidation increases; see Figure 1.1. At this stage secondary oxidation products such as carbonyls can be detected.

\section{Termination}

The propagation cycle is terminated by a recombination of two radicals yielding nonradical products.

$$
\begin{array}{ll}
\mathrm{R} \cdot \mathrm{R} \cdot & \rightarrow \\
\mathrm{R} \cdot+\mathrm{RO}_{2} \cdot & \rightarrow \\
\mathrm{RO}_{2}+\mathrm{RO}_{2} \cdot & \rightarrow
\end{array} \quad \text { Non-radical products }
$$

Under normal oxygen pressure and moderate temperatures reaction VIII is the predominating termination reaction since reaction $\mathrm{V}$ is rate-determining and peroxyl radicals are the dominating radical species. Reactions VI and VII can be ignored under these conditions unless oxygen access is limited by, for example, diffusion or when the alkyl radical is very stable towards reaction with oxygen. If this is the case, reaction VI predominates and autoxidation becomes a function of oxygen concentration. At intermediate oxygen pressure all three termination reactions contribute [Al-Malaika, 1993].

Recombination of two peroxyl radicals (reaction VIII) commonly proceeds via an intermediate tetroxide.

(VIIIa)

$$
2 \mathrm{RO}_{2} \cdot \quad \rightarrow \quad \text { ROOOOR }
$$

Primary peroxyl radicals react faster than secondary radicals, which in their turn react faster than tertiary radicals. When at least one of the peroxyl radicals is primary or secondary, the tetroxide, through a cyclic transition state, decomposes into a ketone, an alcohol, and a molecule of oxygen. This reaction is generally referred to as the Russell mechanism [Russell, 1957]; see reaction VIIIb in section 1.4.2. If both peroxyl radicals are tertiary, the reaction is more complex. The tertiary peroxyl radicals can decompose by beta-scission and then by hydrogen abstraction yield primary or secondary radicals, which in turn can react with the substrate, resulting in further propagation or in reaction with another tertiary peroxyl radical in a termination step [Al-Malaika, 1993].

\section{Specific Features of Solid State Oxidation}

As mentioned briefly above, the oxidation of polymers does not for a number of reasons follow the simple homogeneous kinetics of low molecular hydrocarbon oxidation. Polymers are solid materials in which the diffusion of molecules and radicals is highly restricted. The availability of oxygen, due to diffusion limitations, can for example be lower in the bulk of the material than at the surface, resulting in 
an oxidation profile through the sample [Gillen and Clough, 1989; Ahlblad, 1998]. The depletion of oxygen in the bulk, due to limited diffusion, depends on thickness, material, and temperature. The effect is, for example, almost negligible for polyolefins at room temperature but becomes more important at higher temperatures, since then the consumtion of oxygen is faster, whereas the solubility of oxygen is lower [Billingham and Calvert, 1982].

Semicrystalline polymers such as polyolefins and polyamides are inhomogeneous two-phase materials. The tightly packed, dense crystal lamellae of these polymers are more or less impermeable to oxygen. As a result the diffusion coefficient of oxygen strongly depends on the degree of crystallinity. Oxygen together with low molecular weight substances, will be concentrated in the interlamellar amorphous regions of the polymer. These regions also contain reactive unsaturated and oxidised groups excluded from the lamellar crystal. Oxidation is thus limited to the amorphous regions and to the surfaces of the crystallites [Buchachenko, 1976; Billingham and Calvert, 1983]. Even though this is true for most polymers, in particular the ones discussed in this work, i.e. polypropylene, polyethylene and polyamides, there are exceptions. Billingham et al [Billingham et al 1976] have shown that in poly (4-methyl-pentene-1) the crystalline regions oxidise more rapidly than the amorphous ones.

Non-homogeneous distribution of initiating species, e.g. metal ion impurities and other impurities, will also lead to inhomogeneous oxidation. The oxidation starts in one spot and spreads outwards by propagation resulting in a localised oxidation zone generally referred to as a "hot spot". As a result a polymer sample can have lost its mechanical properties but still remain unoxidised in most parts [Richters, 1970; Billingham and Calvert, 1982; Billingham, 1989].

A further reason for heterogeneous oxidation is uneven distribution of the stabiliser due to consumption, solubility, diffusivity, or physical loss by evaporation or blooming [Bair, 1973; Billingham and Calvert, 1982; Viebke, 1996]

\section{Oxidation of Polyolefins}

As discussed previously, polypropylene is more susceptible towards oxidative degradation than polyethylene owing to its higher number of tertiary, and thus more easily abstractable, hydrogens. Degradation can result in either chain scission or crosslinking, the predominating reaction being determined by the oxidation conditions, temperature, and polymer. Polypropylene is more susceptible to chain scission than polyethylene, which has a higher tendency towards cross-linking [Adams, 1970; Holmström and Sörvik, 1976; Charkraborty and Scott, 1977].

\section{Oxidation of Polyamides}

Extensive work has been done to elucidate the mechanisms of the photo- and thermooxidation of polyamides [Sharkey and Mochel, 1959, Levantovskaya et al, 1964; Karstens and Rossbach, 1989; Forsström, 1999]. According to the generally accepted radical chain mechanism, the initiation step is a hydrogen abstraction from the most susceptible hydrogen, which is the hydrogen on the $\mathrm{N}$-vicinal methylene group. 


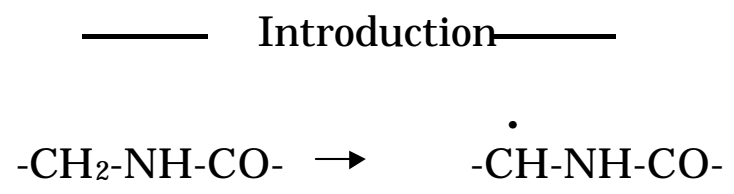

On its reaction with oxygen this radical will form a peroxyl radical.

\section{Embrittlement due to Oxidation}

Practically the service life of a polymer ceases because of a decrease in mechanical properties. This decrease is often rapid and usually takes place at the end of the induction period. There is, however, not a very clear correlation between embrittlement and production of oxidation products or oxygen uptake.

Embrittlement of polymeric materials is not fully understood, but it is quite clear that chain scission in the amorphous interlamellar layers is responsible for the transition from ductile to brittle fracture [Billingham and Calvert, 1982 \& 1983]. Thus, a brittle oxide skin will facilitate the initiation of stress cracks during creep at low stress levels.

\section{Accelerated Ageing}

In order to be able to study oxidative degradation within a feasible time frame, it is often necessary to accelerate the degradation. The acceleration can be brought about by heat, UV light, mechanical stress, or high energy radiation, i.e. factors which are known to promote the degradation of polymers; see section 1.3. Thermal acceleration by so called oven ageing is the most common way to promote oxidative degradation. The results from these experiments can then be interpolated with the Arrhenius equation to give an interpretation of the reactions at the actual service temperature. One major problem is, however, that the reactions at the accelerating temperature are not necessarily the same or of the same proportions as those at the service temperature. This could lead to very inaccurate conclusions as to the life time of a polymer or the effectiveness of a stabiliser [Gugumus, 1987; Gijsman, 1994]. As mentioned above, in the section Specific Features of Solid State Oxidation, the diffusion limited oxidation, which might lead to heterogeneous oxidation, is also very temperature-related. At room temperature the effect is almost negligible but at higher temperatures it is often very obvious [Billingham and Calvert, 1982].

\subsubsection{Stress-Induced Degradation}

Degradation is known to be increased by mechanical stress. If a chemical bond is put under sufficiently high stress, it will break. However, even though this phenomenon is well known and well studied, it is still not well understood. It is also noteworthy that high elastic straining of a chain can only be achieved if the chain cannot relieve stresses internally by change of conformation or externally by slippage [Kauch, 1978].

Mechano-chemical phenomena in polymers have been known for a long time. Observations of degradation of natural rubber during mastication was reported by Staudinger in 1929 [Staudinger, 1929]. Kauzman and Eyring [Kauzmann and Eyring, 1940] suggested that mechanical rupture of primary bonds was possible during mastication of natural rubber and that the produced free radicals would recombine unless stabilised by admission of oxygen. Watson and co-workers 
recognised the importance of mechano-degradation of rubbers [Pike and Watson, 1952] and plastics [Ceresa and Watson, 1959] during their fundamental studies of mastication. By the development of the electron spin resonance (ESR or EPR) technique, which can count and characterise free radicals, extensive work on mechano-chemical degradation was carried out during the 1960s and 70s [Bresler et al, 1959; Zhurkov et al, 1964; Butyagin et al, 1965; Peterlin, 1971; Lloyd et al, 1972 \& 1974; Rånby and Rabek, 1977; Kauch, 1978]. It was found that mechanical treatment of polymers, e.g. stretching, tearing, grinding, milling, sawing, and fatiguing, causes chain scissions leading to formation of macro-radicals, which in turn cause degradation and/or cross linking [Terselius et al, 1986]. Environmental stress cracking, discoloration, and embrittlement are often due to bond rupture [Casale and Porter, 1978].

Eyring and co-workers [Glasstone et al, 1941] described the concept of flow in terms of thermally activated jumps of molecules across an energy barrier, and with this theory they laid the foundation to fracture kinetics. Tobolsky and Eyring [Tobolsky and Eyring, 1943] considered the general decrease in secondary bonds, while Zhurkov and co-workers [Zhurkov et al, 1953, 1955a \& 1955b] and Bueche [Bueche, $1955,1957 \& 1958]$ considered the primary bonds to be the strength-controlling factor. These authors arrived at an Arrhenius type expression [Zhurkov et al, 1972], characterised by a subtraction from the activation energy for scission of an interatomic bond term, $\mathrm{U}_{0}$, a quantity that is proportional to the applied stress, $\sigma$. The expression is generally referred to as the Zhurkov equation. It is based on an experimentally established relation between life time, $\tau$, of a solid under tensile stress, $\sigma$, and absolute temperature, $\mathrm{T}(\mathrm{K})$ :

$$
\tau=\tau_{0} \exp \left[-\left(\mathrm{U}_{0}-\gamma \sigma\right) / \mathrm{RT}\right]
$$

where $\tau_{0}$ is the period of the thermal oscillations of the bonded atoms and $\gamma$ is a structural coefficient which defines the actual loads in the stressed body. Zhurkov [Zhurkov et al, 1972] claimed that the microprocess of polymer fracture proceeds in three stages: (1) deformation of interatomic bonds during loading, with the result that the energy needed for atomic bond scission decreases to $U=U_{0}-\gamma \sigma$, (2) scission of the strained bonds as a result of thermal fluctuations with the formation of chemically active free radicals, (3) nucleation of sub-micro cracks as a result of the scission of macromolecules.

Zhurkov's observations as well as his theory have been seriously disputed by Kauch [Kauch, 1978], Peterlin [Peterlin, 1981] and others, as reviewed by Terselius et al [Terselius et al, 1986]. One of the objections was made by DeVries and co-workers [Lloyd et al, 1972], who stated that Zhurkov's as well as other molecular models of fracture were oversimplified in that they neglected the difference in stress among the polymer chains. They pointed out that the stress term $\sigma$ is the atomic stress on a bond in a polymer chain and it is not likely to be equal or proportional to the applied macroscopic stress, independent of time. This has also been discussed by a number of other authors [Peterlin, 1969; Roylance, 1978; Kauch 1978] 
The work on mechano-chemical degradation of polymers has almost exclusively been concentrated on fracture of highly oriented material. Kauch [Kauch, 1978] concludes that there is little support for the opinion that chain scission controls failure processes of unoriented polymeric materials. Instead, the structural weakening of a material during loading is associated with disentanglement, chain slip, and void opening.

There has also been some controversy regarding the issue of chain scission during processing. Scott [Scott, 1995] argues that the main mechanism for radical formation during processing is mechanical scission due to shearing forces, while Billingham and Calvert [Billingham and Calvert, 1983] argue that there is little unequivocal evidence that such mechanical scission really occurs. Due to the difficulty of performing reliable experiments the question is still open.

\subsubsection{Stress-Induced Oxidative Degradation}

As discussed in the previous section a chemical bond will break if placed under sufficiently high stress, whereas a more modest stress is thought to accelerate chain scission caused by a chemical reaction, i.e. stress-accelerated or stress-aided chemical degradation. There seems to be a bit of confusion in the literature about the difference between stress-induced degradation and stress-induced oxidative degradation. Results and theories which originate from studies on fracture kinetics have been applied directly to the oxidative degradation of stressed polymers. The prevailing theory, which is summarised in a review by White and Rapoport [White and Rapoport, 1994], is that the stress lowers the activation energy for the oxidation of the polymer in much the same way as proposed by Zhurkov [Zhurkov, 1972] for chain scission (eqn XI).

On the basis of the Zhurkov theory, Czerny [Czerny, 1972] studied the effect of tensile stress on thermo-oxidative and photo-oxidative degradation of polypropylene. He measured weight loss, crack development and time to embrittlement and found that they were accelerated by tensile stress. Above a critical stress, a calculated activation energy, based on the temperature dependence of weight loss, decreased by $15 \%$ for stressed polymers as compared with unstressed ones. Below the critical stress no acceleration of oxidation was found.

In contradiction with the theory of the stress acceleration of oxidation Popov and coworkers [Popov et al, 1984] state that stress does not necessarily increase reactivity but may leave it unaffected or even inhibit it. Lemair and co-workers [Lemair et al, 1996] go even further and conclude from their experimental work that the chemical reactions during photochemical, thermal and hydrolytic ageing do not depend on mechanical stress. Internal or external stress only modifies the physical consequences of the chemical reactions, not the kinetics. Billingham and Calvert in a review [Billingham and Calvert, 1982] conclude that it is not clear that stress without gross local deformation and chain breakage can lead to enhanced oxidation. Scott [Scott, 1984] states that the same oxidative chain reaction is involved with or without the application of stress and that the primary effect of stress is to increase the rate of formation of radicals. 
The oxidation of stressed polymers is extensively discussed in a book by Popov and co-workers [Popov et al, 1991].

In addition to the direct effect that stress is supposed to have on oxidation it can also change the diffusion rates of various mobile molecules. It can do so by two opposing effects, either by dilatation which will lead to an increased diffusion rate or by orientation which will decrease it [Popov et al, 1991; White and Rapoport, 1994]. It is mainly the orientation of amorphous segments that will be decisive for the change in diffusion rate since the crystalline regions are more or less impermeable to diffusing molecules such as oxygen .

\subsection{Luminescence}

\subsubsection{Luminescence Phenomena}

Excess energy of an excited substance is usually lost as heat, through vibrations, and by collisions with surrounding molecules, but occasionally it is emitted as radiation. When this radiation is emitted in the visible light region, it is referred to as luminescence. The mode of excitation can vary and luminescence phenomena are often named after the source of excitation, e.g. electroluminescence from electric energy excitation and sonoluminescence from excitation by sound waves. Fluorescence and phosphorescence, which are both due to excitation by light, are widely used as analytical tools in polymer science [George, 1989a]. The luminescence phenomena of main interest in this work are chemiluminescence, originating from a chemical reaction, thermoluminescence, originating from thermal excitation, and triboluminescence, originating from mechanical excitation. These luminescence phenomena will be further discussed in the following sections.

\subsubsection{Chemiluminescence}

Chemiluminescence was first observed in biological sources such as the fire fly, luminescent bacteria and marine organisms. This type of luminescence is now termed bioluminescence and is a phenomenon that has been known and studied for a long time [Brolin and Wettermark, 1992]. The history of chemiluminescence from polymers is, on the other hand, relatively short. In 1961 Ashby [Ashby, 1961] reported that light was emitted from polymers heated in air. Because of the relationship between light and oxidation the term "oxyluminescence" was used. Ashby saw the possibility of using chemiluminescence as a tool for testing the stability of polymers and studied the role of oxygen concentration and the effect of antioxidants. A few years later, Schard and Russell [Schard and Russell, 1964] continued these studies and made proposals concerning the origin of the emitted light.

The development of very sensitive photomultiplier systems and a better understanding of the phenomena have now made it possible to use the measurements of chemiluminescence (CL) a valuable method of establishing degrees of degradation and of studying degradation mechanisms. In their review MatisováRychlá and Rychly [Matisová-Rychlá and Rychly, 1996] summarise the variety of 
possible chemical and physical pathways leading to the appearance of light from thermal oxidation of polymers.

Experiments with filters have shown that CL emission from polymers is in the blueviolet region $(\sim 400-500 \mathrm{~nm})$. The low intensity of emission indicates a "forbidden" transition from a triplet to a singlet state, i.e. phosphorescence. The emission spectra of CL often agree with that of carbonyl cromophores [Matisová-Rychlá et al, 1978; Mendenhall et al, 1978; George, 1989b]. Reaction (XII), the deactivation of an excited keton, is the reaction generally believed to be responsible for CL from polymers.

$$
R^{-O_{R^{\prime}}} \stackrel{O^{*}}{C} \stackrel{R^{\prime \prime}}{C_{R^{\prime}}}+h v
$$

Several mechanisms have been suggested to produce the energy required to populate a carbonyl triplet state, which is at least 290 to $340 \mathrm{KJ} / \mathrm{mol}$ [George, 1989b]. Direct homolysis of hydroperoxides (shown below, reaction XVI) [Reich and Stivala, 1967; Zlatkevich, 1985], disproportion of alkoxy radicals [Quinga and Mendenhall, 1983] and $\beta$-scission of alkoxy radicals [Audouin-Jirackova and Verdu, 1987] are all exothermic enough. However, the most widely accepted mechanism is the highly exothermic $(460 \mathrm{KJ} / \mathrm{mol})$ bimolecular termination of primary or secondary alkyl peroxyl radicals, i.e. the Russell mechanism. It proceeds via an intermediate tetroxide to give an exited carbonyl, an alcohol, and oxygen Russell, 1957; Vasiliev, 1970].

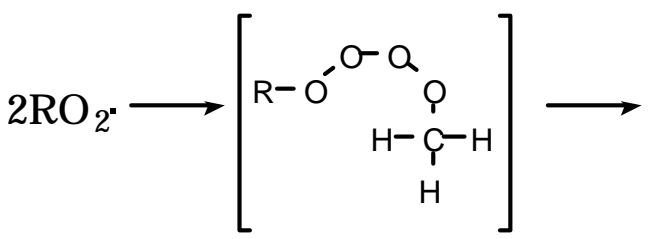

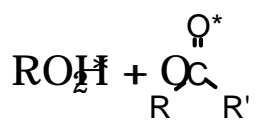

George [George, 1989b] suggests that there may be several light emission processes occurring in the polymer and Lacey and Dudler [Lacey and Dudler, 1996b] suggest that the identity of the CL emitting species changes with oxidation time.

Polypropylene, in which tertiary radicals predominate, nevertheless gives CL. This has been an argument against the validity of the Russell mechanism, which requires at least one of the peroxy radicals to be primary or secondary. However, Mayo and co-workers [Niki et al, 1973; Mayo, 1978] showed that termination reactions are accompanied by production of alkoxy radicals which will cleave to produce, ultimately, primary and secondary alkyl peroxy radicals. These in their turn will react with tertiary peroxy radicals via the Russell mechanism and thus give CL.

In the department of Polymer Technology at the Royal Institute of Technology (KTH), Stockholm, the CL technique has over the years been applied to studies of a large number of oxidating systems [Albertsson et al, 1992; Mattson, 1993; 
Barenstedt, 1994; Kron, 1996; Malmström et al, 1998; Ahlblad, 1998; Forsström, 1999].

\section{Chemiluminescence in Oxidative Atmosphere}

The intensity, I, of chemiluminescence will depend on the rate of the luminescent reaction, $R$, the overall efficiency of the formation and emission of excited species, $\Phi$, and a geometrical factor, $\mathrm{G}$, which is a product of the fraction of emitted photons that are detected and the detection efficiency [Billingham et al, 1991].

$$
\mathrm{I}=\mathrm{G} \Phi \mathrm{R}
$$

$\Phi$ is thus the probability that the termination reaction leads to the emission of a quantum from the excited carbonyl oxidation product. $\Phi$ is typically $10^{-9}$ but is not necessarily constant throughout the measurement due to, for example, yellowing.

If the CL intensity from the oxidation is assumed to be generated by reaction VIIIb with a rate constant $\mathrm{kviIb}$, the intensity will be proportional to the termination rate:

$$
\mathrm{I}=\mathrm{G} \Phi \mathrm{kV} \mathrm{VIIb}_{\mathrm{III}}\left[\mathrm{RO}_{2}\right]^{2}
$$

In the steady state rates of initiation and termination are equal $\left(r_{i}=r_{t}\right)$ and the CL intensity is related to the initiation rate as:

$$
\mathrm{I}=\mathrm{G} \Phi \mathrm{r}_{\mathrm{i}}
$$

The intensity of chemiluminescence generated upon degradation of a polymer has been found to be enhanced by various degradative stimuli, e.g.. UV light, heat and stress. The spectral distribution in all cases was found to be similar. This suggests that the overall mechanism of the reaction is similar and that only the type and relative proportions of the initiation and propagation steps are different due to the various stimuli that bring about the degradation [George et al, $1982 \& 1989 b$ ].

\section{Chemiluminescence in Inert Atmosphere}

In an inert atmosphere no further oxidation of the polymer is possible but it was early observed that polymers heated in an inert atmosphere still emit light [Matisová-Rychlá et al, 1978 \& 1980; George et al, 1983; Billingham et al, 1988 \& 1991]. Upon heating a polymer specimen in an inert atmosphere, the CL intensity will increase up to a maximum and then decrease down to the level of the background noise. If the specimen is cooled down, still in an inert atmosphere, and then re-heated, only a very low signal can be detected; see Figure 1.3. 


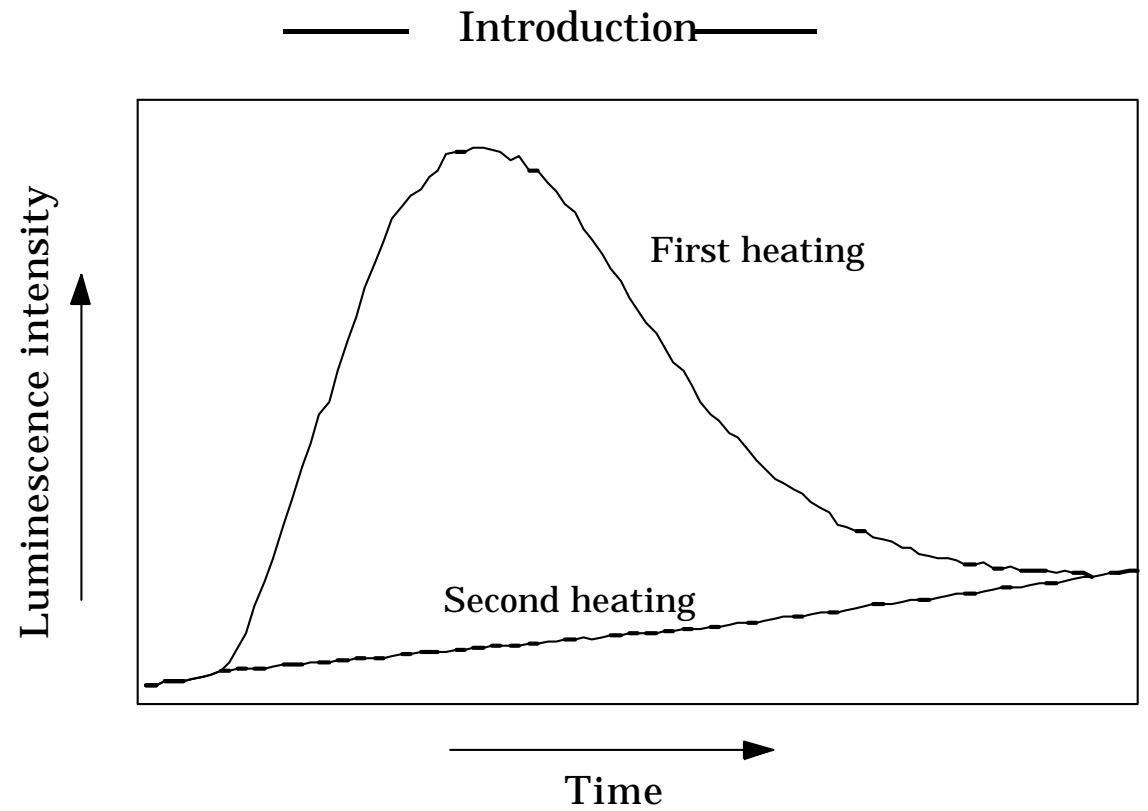

Figure 1.3 Schematic drawing of the CL curves resulting from the first and second heating cycles in an inert atmosphere.

Since the CL emission decreased upon treatment of polypropylene with peroxidedestroying agents, such as sulphur dioxide, it was concluded that the emission originated from hydroperoxides present in the material [Billingham et al, 1988]. Reaction III, i.e. the bimolecular decomposition of hydroperoxides, directly produces peroxyl radicals, which in their turn can terminate and yield CL. Reaction II, i.e. the unimolecular decomposition of hydroperoxides, can via a proposed cage-reaction yield an excited carbonyl and water [Reich and Stivala, 1967; Zlatkevich, 1985]:

$$
\mathrm{ROOH} \rightarrow \quad[\mathrm{RO} \cdot+\cdot \mathrm{OH}] \longrightarrow \quad>\mathrm{R}=\mathrm{O}^{*}+\mathrm{H}_{2} \mathrm{O}
$$

The area under the CL emission peak is denoted Total Luminescence Intensity (TLI) and has been found to be proportional to the hydroperoxide concentration in the early stages of the oxidation of polypropylene [Billingham et al, 1988]. Billingham and Kron with co-workers [Billingham et al, 1991; Kron et al, 1996, Kron 1996] have found, however, that the TLI value and the peroxide concentration in PP increases proportionally up to a maximum, after which the TLI decays faster than the peroxide concentration.

Other explanations of the origin of luminescence from polypropylene heated in an inert atmosphere have also been suggested [Matisova-Rychlá et al, 1978 \& 1980].

\subsubsection{Imaging Chemiluminescence}

With an imaging chemiluminescence instrument it is possible to see the spatial resolution of the emitted light. Thus not only the degree of oxidation but also the position of the oxidation can be established. At the present time there are only a few ICL instruments in the world [Fleming and Craigh, 1992; Hosoda et al, 1993, Lacey and Dudler, 1996a, 1996b \& 1996c; Ahlblad, 1998], but due to further technical development and advancement of the theoretical knowledge of the CL mechanisms, the number of instruments is most likely going to increase. One major problem with the ICL technique is that the temperature variations in the measuring oven must be 
negligible in order not to cause differences in the oxidation rate due to a nonuniform temperature in the test specimen. ICL has, for instance, been used to measure heterogeneous oxidation and spreading of oxidation between particles. It is also useful in measuring a number of samples at the same time. This increases the efficiency of the experiments as compared with when conventional CL is used and each specimen has to be measured separately.

\subsubsection{Thermoluminescence}

Thermoluminescence (TL) (also referred to as radiothermoluminescence or charge recombination luminescence) is the thermally stimulated emission of light that follows previous absorption of energy from radiation. It is distinguished from photoluminescence phenomena, such as fluorescence and phosphorescence, by its ability to emit light upon heating long after irradiation [Fleming and Hagekyriakou, 1984; McKeever, 1985; Zlatkevich, 1989; George, 1989a; Fleming, 1990; Charlesby, 1991]. Kron et al [Kron et al, 1997] have shown that for $\gamma$ and $\beta$ irradiation of HDPE and LLDPE this time can be as long as several years. The probable source of thermoluminescence in organic solids is the recombination of trapped charges. Upon irradiation of polymers not all electrons ejected from their parent molecules recombine. Instead some of them are trapped either physically or chemically. A physically trapped electron is localised in cavities or voids created by imperfections in the structure of the polymer, such as crystal imperfections in semi-crystalline polymers. In a chemical trap the electron is bound to some particular molecule and resides within the characteristic molecular orbitals of that molecule [Zlatkevich, 1989]. The irradiation is usually carried out at a low temperature, and upon subsequent heating the electrons are released from their traps due to molecular motions. $\alpha, \beta$ and $\gamma$ transitions would be expected to break up electron traps and thus give rise to luminescence. A number of authors have used TL to study the physical properties of polymers [Charlesby and Partridge, 1963; Boustead and Charlesby, 1970; Fleming and Hagekyriakou, 1984; Markewicz and Fleming, 1988; Zlatkevich, 1989].

\subsubsection{Triboluminescence}

The first report of triboluminescence in the literature dates back to Francis Bacon's The Advancement of Learning [Bacon, 1605]. Bacon found that lumps of sugar emitted light when scraped. Triboluminescence takes its name from Greek tribein 'to rub' and is defined as "the emission of light caused by the application of mechanical energy to a solid", i.e. triboluminescence is produced by direct mechanical excitation, e.g. crushing of crystals or tearing open gummed envelopes. Since the definition of the phenomenon is very broad, mechanical methods and mechanisms of excitation can be very different. Of the three luminescence phenomena described here triboluminescence is the least studied and the least understood. This is especially true for polymers. In his review on triboluminescence Zink [Zink, 1978] states that the borderline between triboluminescence, thermoluminescence and chemiluminescence is often fuzzy. For example, the mechanical energy applied to a crystal in a triboluminescence experiment could be converted to heat, which in its turn could cause either thermoluminescence or, through a chemical reaction, chemiluminescence. A number of authors have discussed the occurrence of triboluminescence during CL measurements of stressed 
specimens [Butyagin et al, 1970; Fanter and Levy, 1978; Monaco and Richardson, 1989].

\subsubsection{Stress-Induced Chemiluminescence}

Since chemiluminescence is a very sensitive method of studying oxidative degradation, it has been used to measure the effect of stress on oxidation of polymers, i.e. stress-induced chemiluminescence (SCL). SCL is by definition a type of triboluminescence, and it is likely that SCL and other forms of triboluminescence can occur at the same time. SCL is, however, the only type of tribo-induced luminescence that is oxygen dependent and can therefore be sorted out by measurements in inert and oxidative atmospheres.

One of the early reports of luminescence accompanying mechanical deformation of polymers was published by Butyagin and co-workers in 1970 [Butyagin et al, 1970]. They measured the total luminescence from films deformed by air pressure. Luminescence was observed when the films were stretched, suddenly contracted, or ruptured. In general the luminescence intensity increased both with the rate of deformation and with the film thickness. From experiments with two different photomultipliers, which were sensitive to different regions of the spectrum, they concluded that the detected luminescence was produced by several types of processes, i.e. CL, TL and triboluminescence.

In 1977 Mendenhall [Mendenhall, 1977] reported in a paper on analytical applications of chemiluminescence that the accelerating effect of stress on polymerageing reactions could be studied by using CL. In 1978 Fanter and Levy [Fanter and Levy, 1978] coined the expression "stress chemiluminescence" (SCL) and were among the first to design a special system for studying SCL. They used a miniature tensile unit, a chamber with a controlled environment and a luminescence detection system with associated optics, integrated into a single unit. The tensile unit could exert forces up to $800 \mathrm{~N}$. The materials studied were an epoxy system and polyamide 66. Triboluminescence was eliminated as an explanation of the emitted light by a series of measurements in different atmospheres. Fanter and Levy also illustrated the dependence of the SCL signal on both the composition of the polymeric material and the environment. Thus, the moisture content in the material had a profound effect on the signal. Moreover, some suggestions were made as to the origin of the light. These suggestions were mainly based on the theory that stress lowers the activation energy of a thermooxidative reaction.

George and co-workers [George et al, 1982] used a different approach in their SCL work. In their apparatus the stress was applied by an Instron tensile testing machine equipped with a photomultiplier tube. Their work concentrated on SCL from polyamide fibres. They observed a linear increase in luminescence intensity at low strains and an exponential increase at high strains. The linear component was attributed to a local temperature rise from internal and external frictional effects in the fibre bundle. The exponential component showed a very good correlation with electron spin resonance (ESR) measurements made by DeVries and co-workers [Lloyd et al, 1972] on the same type of polyamide fibres. Both the ESR and the SCL measurements showed that radicals start to form at $>60 \%$ of ultimate straining. 
The radicals were concluded to originate from progressive chain scission of taut tie molecules in the amorphous regions of the polymer.

In a study of the degradation of stressed polyamides [O'Shea, 1987; George and O'Shea, 1989 \& 1990], luminescence was observed during tensile testing of injectionmoulded specimens. The instrument used was a similar set-up as described above with a photomultiplier attached to an Instron tensile testing machine. Two luminescence peeks were observed, one at necking and one during the strain hardening period. The luminescence at necking was thought to be chemiluminescence from chain scission in breaking up the initial spherulitic structure. The second peak was attributed to chain scission of taut tie molecules in the microfibrillar structure. Chain scission at necking has not with any measuring technique been shown to occur, and the emission observed at necking was therefore thought to contain new information about the mechanisms.

Monaco and Richardson [Monaco and Richardson, 1989] presented SCL results from epoxy resins, Kevlar fibres and silicon cushions. Like Fanter and Levy they showed that moisture content had a major effect on the SCL signal for the epoxy material. They made some qualitative measurements on epoxy dog-bone shaped specimens, which had been deliberately damaged, and found a relationship between the amount of emitted light and the load at failure. The higher the SCL signal, the lower the load at failure.

In their work on fracto-emission Dickinson and co-workers Dickinson et al, 1990, $1993 \&$ 1994] investigated the emission of particles caused by deformation and fracture of materials. The observed particles were electrons, ions, neutral species, long wave-length electromagnetic radiation as well as photons. The materials studied ranged from oxide coatings on metals and inorganic crystals and glasses to organic crystals and polymers. In their study of electron and photon emission accompanying deformation and fracture of polycarbonate Dickinson et al [Dickinson et al, 1993] concluded that the emission both at necking and fracture was due to bond breakage.

Hosoda and co-workers [Hosoda et al, 1993] used both conventional and imaging CL to study mechanically deformed polymers. They fitted experimental data obtained from SCL experiments on unaxially drawn polyamide 6 sheets to the Zhurkov equation (see section 1.3.2), but in doing so they confused their experimental data with theories originating from studies of fracture kinetics (see section 1.3.3). They also obtained an image of an unaxially stressed specimen which contained a central hole. The image showed that the luminescence was concentrated in the area above and below the hole where the stress concentration was highest.

Zlatkevich [Zlatkevich, 1997] measured the induction period of oxidation and oxidation rate constants by using conventional CL technique in his work on stressed sulphur vulcanised latex films. The films were aged at temperatures between $130^{\circ} \mathrm{C}$ and $160^{\circ} \mathrm{C}$ during unaxial elongations from $20 \%$ to $200 \%$. He found that the induction period of oxidation was extended with deformation in the $130-150^{\circ} \mathrm{C}$ temperature region. The extension reached a limiting value at about $60-70 \%$ and 
remained unchanged up to $200 \%$. The effect became less pronounced with increasing temperature and at $160^{\circ} \mathrm{C}$ the induction period was not changed with deformation. The extension of the induction period was ascribed to a decrease in the effective concentration of hydroperoxides. A speculative suggestion was made that stretching of the nonuniform network creates microregions within which the thermal decomposition of hydroperoxides does not lead to the oxidative chain propagation reaction.

Summarising these SCL reports, it can be concluded that scientists have made a large number of observations of luminescence from several polymeric materials stressed in a variety of ways. However, they have not given an unambiguous interpretation of their observation. 


\section{EXPERIMENTAL}

\subsection{Materials and Processing}

\subsubsection{Polyamide 6}

The polyamide 6 (PA6) used in the experiments described below appeared both as film and as granules. Sheets of blow moulded PA6 film were supplied by Nyltech, Italy. These films contained different amounts and types of stabilisers. The stabilisers were Irganox 1098, which is a phenolic radical scavenger, and Irganox B1171. The latter is a 50-50\% mix between Irganox 1098 and Irgafos 168, which is an organic phosphite that works as a hydroperoxide decomposer. The influence of stabiliser concentration and type of stabiliser on the oxidation of these films is described in detail by Forsström [Forsström, 1999].

Three different batches of granules for injection moulding were supplied by DSM in Holland. One batch was reportedly stabiliser-free, one contained Irganox 1098, and one contained Irganox B1171.

In addition to this, commercial grades of PA6 granules, supplied by DuPont (Zytel) and Nyltech (Sinamid), were used in the experiments.

\subsubsection{Polyamide 66}

Commercial grades of polyamide 66 (PA66) granules from DuPont (Zytel) and Nyltech (Technyl A216) were used for injection moulding.

\subsubsection{Polypropylene}

Polypropylene (PP) granules for injection moulding were supplied by Borealis. Two different types were used, one commercial grade and one which was reportedly additive-free, but most probably contained some type of storage stabiliser.

\subsubsection{High Density Polyethylene}

Reportedly additive-free high density polyethylene (HDPE) powder was supplied by Borealis.

\subsubsection{Injection Moulded Tensile Specimens}

Tensile specimens were made using a Battenfeldt Plus 250 injection moulding machine. Two different types of dog-bone shaped specimens were used: ASTM D 638 type M-I and a specimen specially designed to be used in the SCL instrument (see Figure 2.1) The latter specimen was designed to develop a well defined neck and a short cold drawing region. The mould was designed to produce specimens of four different thicknesses, $1,2,3$, and $4 \mathrm{~mm}$, respectively. 


\section{Experimental-}

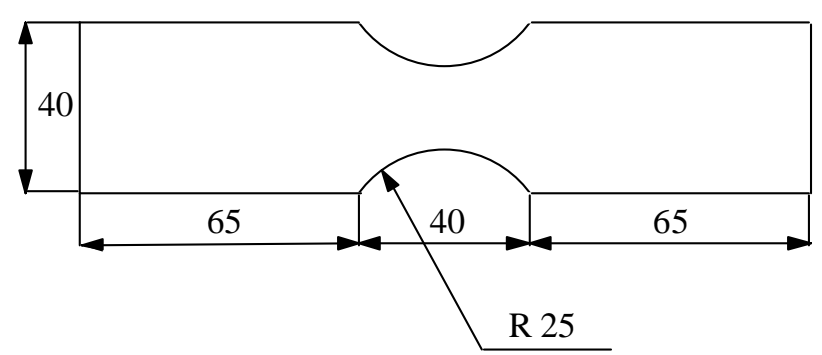

Figure 2.1. Schematic drawing of the specially designed dog-bone shaped tensile test specimen.

\subsection{Ageing Conditions and Treatments}

\subsubsection{Oven Ageing}

Injection moulded specimens were oven aged in air for 72 hours at $120^{\circ} \mathrm{C}$ for PA6 and $95^{\circ} \mathrm{C}$ for PP and HDPE.

\subsubsection{Creep Ageing}

Specimens were oven aged under constant load in a specially designed creep-ageing oven. A fan minimised the temperature gradients in the oven. The temperature still varied slightly (about $\pm 1^{\circ}$ ) between the different positions in the oven. Either all specimens were loaded with the same weight and one specimen was taken out each day during a seven-day period or the specimens were loaded with different weights and taken out on the same day. The ageing temperatures were $95^{\circ} \mathrm{C}$ for the $\mathrm{PP}$ specimens, $110^{\circ} \mathrm{C}$ for the $\mathrm{HDPE}$ specimens, $120^{\circ} \mathrm{C}$ for the PA6 film strips and $130^{\circ} \mathrm{C}$ for the PA6 specimens, unless otherwise specified.

\subsubsection{UV Irradiation}

ASTM D 638 type M-I PP specimens were UV-irradiated in a high-power microwave irradiator from Fusion UV Curing System (model F 600) D-bulb. The UV dose was $87 \mathrm{~mJ} / \mathrm{cm}^{2}$. The specimens were passed under the UV-light source 10 times, each time for $0.018 \mathrm{~s}$, which was short enough to avoid a temperature increase in the specimen. This prevented thermal decomposition of unstable hydroperoxides formed during UV-induced oxidation.

Thermoluminescence was induced by irradiation with a Luxor $15 \mathrm{~V} 150 \mathrm{~W}$ Tungsten halogen lamp from ICI, equipped with a fibre optic tip. The optical output was filtered to between 380 and $520 \mathrm{~nm}$, and the specimens were irradiated for $10 \mathrm{~s}$, unless otherwise specified. Both the desk lamp and the ceiling lamps in the laboratory are fluorescent tube types.

\subsubsection{Sulphur Dioxide Treatment}

The specimens were put in a gas-tight vessel, which was filled with sulphur dioxide gas. The gas was allowed at least 24 hours to react. 


\subsection{Analytical Techniques}

\subsubsection{Stress-Induced Chemiluminescence (SCL) Paper [I]}

\section{SCL Instrument}

Since there are no commercially available CL instruments in which a stress can be applied to a test specimen, a new instrument had to be constructed. In the literature two different types of equipments are reported. One is based on a conventional CL instrument equipped with a straining device [Fanter and Levy, 1978; Monaco and Richardson, 1989] and the other is a tensile testing machine which has been fitted with a photon counting system [George et al, 1982]. The latter type was chosen since it enables larger deformations and better control of the load/extension process. Its construction, however, is more complex.

The instrument was built onto an Instron model 1122 bench top tensile testing machine; see Figure 2.2. The elongation rate is set on the Instron control unit and can be varied between 0.01 and $1000 \mathrm{~mm} / \mathrm{min}$. The instrument can also be used for creep experiments, in which the load is kept constant, and for compression measurements.

A photomultiplier tube (PMT), model H6180-01 from Hamamatsu, sensitive from 300 to $650 \mathrm{~nm}$ and with a maximum sensitivity at $400 \mathrm{~nm}$ was used to detect the emitted photons. In order to increase the collection of photons emitted from the test specimen, a lens system consisting of a Melles Griot 01CMP019 fused silica condenser was used to project the light emitted from the specimen onto the photocathode surface. The diameter of the spot from which the photons are collected can be selected to $40 \mathrm{~mm}$ or less. The PMT was mounted on a slide for horizontal movement; see Figure 2.3. This enables photon detection from different parts of the specimen, e.g. the edge or the centre. In order to keep the selected spot of the specimen in focus during extension, the PMT system was placed inside a box which, by means of a pulley fixed to the drawing cross beam of the Instron, was made to travel at half the elongation rate. 


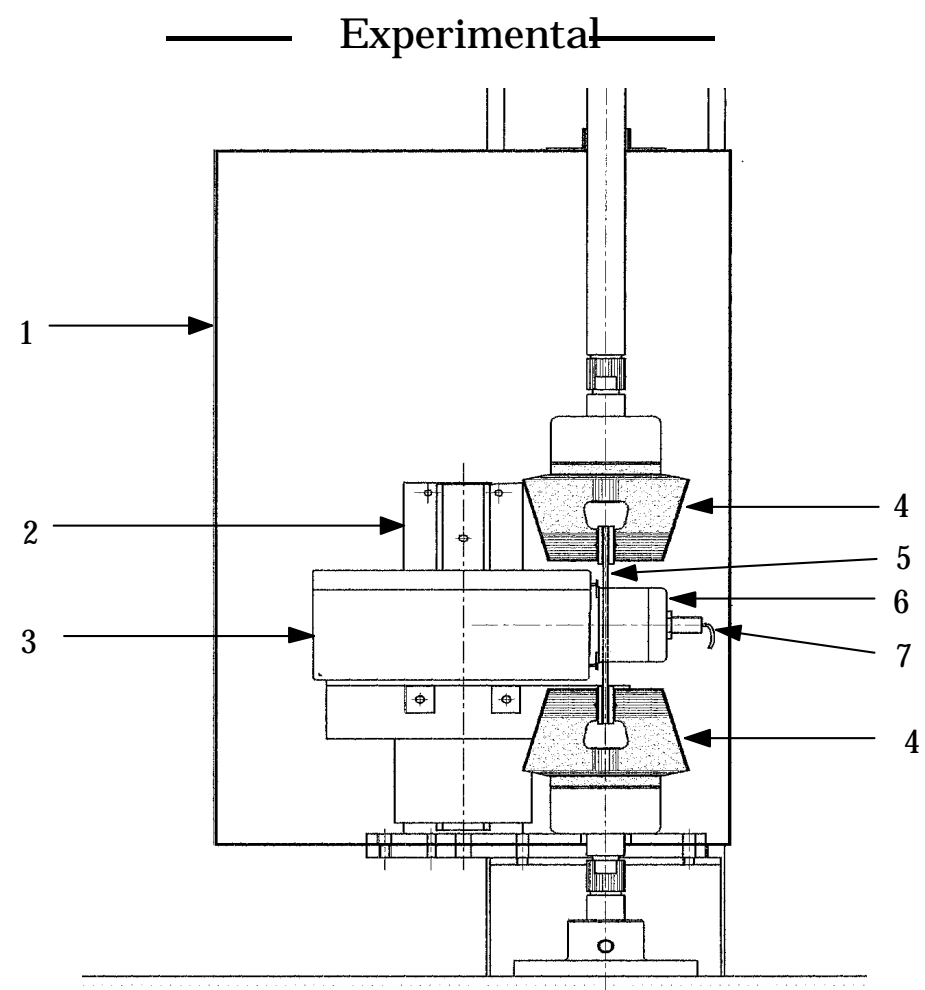

Figure 2.2. Side view of the SCL instrument. (1) Light-tight chamber, (2) Slide for vertical movement of the PMT package, (3) PMT package, (4) Instron grips, (5) Test specimen, (6) Environmental chamber, (7) IR sensor.

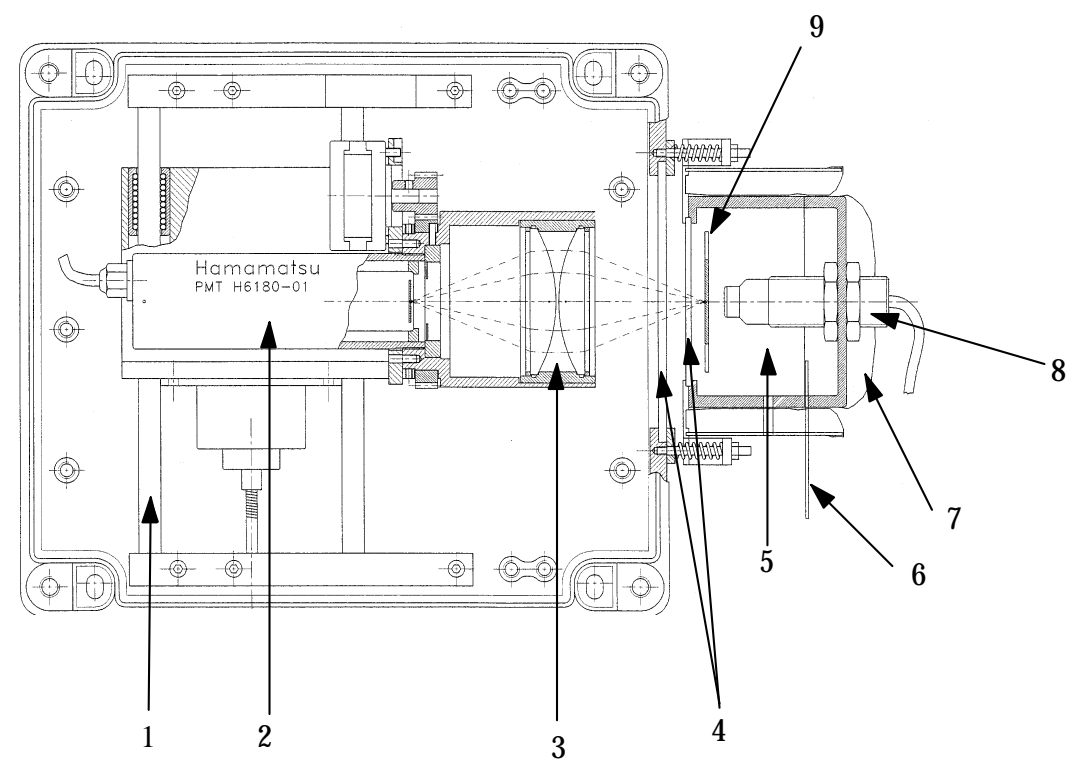

Figure 2.3. Top view of the PMT package. (1) Slide for horisontal movement of the photomultiplier, (2) Photomultiplier, (3) Lens system, (4) Quarts windows, (5) Gas inlet, (6) Thermocouple, (7) Insulation, (8) IR-sensor, (9) Test specimen.

Due to the large area of the light-tight chamber surrounding the set-up, it is not suitable for effective temperature and atmospheric control. This is instead achieved by using a small environmental chamber fitted to the PMT box; see Figure 2.3. The 
chamber is insulated to prevent heat loss and to protect the PMT from high ambient temperatures. The inevitable temperature rise in the light-tight chamber is minimised by using a fan and a water cooling device, which is fitted on the outside of the light-tight chamber. This set-up prevents condensation and water leakage into the sensitive electronic parts of the instrument.

The test specimen is inserted through the chamber and clamped into the grips of the Instron. An electrically heated gas is let into the chamber, which is also electrically heated. The temperature is controlled by PID regulators connected to a thermocouple inserted into the chamber. This system guarantees a controlled heating rate for temperature ramp experiments. The temperature can be set between ambient and $200^{\circ} \mathrm{C}$ with a fluctuation less than $\pm 0.5^{\circ} \mathrm{C}$ at a constant temperature. The temperature is, however, always higher at the top outlet of the oven since it is a narrow opening through which the warm gas flows out. The heating rate is controlled by the power supply and is maximum $12^{\circ} \mathrm{C} / \mathrm{min}$. The volume of the environmental chamber is $250 \mathrm{ml}$. A gas flow meter ensures a steady gas flow rate.

To prevent air leakage into the chamber during measurements in an inert atmosphere, a high gas flow is used and a slight over-pressure is built up in the chamber prior to a measurement. Since both the test specimen and the chamber are moving during extension, tight specimen inlets have to be used to prevent oxygen leakage into the chamber. The inlets are adjustable to permit the use of different specimen geometries.

The specimen dimensions are limited to maximum $50 \mathrm{~mm}$ in width and $4 \mathrm{~mm}$ in thickness. The minimum gauge length is $110 \mathrm{~mm}$ due to the dimensions of the PMT box and the environmental chamber.

The temperature of the specimen can be measured by a non-contact IR sensor, which is mounted opposite the PMT. This enables control of the true temperature of the polymer, which is important since the temperature of the test specimen increases on drawing. The detection spot of the IR sensor is $5 \mathrm{~mm}$ in diameter. The maximum ambient temperature for the sensor is $80^{\circ} \mathrm{C}$ without external cooling. Because of this it is dismounted during constant load/high temperature measurements. During these measurements the elongation rate is so low that no increase in temperature over the ambient temperature is expected in the specimen.

Data on load, recorded by the Instron control unit, temperatures, and photon counts are put into a PC computer and collected in a specially designed software program. The gate-time of the PMT, the temperature and the load can be set at any number from $1 \mathrm{~s}$ and upwards.

\section{SCL Measurements}

The SCL instrument is very user-friendly. The test specimen is simply inserted through the inlets of the environmental chamber and clamped into the Instron grips. The door to the light-tight chamber is then closed, the PMT is turned on and is allowed to stabilise to the background noise for about $10 \mathrm{~s}$. The temperature is set on the PID regulator for both the environmental chamber and the gas. If the 


\section{Experimentał}

measurement is run at a constant temperature, the chamber is allowed to stabilise at that temperature for at least 30 minutes. The specimen is then inserted and the measurement started. For ramped temperature experiments the heating rate is set and the specimen is inserted at room temperature.

If an inert atmosphere is to be used, the gas is allowed to flow through the environmental chamber for at least 10 minutes to ensure that no oxygen is present. The gas flow rate of nitrogen in the experiments was $1600 \mathrm{ml} / \mathrm{min}$. The elongation rates were $5 \mathrm{~mm} / \mathrm{min}$ for the specially desigend specimens and $20 \mathrm{~mm} / \mathrm{min}$ for the ASTM specimens, unless otherwise specified.

\subsubsection{Conventional Chemiluminescence (CL)}

\section{Instrument}

Conventional chemiluminescence measurements were performed on a commercially available equipment; CLD100 CL-Detector from Tohoku Electronic Industrial Co., Japan. It consists of a photomultiplier tube with a bialkali photocathode, connected to a PC-controlled photon counting device. The photomultiplier is sensitive to wavelengths between 280 and $650 \mathrm{~nm}$ with a maximum sensitivity between 400 and $450 \mathrm{~nm}$. The photocathode is cooled to $-20^{\circ} \mathrm{C}$ in order to minimise the dark count.

The temperature can be controlled between room temperature and $180^{\circ} \mathrm{C}$. The average heating rate is approximately $15^{\circ} \mathrm{C} / \mathrm{min}$ and cannot be changed. The test chamber is cylindrical with a diameter of $50 \mathrm{~mm}$ and a depth of $10 \mathrm{~mm}$. The total volume of the oven is approximately $30 \mathrm{ml}$. The large volume enables measurements of a wide range of solid or liquid samples. Both the walls and the bottom of the chamber are surrounded by heating elements as well as the last part of the gas pipe. Gas flow meters ensure a steady gas flow rate.

\section{Measurements in Oxidative Atmosphere}

Isothermal CL measurements were carried out in air or pure oxygen in order to follow the oxidation in situ. The gas flow rate was typically $80 \mathrm{ml} / \mathrm{min}$. The test chamber was pre-heated before the specimens were placed in it to minimise the time to attain isothermal conditions.

\section{Measurements in Inert Atmosphere}

Temperature ramp experiments in nitrogen were run on pre-aged specimens in order to calculate the total luminescence intensity (TLI) value. The test chamber was flushed with nitrogen for at least 30 minutes at $25^{\circ} \mathrm{C}$ before the temperature was increased to $150^{\circ} \mathrm{C}$ at an average heating rate of $15^{\circ} \mathrm{C} / \mathrm{min}$ and then kept at $150^{\circ} \mathrm{C}$ throughout the measurement.

The gas flow rate of nitrogen was $140 \mathrm{ml} / \mathrm{min}$. The TLI value was determined by calculating the area under the CL curve from a temperature ramp experiment in nitrogen [Billingham et al, 1988]. The TLI value has been shown to be proportional to the amount of hydroperoxides in a polypropylene sample during the early stages of oxidation [Kron et al, 1996]. However, for polyamides this conclusion has been questioned [Lánská et al, 1998]. 


\section{Experimental}

\subsubsection{Imaging Chemiluminescence (ICL)}

\section{ICL Instrument}

The imaging chemiluminescence system used was developed at the Department of Polymer Technology, KTH. The ICL measurements were performed on an Argus50/VIM3 system, with ultra-high sensitive image acquisition and analysis, from Hamamatsu photonics K. K. The specimen is placed in an oven, light-tightly connected to the photon counting device. The positions of the photons emitted from the specimen are registered during the measurement. This results in an image of the accumulated CL emission, describing the total luminescence intensity (TLI) at each point of the specimen with a resolution of approximately $30 \mu \mathrm{m}$. However, the spatial resolution of the obtained image is reduced by other factors such as the signal-to-noise ratio and optical effects e.g. light scattering and internal reflection. The instrument is described elsewhere in detail [Ahlblad et al, 1997; Ahlblad, 1998].

\section{ICL Measurements in Oxidative Atmosphere}

Isothermal ICL measurements were performed in air under a gas flow of $60 \mathrm{ml} / \mathrm{min}$. The light intensity was measured for 10 minutes once every hour. This gave the position of the in situ oxidation of the specimen.

\section{ICL Measurements in Inert Atmosphere}

The distribution of oxidation in pre-aged specimens was measured in temperature ramp experiments in nitrogen. The gas flow rate was $70 \mathrm{ml} / \mathrm{min}$. The test chamber was purged with nitrogen for at least 30 minutes at $25^{\circ} \mathrm{C}$ before experiment. Then the temperature was increased to $150^{\circ} \mathrm{C}$ at an average heating rate of $8.5^{\circ} \mathrm{C} / \mathrm{min}$ and kept at $150^{\circ} \mathrm{C}$ throughout the measurement. The intensity of the light was measured during 3 minutes every 10th minute.

\subsubsection{Iodometry}

Iodometric measurements were performed on the polyamide to verify the presence of hydroperoxides in the specimens. The specimens were cut in small pieces, approximately $3 \times 3 \mathrm{~mm}$. About $20 \mathrm{~g}$ polyamide was added to a mixture of $7 \mathrm{ml}$ of a solution consisting of 10 parts isopropanol and 1 part acetic acid and $2 \mathrm{ml}$ of a saturated solution of $\mathrm{NaI}$ in isopropanol (10 g NaI in $50 \mathrm{ml}$ of isopropanol). This mixture was, while protected from light, allowed one hour to react. The reaction was terminated by adding $1 \mathrm{ml}$ of deionised water. The concentration of $\mathrm{I}_{3}{ }^{-}$was assessed spectroscopically as the absorption at $360 \mathrm{~nm}$, using a Hewlet Packard 8451A UV-Vis spectrophotometer. A reference solution without polyamide was treated in the same way and used to subtract the interference from $\mathrm{I}_{3}$ - formed due to oxygen and light.

\subsubsection{FTIR}

A Perkin Elmer Spectrum 2000 FT-IR spectrometer was used to monitor the buildup of carbonyl groups in the material during ageing. The Attenuated Total Reflection (ATR) technique was used since the specimens were too thick for the transmission mode. Each spectrum was based on 20 scans. 
For polyamide 6 and 66 the carbonyl index was calculated by relating the absorbance at $1728 \mathrm{~cm}^{-1}$, assigned to carbonyls formed during oxidation, to an internal standard peak, at $1201 \mathrm{~cm}^{-1}$. This peak was selected since it is relatively insensitive to the ageing of polyamides [Forsström et al, 1999].

For PP the carbonyl index was calculated by relating the absorbance at $1710 \mathrm{~cm}^{-1}$, assigned to carbonyls formed during oxidation, to an internal standard peak, at 1455 $\mathrm{cm}^{-1}$. This peak was chosen as internal standard even though it is related to the orientation of the material and thus will change if the specimen is oriented during creep ageing. Another choise would have been to use the peak at $2720 \mathrm{~cm}^{-1}$ which is not affected by either crystallinity or orientation [Rabello and White, 1997], but this peak was very small. Moreover, when the ATR technique is used the measuring depth varies with the wavelength and thus a reference peak closer to the measuring peak is preferable. The orientation was also shown by x-ray diffraction to be negligible even for the highest loaded specimens.

\subsubsection{Ultaviolet Spectroscopy}

Ultraviolet (UV) Spectroscopy on aged PA6 films was carried out using a Hewlett Packard 8451A Diode Array Spectrophotometer. UV absorption was used to monitor chemical ageing of the polymer by measuring the absorption at $245 \mathrm{~nm}$. The exact nature of this absorption is unknown, but it is closely related to oxidative degradation and yellowing of polyamides [Lemair et al, 1991; Renschler, 1985; Renschler et al, 1984]. The absorption at $245 \mathrm{~nm}$ follows Lambert-Beer's law up to 2 absorption units (au), after which it starts to deviate from a straight line. The results in which the absorption exceeds 2 au have been corrected to correspond to the concentration of the absorbing function.

\subsubsection{Tensile Testing}

The mechanical properties of the oxidised specimens were measured by an Instron model 5566 bench top tensile testing machine. The elongation at break was chosen as the key property. The reported value is based on the average of data for five PA6 film specimens and for three PP specimens. The polyamide test specimens were pretreated and tested at $50 \% \mathrm{RH}$ and $25^{\circ} \mathrm{C}$. The elongation rate was $10 \mathrm{~mm} / \mathrm{min}$, unless otherwise specified.

The load at yield was measured at $95^{\circ} \mathrm{C}$ for PP, $110^{\circ} \mathrm{C}$ for $\mathrm{HDPE}$ and $120^{\circ} \mathrm{C}$ for PA6 film and at $130^{\circ} \mathrm{C}$ for PA6 injection moulded bars by using an Instron 3119-009 temperature chamber. The elongation rate was $0.1 \mathrm{~mm} / \mathrm{min}$.

\subsubsection{DSC}

A Mettler DSC 820 was used to investigate the change in crystallinity during ageing. PA6 film samples of $4.0 \pm 0.5 \mathrm{mg}$ were heated from $100^{\circ} \mathrm{C}$ to $300^{\circ} \mathrm{C}$ at a heating rate of $10^{\circ} \mathrm{C} / \mathrm{min}$ under a constant nitrogen flow of $80 \mathrm{ml} / \mathrm{min}$. The mass crystallinity $\left(\mathrm{w}_{\mathrm{c}}\right)$ was calculated from the given heat of fusion $\Delta \mathrm{H}$ and $\Delta \mathrm{H}^{\circ}$, i.e. the heat of fusion for $100 \%$ crystalline material, which for polyamide 6 is $184.2 \mathrm{~kJ} / \mathrm{kg}$ [Polymer Handbook, 1989]. 
PP samples of $10 \pm 1 \mathrm{mg}$ were heated from $80^{\circ} \mathrm{C}$ to $250^{\circ} \mathrm{C}$ at a heating rate of $10^{\circ} \mathrm{C} / \mathrm{min}$ under a constant nitrogen flow of $80 \mathrm{ml} / \mathrm{min}$. Since the change in crystallinity was very low, the change in melt temperature $\left(\mathrm{T}_{\mathrm{m}}\right)$ with ageing time was evaluated instead.

\subsubsection{X-ray Diffraction}

X-ray diffraction was used to investigate any change in crystalline orientation due to the application of stress during ageing. The x-ray scattering patterns were taken by a Statton camera using Ni-filtered $\mathrm{Cu} \mathrm{K} \alpha$ radiation from a Philips PW 1830 generator. No change in the x-ray pattern between an unstressed specimen and a highly stressed one was observed, which means that the change in crystalline orientation was insignificant. 


\section{RESULTS AND DISCUSSION}

\subsection{Luminescence Observed during Tensile Testing of Injection Moulded Polyamides}

[Papers I and II]

Figure 3.1 shows a typical tensile testing curve from a hard, ductile, semicrystalline polymer such as polyamide. The extended yield plateau, typical of injection moulded PA66, is evident. The load drop is defined as necking and is attributed to the reduction in cross-section during the formation of a neck. At necking the original spherulitic structure of the material breaks down and is converted into a microfibrillar structure. The growth of the neck during further drawing is known as cold-drawing and involves travelling of the shoulders of the neck along the specimen while its cross-section is being reduced. The specimen depicted in the figure also shows a second neck formation in the strain hardening region, as can be seen at the end of the load curve.

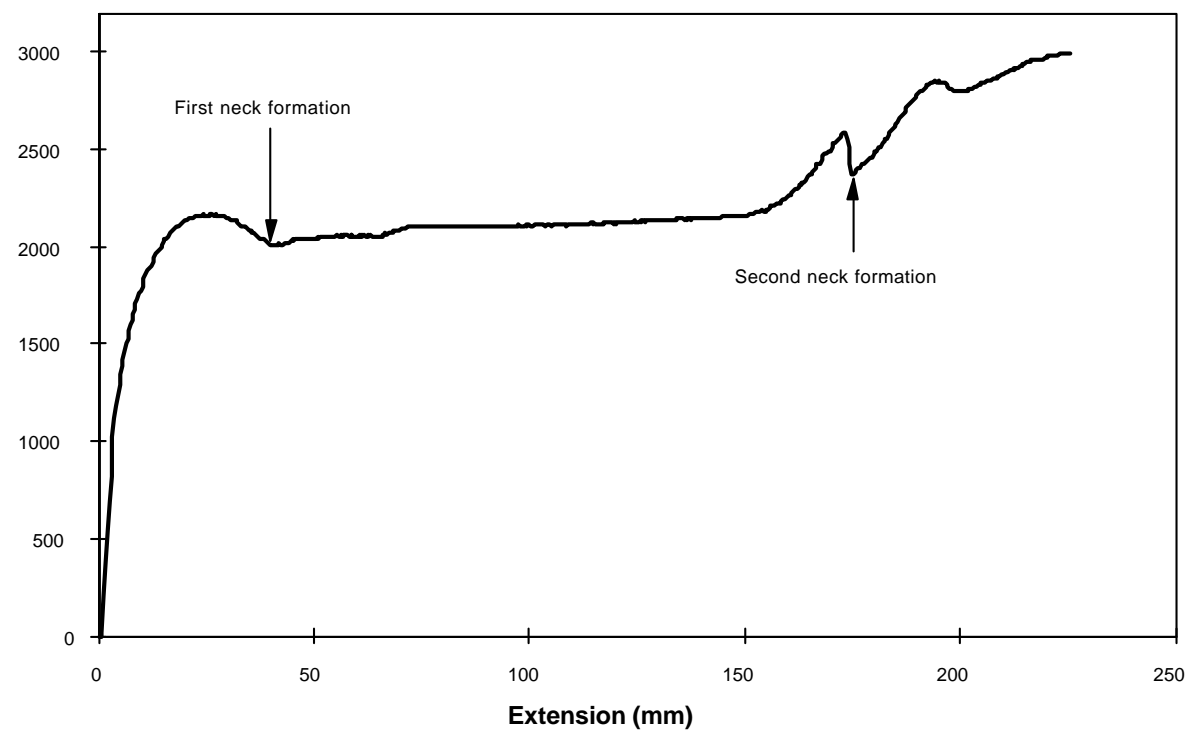

EMBED

Figure 3.1. A typical tensile testing curve from a hard, ductile, semicrystalline polymer such as polyamide.

The simultaneous CL and load-extension curve measured by the SCL instrument of an injection moulded PA66 specimen is shown in Figure 3.2. The curve differs somewhat in appearance from the curves in O'Shea's experiments (described in Section 1.4.6) in that it only contains one peak. However, a few specimens used showed a burst of light at fracture. As can be seen in Figure 3.2, there is in addition to the luminescence at necking also a slight increase in intensity prior to necking, after the yield point. 


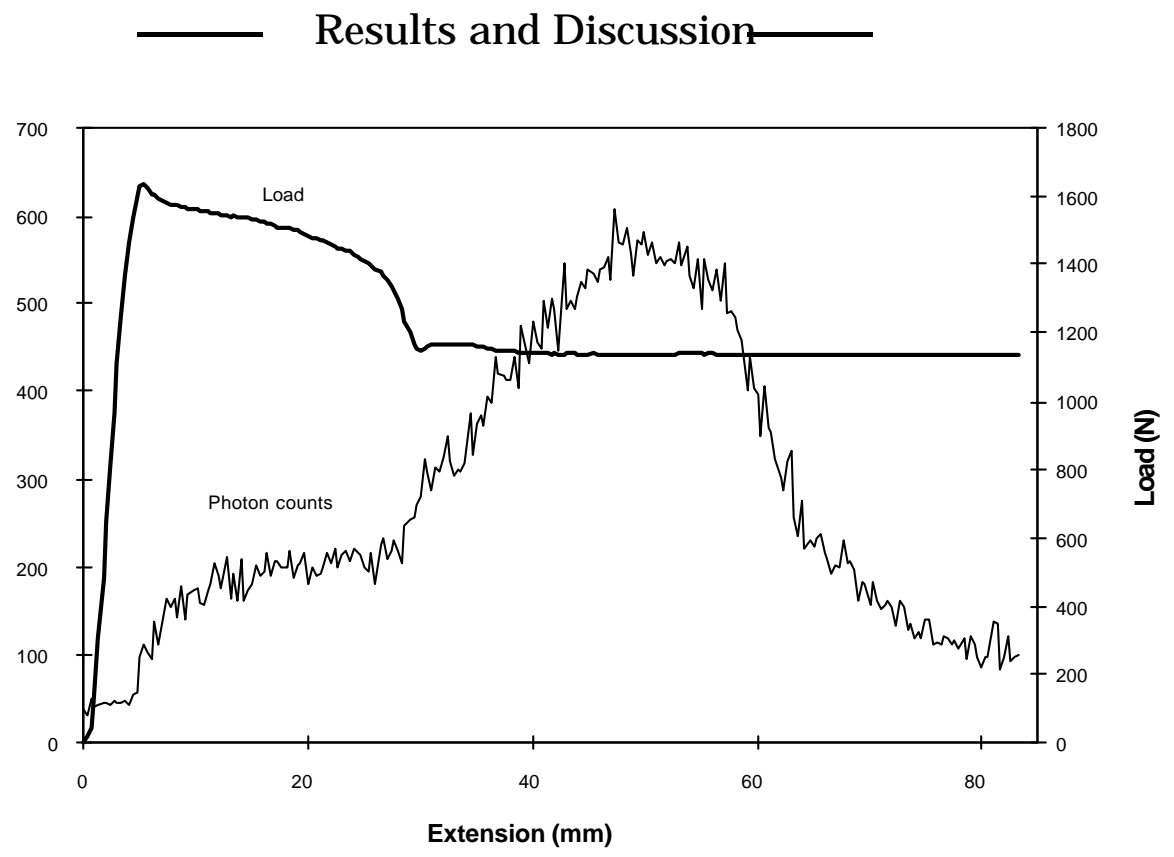

Figure 3.2. The simultaneous CL and load-extension curve from an injection moulded PA66 specimen

\subsubsection{Geometrical Factors Influencing Luminescence}

In some of the specimens used the luminescence peak did not coincide with the onset of necking, but occurred slightly later. The reason for this is that the neck was not always formed at the centre of the specimen. The photomultiplier, on the other hand, always measures at the centre of a specimen. After the initial neck is formed, the neck shoulders travel over the specimen and will thus eventually reach the detection area of the photomultiplier (PMT). As soon as the neck shoulder reaches the detection area of the PMT, the luminescence peak is detected. The observed decrease in intensity is thus not a true decrease in emitted light but is due to the fact that the neck shoulder has travelled out of the detection area of the PMT. The maximum detection area of the PMT is $40 \mathrm{~mm}$ in diameter. If the area is decreased, the peak width will also decrease since the PMT is detecting the neck for a shorter time.

Altogether, this shows that the luminescence observed is strongly related to the neck shoulder and that only very little luminescence is emitted from the material after conversion to a fibrillar structure. Some of the specimens used formed a second neck, as shown in Figure 3.1, which, if it occurred in front of the photo multiplier, also induced luminescence. The second luminescence peak reported by O'Shea was most probably due to a second neck formation.

\subsubsection{Relation between Luminescence Intensity and Stress Induced Adiabatic Heat}

During the extension of a tensile specimen mechanical work is converted to heat. This adiabatic heating will result in a temperature rise of the specimen. The distribution of this heat in the specimen is clearly illustrated by an IR video film that was recorded of a specimen during extension. Three pictures which were taken 
from the film are presented in Figure 3.3. They represent the pre-necking state, neck formation and strain hardening. Before necking the temperature is evenly distributed over the specimen, but at and after necking it is concentrated at the neck shoulders. The emission of luminescence seems to be distributed in the same way. The white circles in the figure show the maximum diameter of the PMT detection area. The neck is formed within the detection area, and the luminescence intensity is thus detected at the drop in the load curve. In the last picture the neck shoulder has travelled out of the detection area, which is now focused on a part of the specimen that is cooling down.

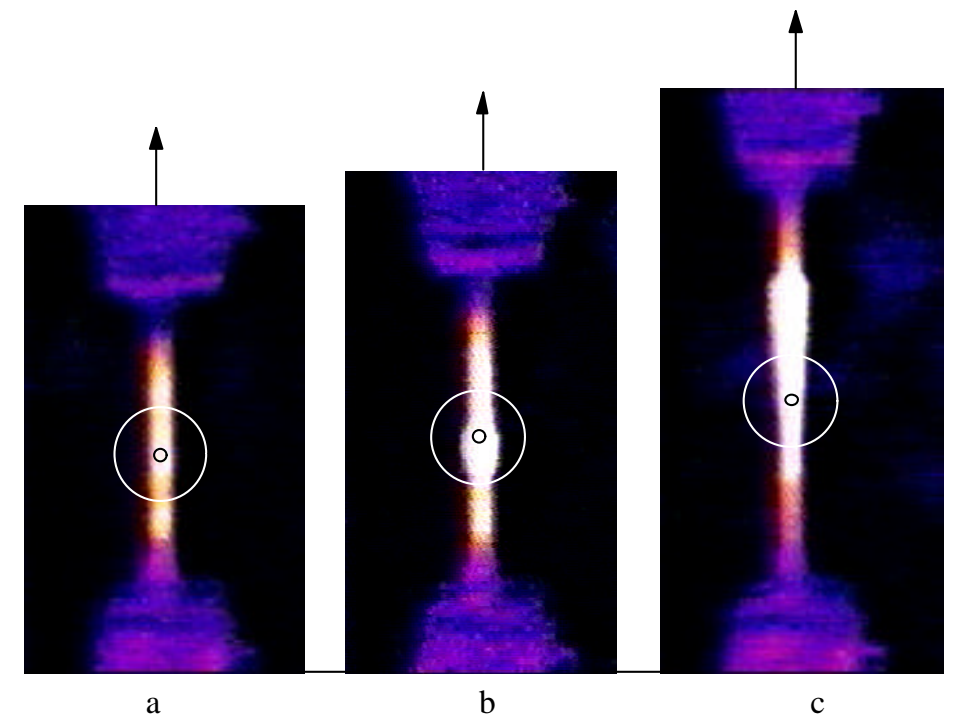

Figure 3.3. Three pictures taken from an IR video film of an ASTM tensile specimen during extension. Picture (a) was taken before necking, (b) at necking and (c) during strain hardening, when the neck shoulder is travelling over the specimen. The white circles represents a photo multiplier detection area of $40 \mathrm{~mm}$ in diameter and the black circles a detection area of $5 \mathrm{~mm}$ in diameter.

The abovementioned observations clearly demonstrate that temperature increase and luminescence emission follow each other. It was, however, not clear whether the luminescence was an effect of the temperature rise or if molecular rearrangements were responsible for both of them. What is clear, however, is that since the heat emission is in the infrared (IR) region and the photomultiplier is only sensitive up to $650 \mathrm{~nm}$, the emission is not the heat itself.

For further investigation of the relation between heat and luminescence intensity a non-contact IR sensor was installed opposite the PMT (see Figure 2.3). It measures the temperature of the specimen during extension. The detection area of the sensor is only $5 \mathrm{~mm}$ in diameter. In order to get a better correlation between the result from the PMT and the sensor, the detection area of the PMT was decreased to $5 \mathrm{~mm}$ in diameter. This corresponds to the black circles in Figure 3.3. A smaller detection area will result in a much sharper luminescence peak since the neck shoulder will travel out of focus much faster. Figure $3.4 \mathrm{a}$ shows the load, photon counts and temperature of the specimen vs. extension. Figure $3.4 \mathrm{~b}$ is a close view of the photon counts and temperature of the specimen vs. extension. As can be seen in the figures, luminescence and temperature follow each other quite closely. 


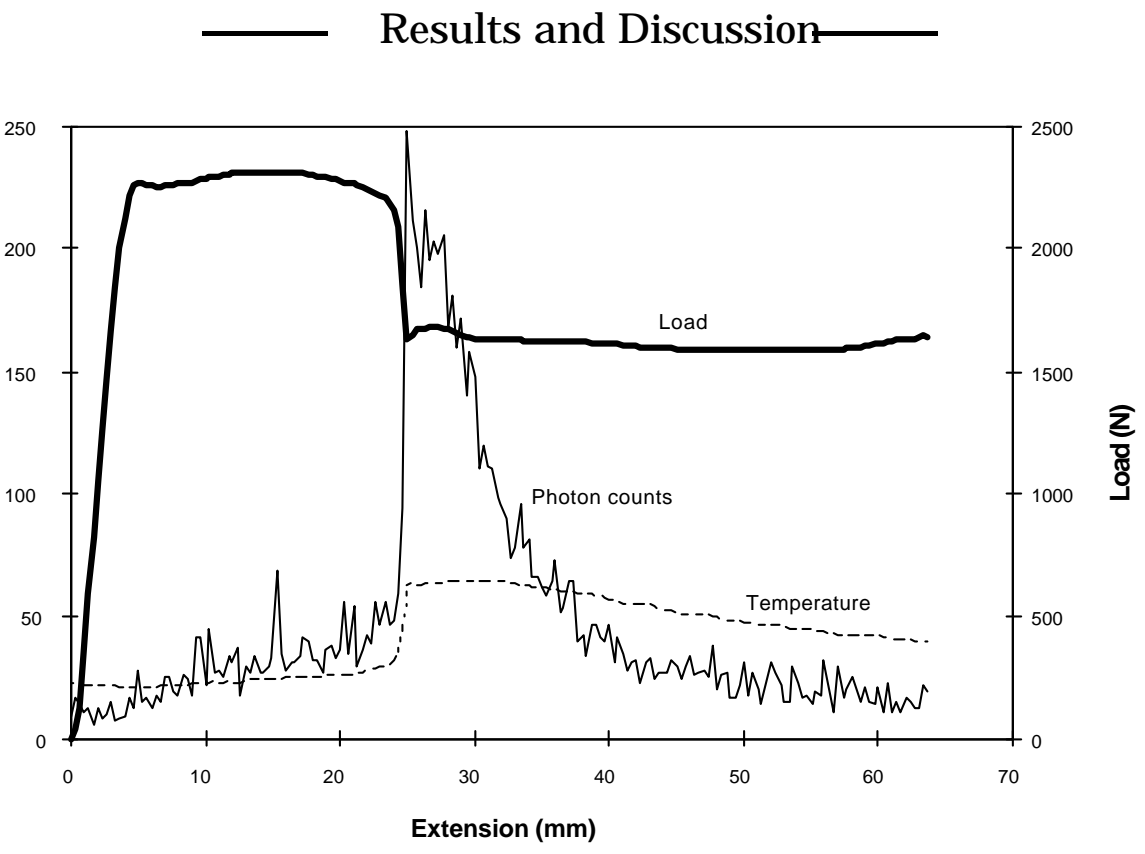

EMBED

Figure 3.4a. The load, photon counts and temperature of the specimen vs. extension.

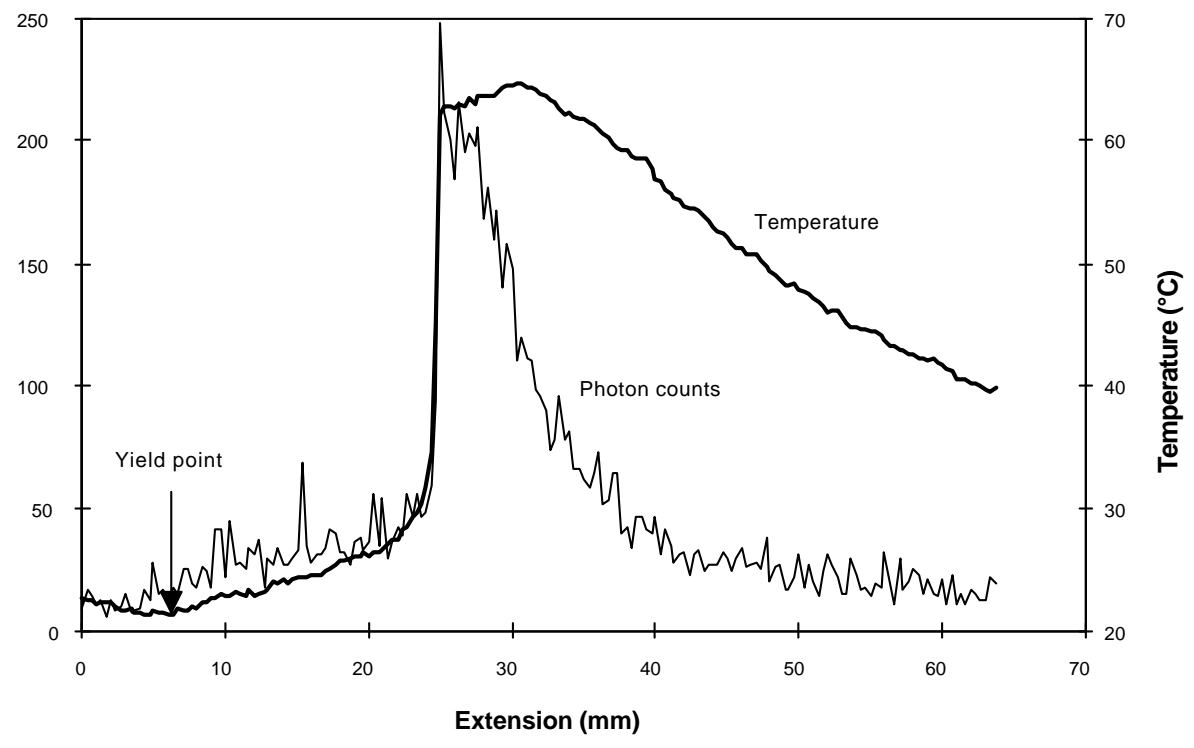

EMBED

Figure 3.4b. A close view of the photon counts and temperature of the specimen vs. extension.

As can be seen in Figure $3.4 \mathrm{~b}$, the decrease in temperature of the specimen is linear while the decrease in luminescence intensity is exponential. This is an indication that the observed light is chemiluminescence since the CL intensity is related to temperature by an Arrhenius type expression. The activation energy was calculated to be $124 \mathrm{~kJ} / \mathrm{mol}$.

\subsubsection{Factors Affecting Luminescence Intensity and Stress Induced Adiabatic Heat}

Polyamides are known to be very hygroscopic due to their ability to form hydrogen bonds [paper VII]. Moisture plasticises the material and lowers the module and maximum load while increasing the strain at break. This results in a decrease in 
heat generation. The luminescence intensity also decreases with increased moisture contents; see Figure 3.5.

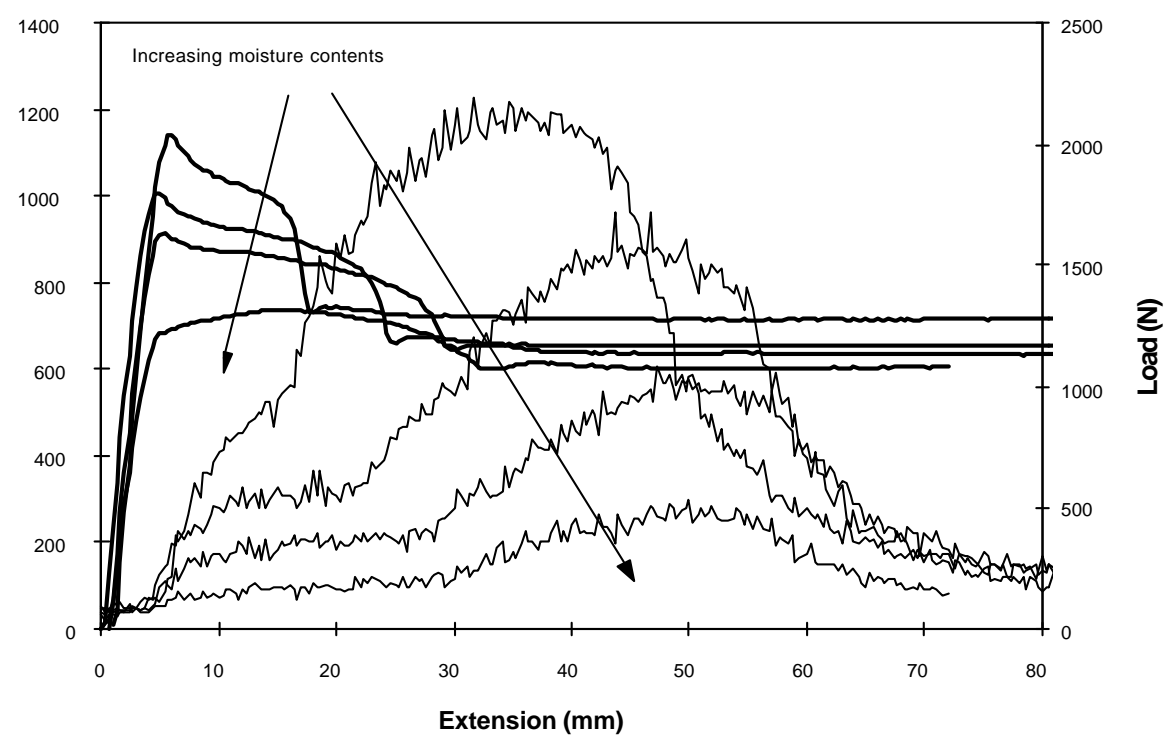

Figure 3.5. Load and photon counts of PA6 specimens with different degrees of moisture content.

The elongation rate during the experiments was normally $20 \mathrm{~mm} / \mathrm{min}$ for the ASTM specimens and $5 \mathrm{~mm} / \mathrm{min}$ for the specially designed ones. Elongation rate is another factor that affects the temperature of the specimen. The higher the elongation rate, the higher the temperature. As expected, the luminescence intensity increased with elongation rate, both at the region before and after necking; see Figure 3.6.

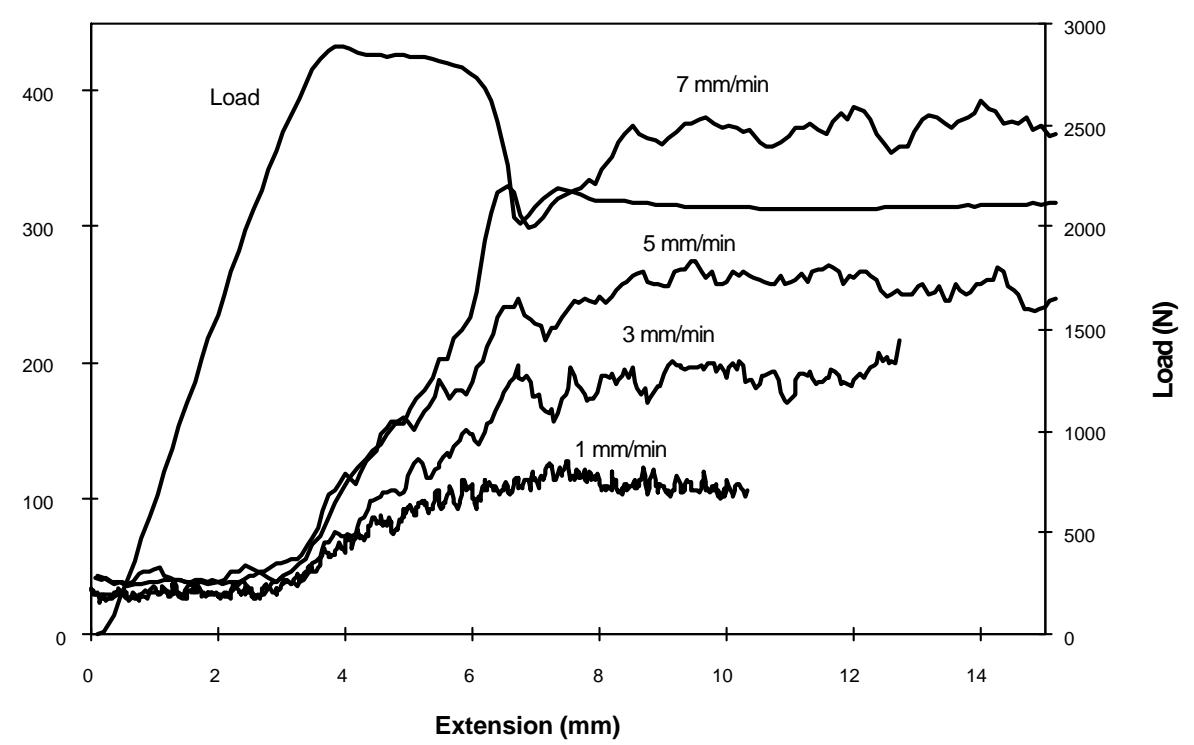

EMBED

Figure 3.6. Influence of elongation rate on the luminescence intensity of PA66 specimens.

\subsubsection{Factors Affecting Luminescence Intensity but not Stress Induced Adiabatic Heat}

The production, properties and applications of PA6 and PA66 are very similar (see Section 1.2.1). The heat produced during extension is the same for both types, as 
can be seen in Figure 3.7, but the luminescence signal is much lower for PA6 than for PA66.

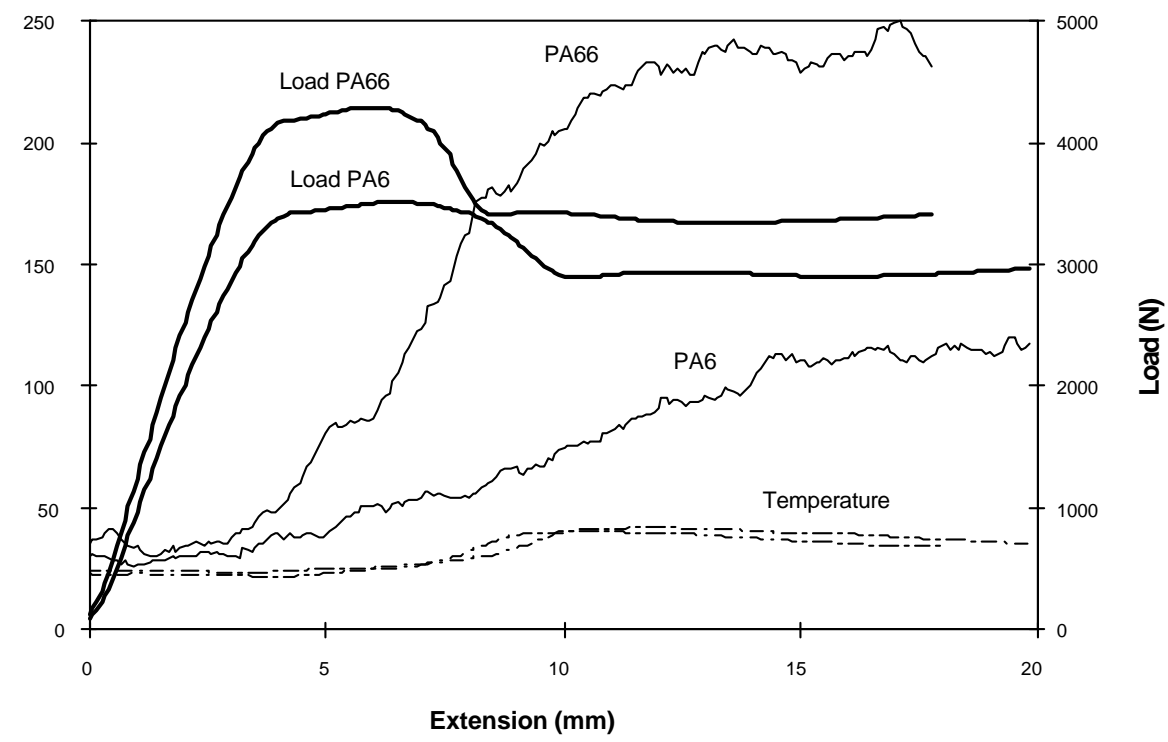

\section{EMBED}

Figure 3.7. The load, photon counts and temperature vs. extension of a PA6 and a PA66 specimen.

Tests with injection moulded specimens of commercial grades of PP, HDPE, and LDPE did not result in any light emission, even though they did give rise to stress induced adiabatic heat upon extension. Specimens injection moulded with unstabilised grades of PP and HDPE, however, gave the same type of luminescence at necking as the polyamides. Neither the luminescence at necking nor the temperature at necking were, however, as high as those observed for the polyamides.

A chemical treatment of the specimens with sulphur dioxide had a great effect on the luminescence signal without decreasing the heat produced during extension. Curve (a) in Figure 3.8 represents an untreated specimen and curve (b) represents a specimen subjected to $\mathrm{SO}_{2}$. 


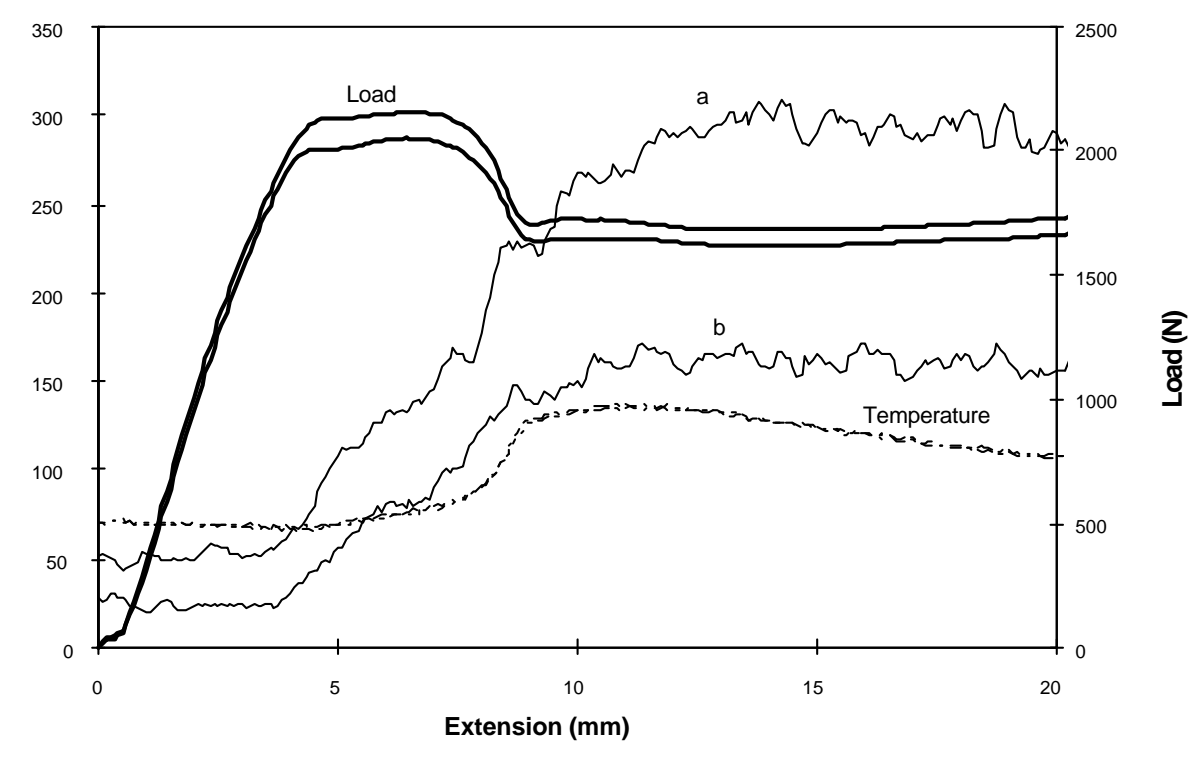

EMBED

Figure 3.8. Curve (a) represents an untreated PA66 specimen and curve (b) from a PA66 specimen treated with $\mathrm{SO}_{2}$.

\subsubsection{Origin of Luminescence}

$\mathrm{SO}_{2}$ is known to decompose hydroperoxides. Thus, the result in Figure 3.8 indicates that hydroperoxides play a part in the luminescence mechanism and that the light emission is chemiluminescence due to hydroperoxide decomposition. The activation energy of $124 \mathrm{~kJ} / \mathrm{mol}$, calculated from data in Figure $3.4 \mathrm{~b}$, also indicates decomposition of hydroperoxides. For studying the possible presence of hydroperoxides in the test specimens, the SCL instrument was used as a conventional CL instrument. Figure 3.9 shows the result of a ramped temperature experiment performed in inert atmosphere. Curve (a) represents the first heating cycle and curve (b) the second heating cycle after the specimen has cooled down to room temperature, still in inert atmosphere (see Section 1.4.2 Chemiluminescence in Inert Atmosphere). The area under the curve is taken to be proportional to the amount of hydroperoxides in the specimen. The large area under curve (a) indicates the presence of hydroperoxides. In the second heating cycle most of the hydroperoxides in the specimen have been destroyed and a much lower signal can be detected. The injection moulded polyamide specimens seemed to contain thermally unstable hydroperoxides right from the start of their service life. Iodometric measurements have verified this. The iodometry was designed to give a qualitative measure of hydroperoxides and no quantification was made. 


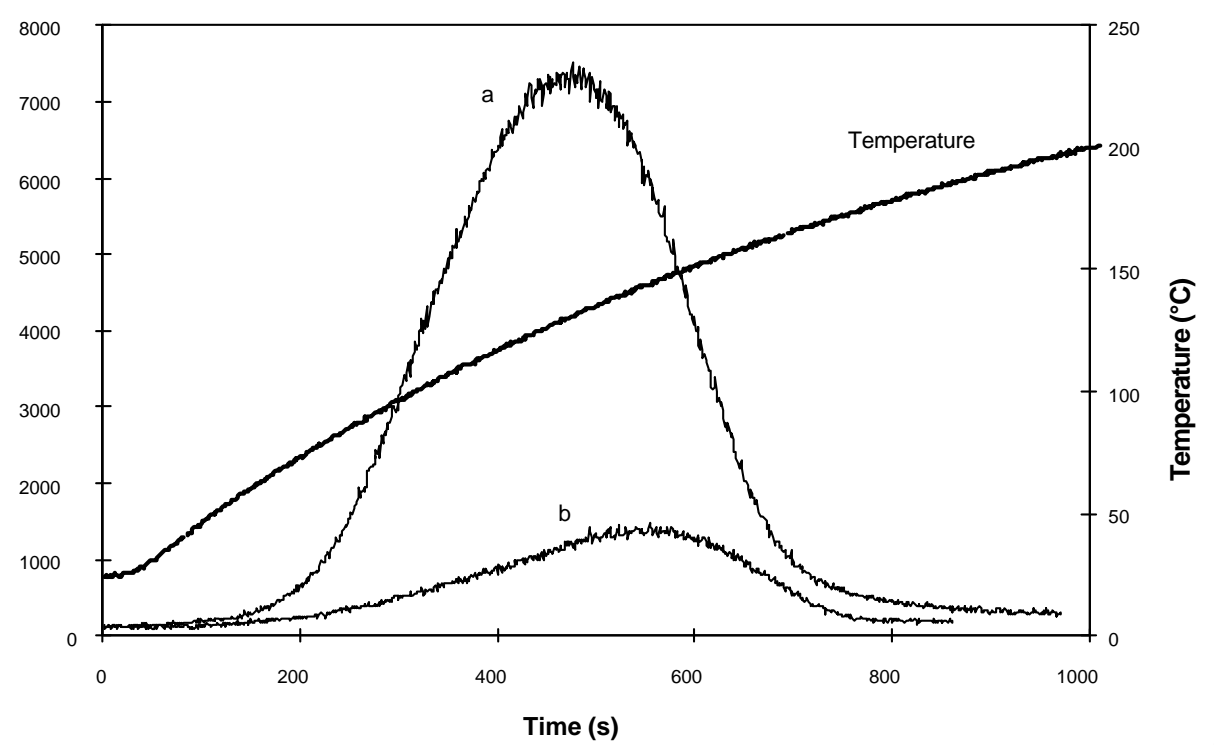

EMBED

Figure 3.9. CL curves for PA66 from the first (curve a) and second (curve b) heating cycles in a ramped CL run in nitrogen.

If the specimen is stressed after the first heating cycle in nitrogen, as shown by curve (b) in Figure 3.10, the luminescence is much lower than if it is stressed under unpreheated conditions, as represented by curve (a). It seems as if the luminescence detected during straining is due to thermal decomposition of hydroperoxides. The stress-induced adiabatic heating, which after necking is localised in the travelling neck shoulders of the specimen, is sufficient to decompose the thermally unstable hydroperoxides that are present in the test material. As can be seen in Figure 3.9, the temperature at which the hydroperoxide decomposition starts is below the temperature induced during extension $\left(65^{\circ} \mathrm{C}\right.$ in Figure 3.4b). However, the actual role of hydroperoxides in polymer chemiluminescence reactions, especially in polyamides, is controversial (see Section 1.4.2 Chemiluminescence in Inert Atmosphere).

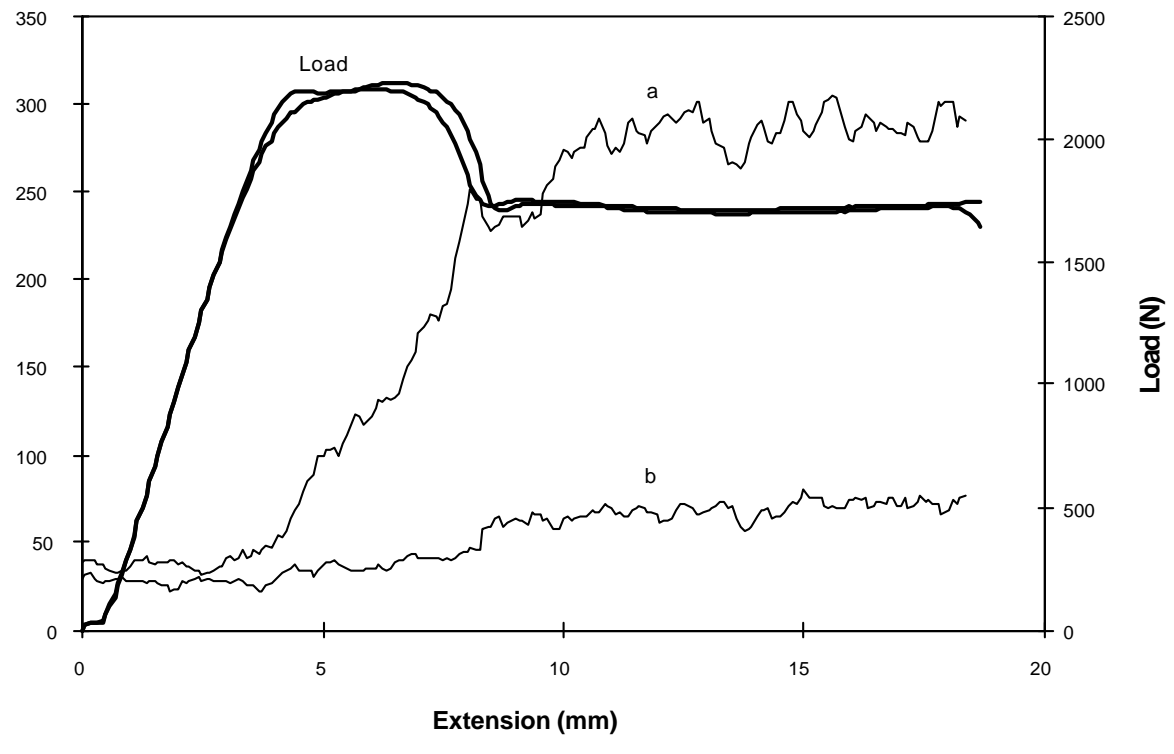

EMBED 
Figure 3.10. Curve (a) represents an untreated PA66 specimen and curve (b) a specimen which has been heat treated in nitrogen.

The detected hydroperoxides were probably induced during processing. This could possibly explain the lower emission from PA6 than from PA66 since one of the main differences between them is a lower melting point for PA6 $\left(225^{\circ} \mathrm{C}\right)$ than for PA66 $\left(265^{\circ} \mathrm{C}\right)$. Thus PA6 requires a lower processing temperature, which reduces the risk of radical formation and susequent hydroperoxide formation. The polypropylene and polyethylene first studied were commercial grades which neither contained any measurable amounts of hydroperoxides nor gave any luminescence. Later studied specimens made from unstabilised grades did, however, produce light emission upon extension. Since these specimens did not have any stabilisers they were expected to contain hydroperoxides induced during processing.

From the abovementioned observations during tensile testing of polyamides it can be concluded that the luminescence at necking is not caused by mechano-chemical chain scission and radical formation when the molecular structure is broken up. Such phenomena may still occur but have no measurable efect on the luminescence observed. Instead the effect of stress is to induce by mechanical work a temperature rise causing decomposition of hydroperoxides and generation of chemiluminescence.

\subsection{Luminescence at Fracture}

\section{Paper [III]}

As mentioned in the previous section, luminescence at fracture was only observed from a few specimens. The reson was that only these specimens fractured within the detection area of the PMT. The tensile specimen specially designed for the SCL instrument (see Section 2.1.5) did, however, almost exclusively fracture within the focus of the PMT. Figure 3.11 shows the load, photon counts and temperature of a PA6 specimen elongated by $5 \mathrm{~mm} / \mathrm{min}$. The increase in the photon emission and in temperature at both neck formations and at fracture are clearly shown.

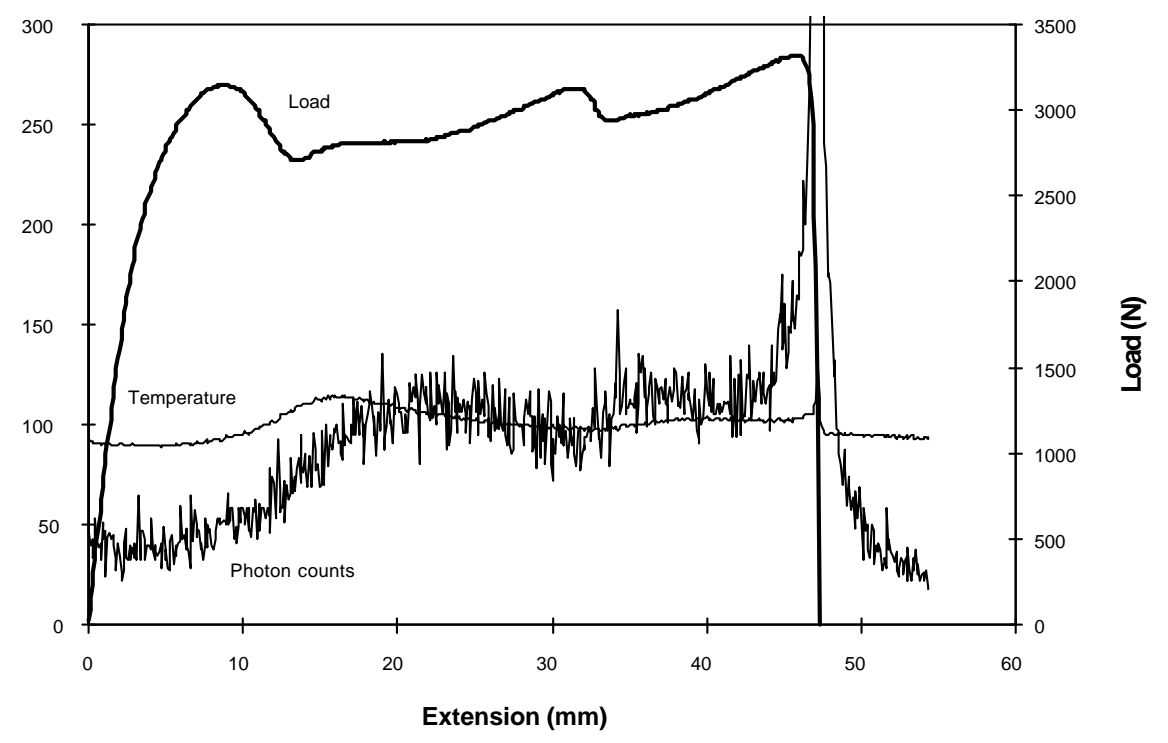


Figure 3.11. Simultaneous SCL and load-extension curve of an injection moulded PA6 specimen. The figure shows load, photon counts and specimen temperature vs. extension.

The luminescence at both neck formations has been ascribed above to hydroperoxide decomposition, but the emission at fracture could be superposed with luminescence from yet another source, e.g. chain scission. In order to investigate this, the hydroperoxides had to be removed prior to the SCL test. Hydroperoxides can be decomposed by e.g. sulphur dioxide or heat treatment in nitrogen. Figure 3.12a shows load and photon counts vs. extension of a PA6 specimen treated with sulphur dioxide.

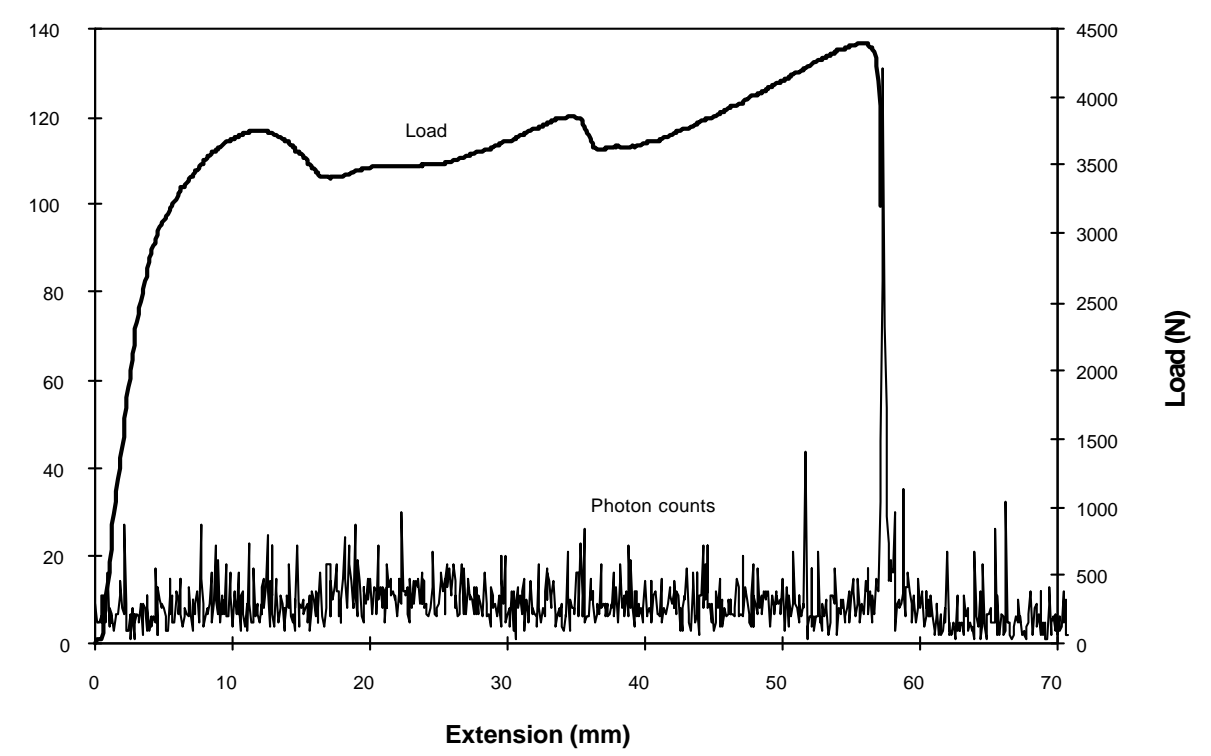

Figure 3.12a. Load and photon counts vs. extension of a PA6 specimen elongated by $5 \mathrm{~mm} / \mathrm{min}$. The specimen was treated with $\mathrm{SO}_{2}$ prior to the measurement and should thus be free from thermally unstable hydroperoxides.

As can be seen in the figure, only very little luminescence (just slightly more than background noise) is emitted from the specimen up until fracture. At fracture there is a sudden burst of light which then quickly decreases down to the level of background noise. The burst of light is, however, not as strong as for the specimen containing hydroperoxides, as shown in Figure 3.11, indicating that the luminescence at fracture is a superposition of hydroperoxide decomposition and some other phenomenon. Figure $3.12 \mathrm{~b}$ is a close view of the load and photon counts at fracture. 


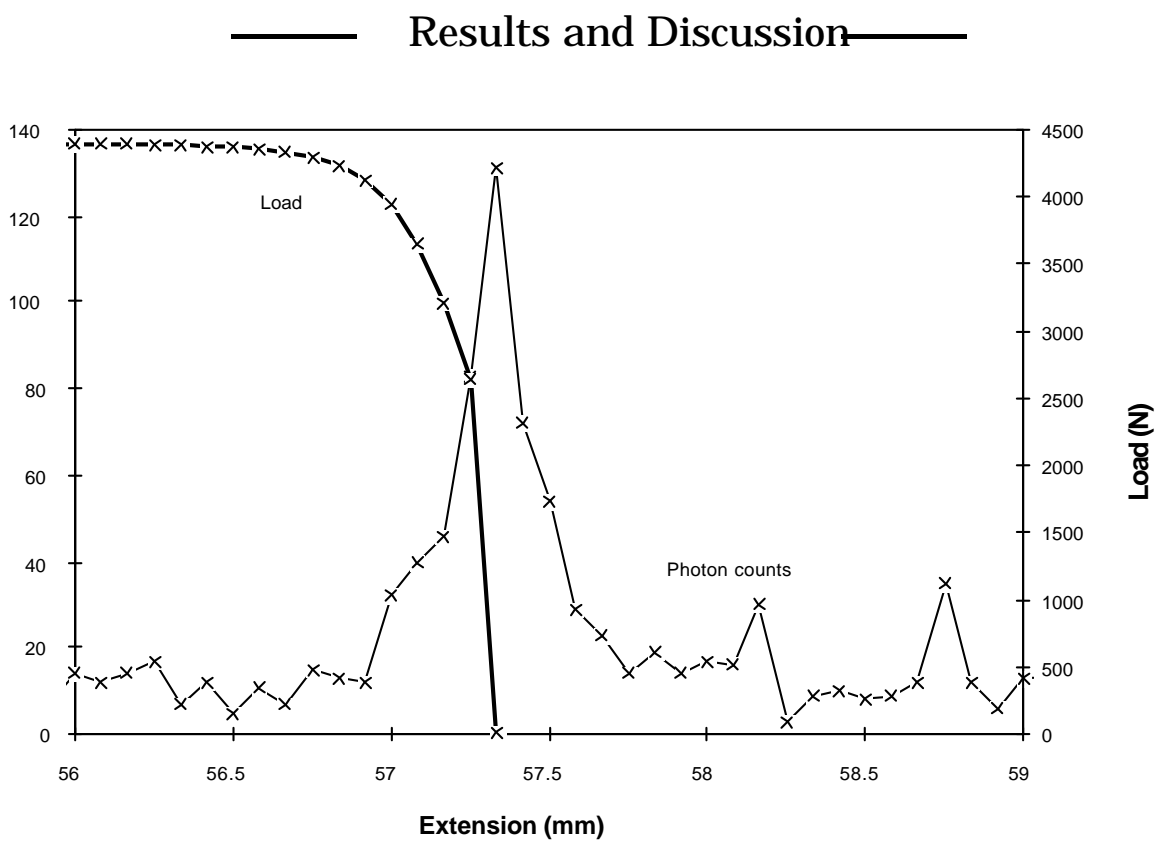

EMBED

Figure $3.12 \mathrm{~b}$. Close view of the load and photon counts at fracture.

Figure 3.12c shows the luminescence and the temperature of the same specimen. Both the first and the second neck formation as well as fracture resulted in an increase in the temperature of the specimen. There was, however, only light emission at fracture. This is a good indication that the hydroperoxides have been decomposed and that the luminescence at fracture has another origin.

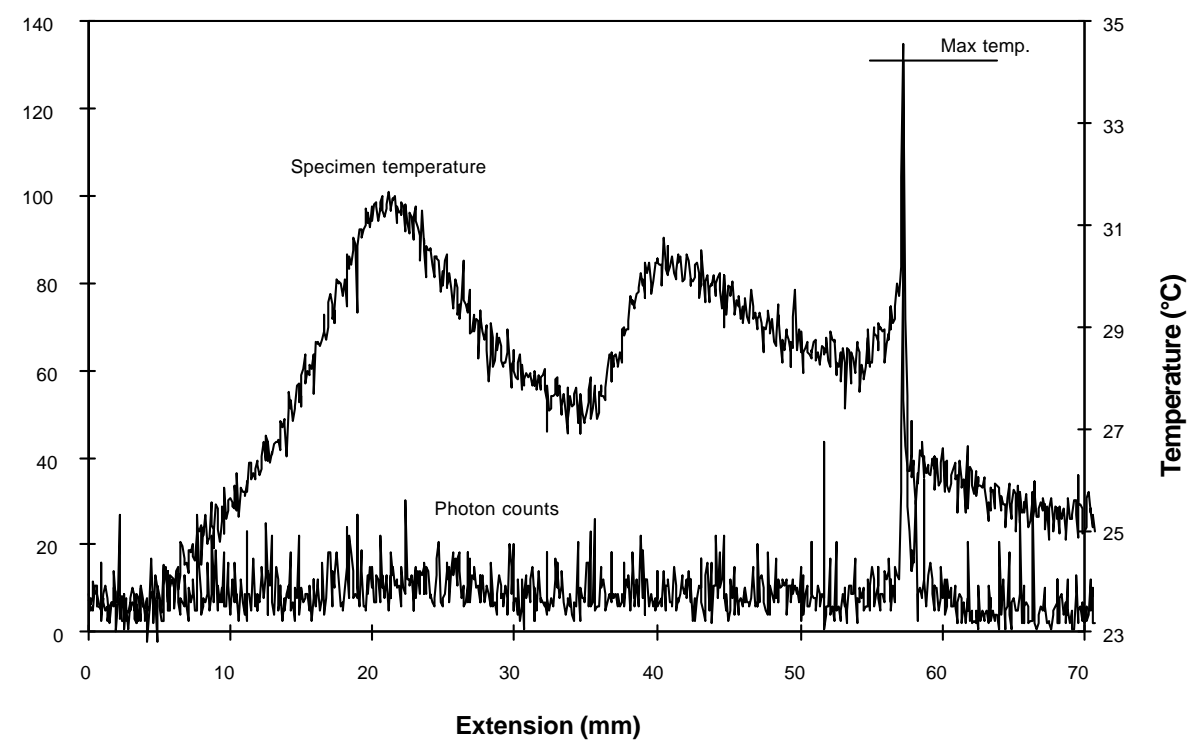

Figure 3.12c. Photon counts and specimen temperature vs. extension of the same specimen as shown in Figure 3.12a and b.

Chemiluminescence originating from peroxyl radicals formed as a result of chain scission is oxygen dependent. Figure 3.13 shows the luminescence from a PA6 specimen which has been stressed in an inert atmosphere. Prior to the measurement the specimen was both treated with $\mathrm{SO}_{2}$ and heat treated in nitrogen. This was done in order to decompose all hydroperoxides and to remove oxygen from the specimen. As can be seen in the figure, there is no burst of luminescence at fracture. Both 
thermo- and triboluminescence should be unaffected by the absence of oxygen and are thus ruled out as a possible source of light. The result shown in Figure 3.13 is therefore a strong indication that the emitted light at fracture of PA6 is chemiluminescence induced by chain scissions.

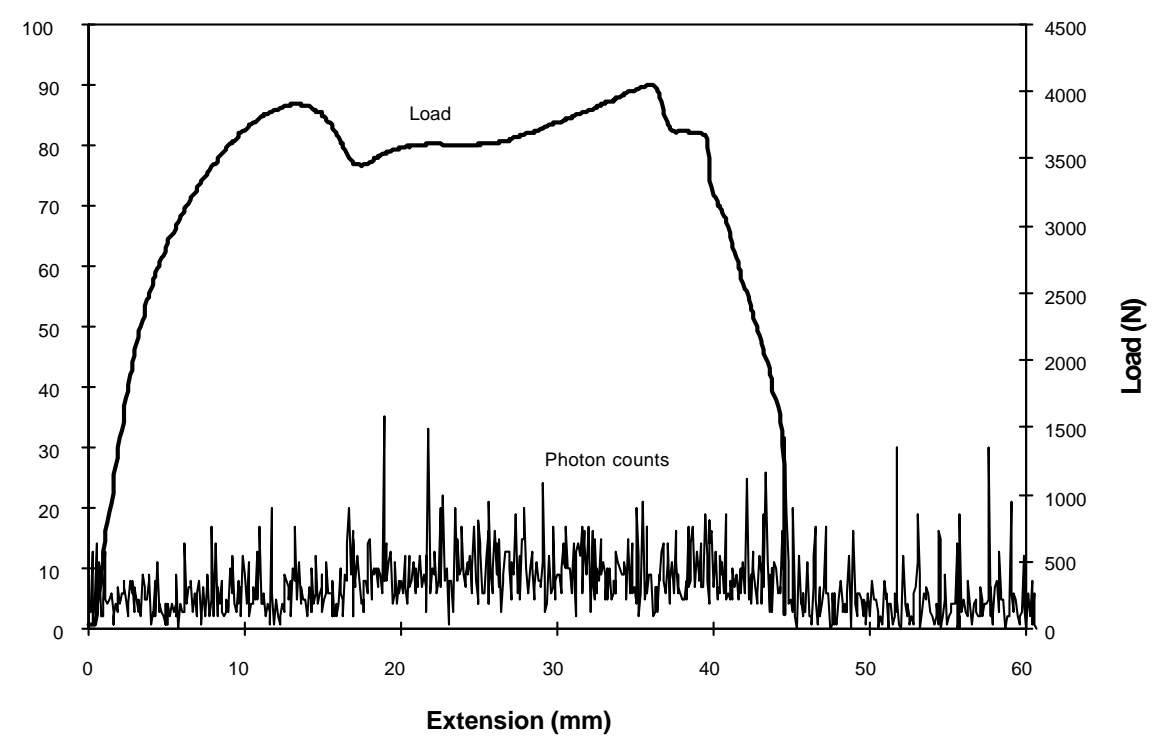

Figure 3.13. Load and photon counts from a heat and $\mathrm{SO}_{2}$ treated PA6 specimen elongated by 5 $\mathrm{mm} / \mathrm{min}$ in an inert atmosphere.

The fracture of an unaged polyamide 6 specimen is ductile at the elongation rates used here. However, a specimen which has been aged in an oven at $120^{\circ} \mathrm{C}$ for 72 hours is no longer ductile but instead brittle. Figure 3.14 shows the load and luminescence from an aged PA6 specimen. Even at brittle fracture PA6 gives a burst of luminescence.

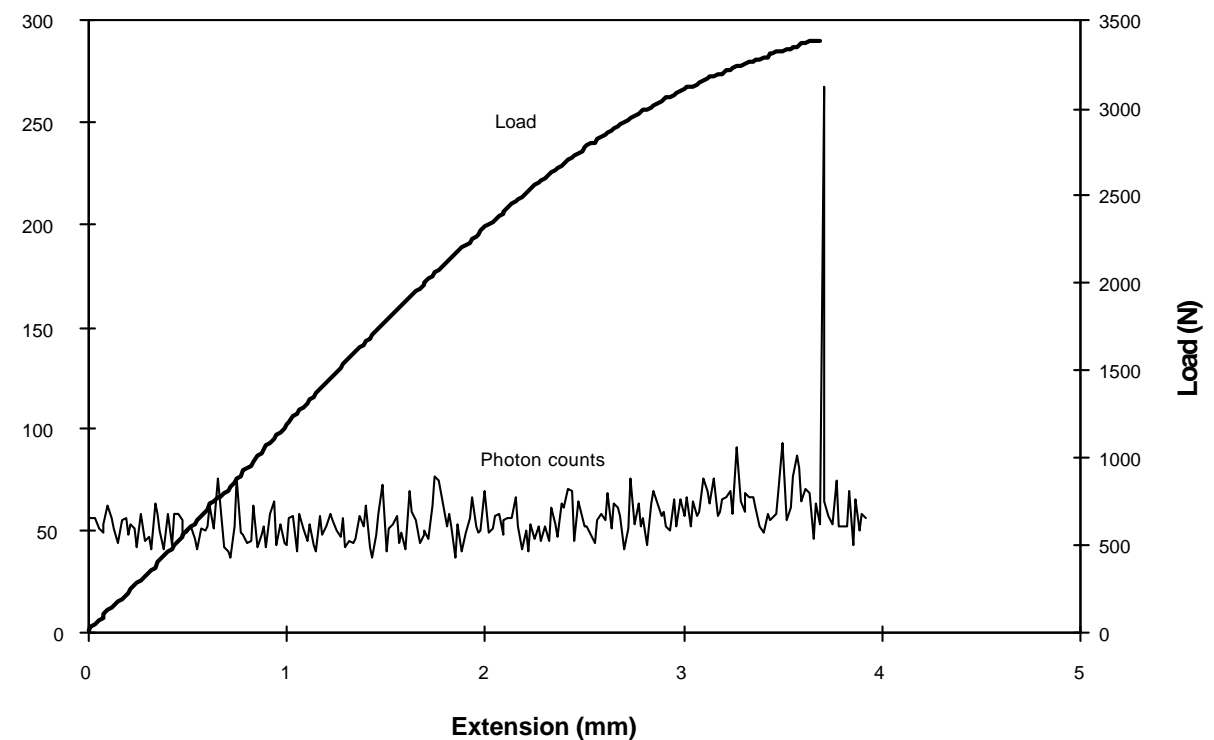

Figure 3.14. Load and photon counts from a pre-aged $\mathrm{SO}_{2}$ treated PA6 specimen elongated by 5 $\mathrm{mm} / \mathrm{min}$. 
HDPE, which was reportedly stabiliser free and thus, due to its poor processing stability contained hydroperoxides originating from processing, gave the same general luminescence as polyamide specimens during tensile testing. Polyethylene, however, is much more ductile than polyamide, showing an ultimate elongation of more than 5 times that of PA6 at an elongation rate of $5 \mathrm{~mm} / \mathrm{min}$. The HDPE specimen was highly oriented prior to fracture and the fracture surface was fibrous. The load and photon counts of an HDPE specimen, after sulphur dioxide treatment, is shown in Figure 3.15a. There is an increase in luminescence at fracture but it is not, as for PA6, a sudden burst of light but rather a continuous increase up to fracture. The load also continuously decreases during this period as a result of a continuous rupture of the fibrous material. Figure $3.15 \mathrm{~b}$ is a close view of the load and luminescence at fracture.

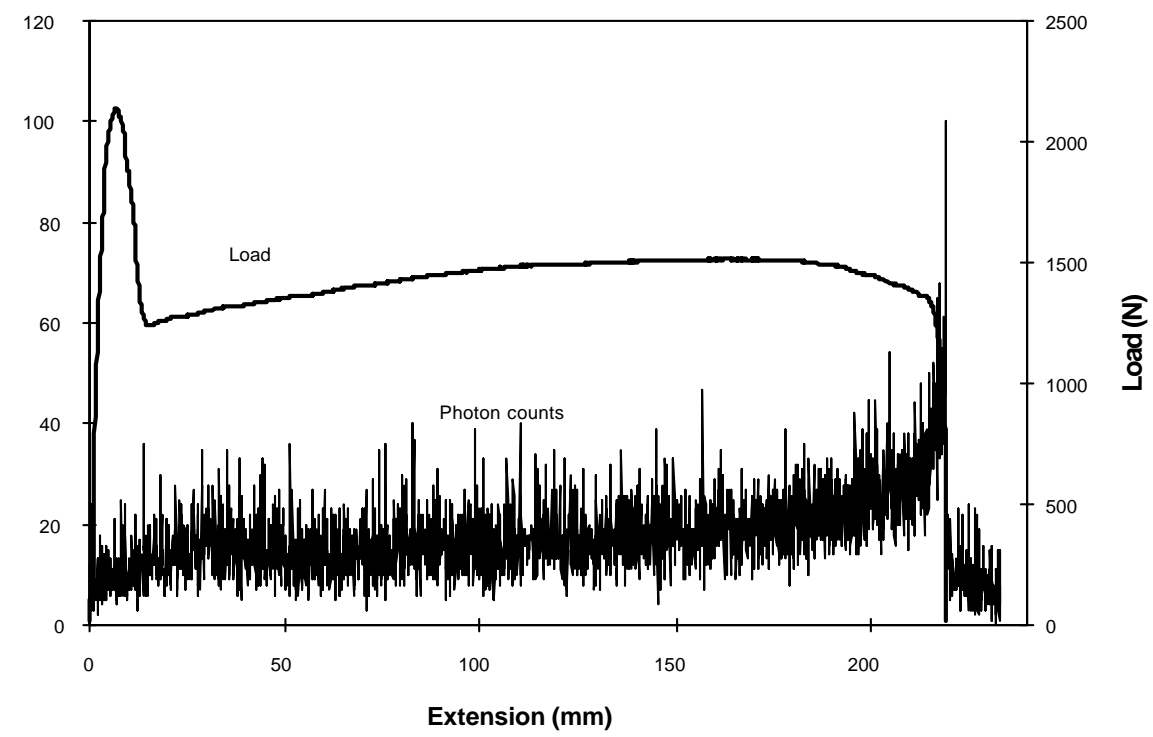

Figure 3.15a. Load and photon counts vs. extension of an HDPE specimen elongated by $5 \mathrm{~mm} / \mathrm{min}$. The specimen was treated with $\mathrm{SO}_{2}$ prior to the measurement and should thus be free from thermally unstable hydroperoxides.

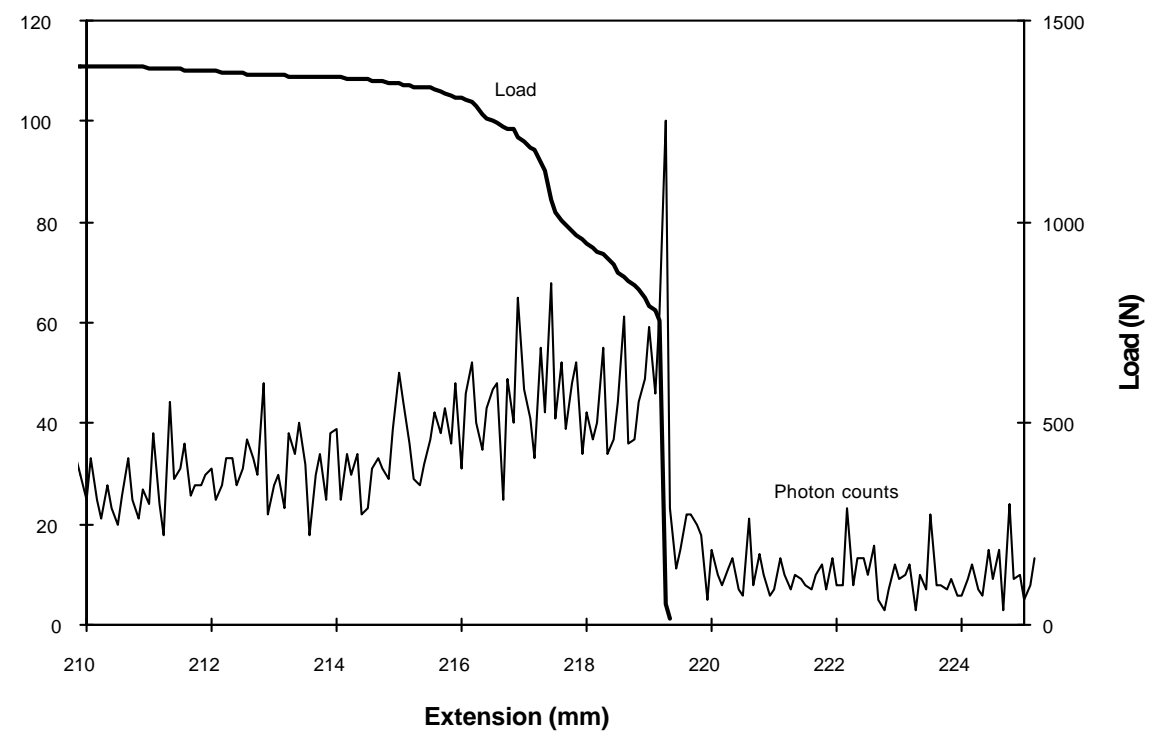


Figure 3.15b. Close view of the load and photon counts at fracture.

If the elongation rate is increased to $50 \mathrm{~mm} / \mathrm{min}$, the fracture of HDPE is not, as can be seen in Figure 3.16, accompanied by luminescence. The luminescence is, however, higher than the level of the background noise during the whole run. The fracture is still ductile, but it occurs after a much shorter extension of the specimen than at the lower elongation rate. The material is thus not oriented to the same extent and the fracture has neither the apperance of a continuous rupture of fibrous material. An aged HDPE specimen, failing by brittle fracture, does not either give luminescence at fracture, as can be seen in Figure 3.17.

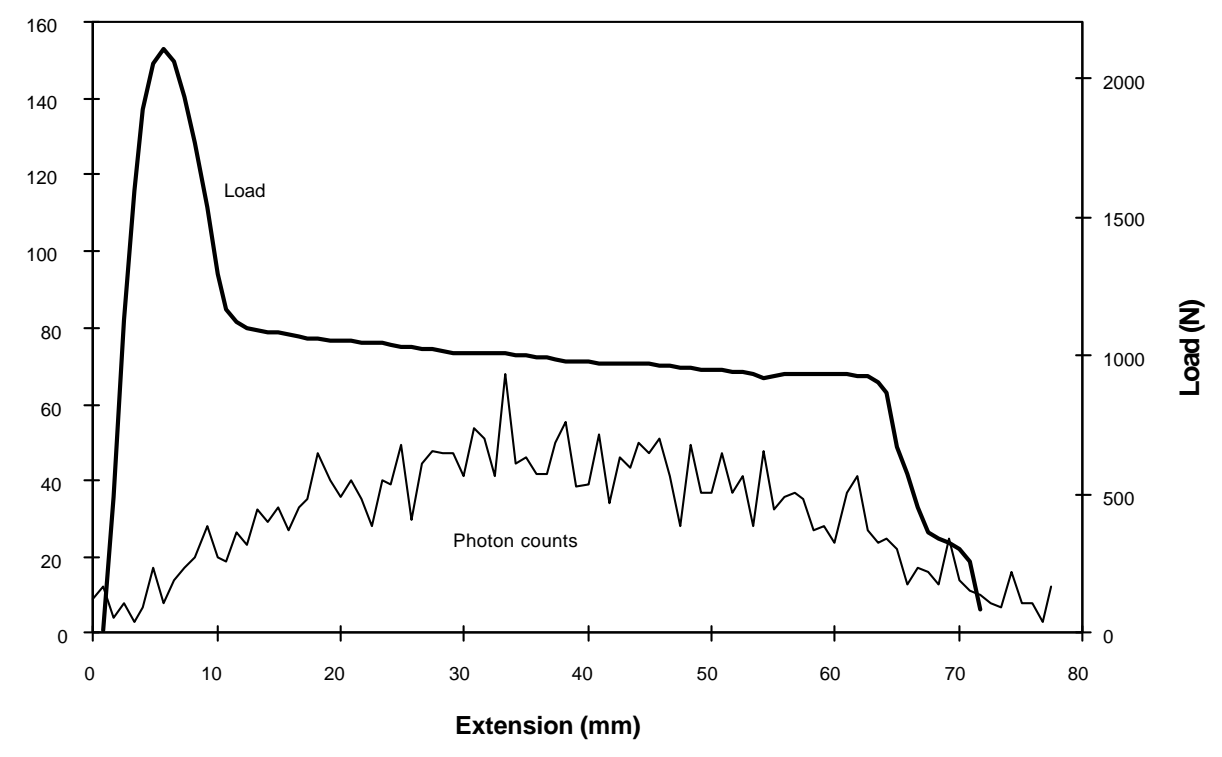

Figure 3.16. Load and photon counts vs. extension of an $\mathrm{SO}_{2}$ treated HDPE specimen elongated by $50 \mathrm{~mm} / \mathrm{min}$.

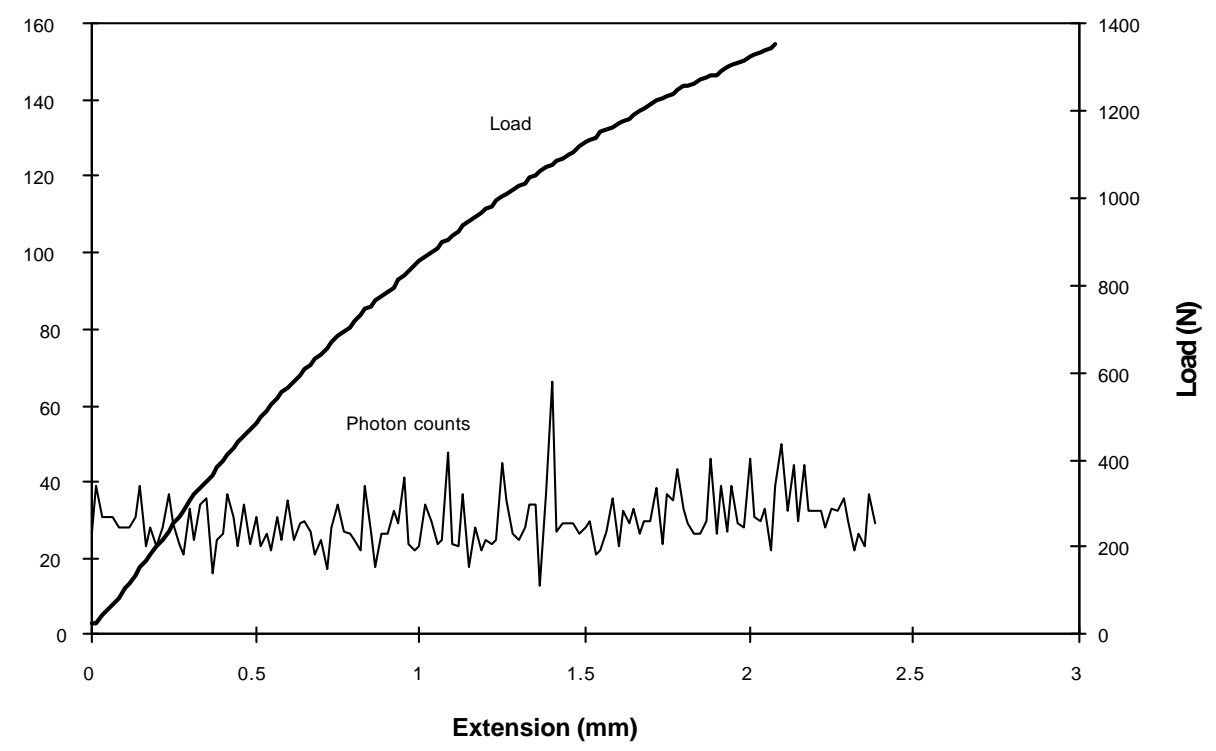

Figure 3.17. Load and photon counts vs. extension for a pre-aged $\mathrm{SO}_{2}$ treated $\mathrm{HDPE}$ specimen showing brittle fracture. The elongation rate was $5 \mathrm{~mm} / \mathrm{min}$. 
Unstabilised $\mathrm{SO}_{2}$ treated polypropylene does not give any luminescence either at ductile or at brittle fracture, see Figures $3.18 \mathrm{a}$ and b. PP is less ductile than HDPE, showing an ultimate elongation of about $2 / 3$ of that of polyethylene at an elongation rate of $5 \mathrm{~mm} / \mathrm{min}$. Neither does PP like HDPE elongated by $50 \mathrm{~mm} / \mathrm{min}$, have the appearance of a fibrous material.

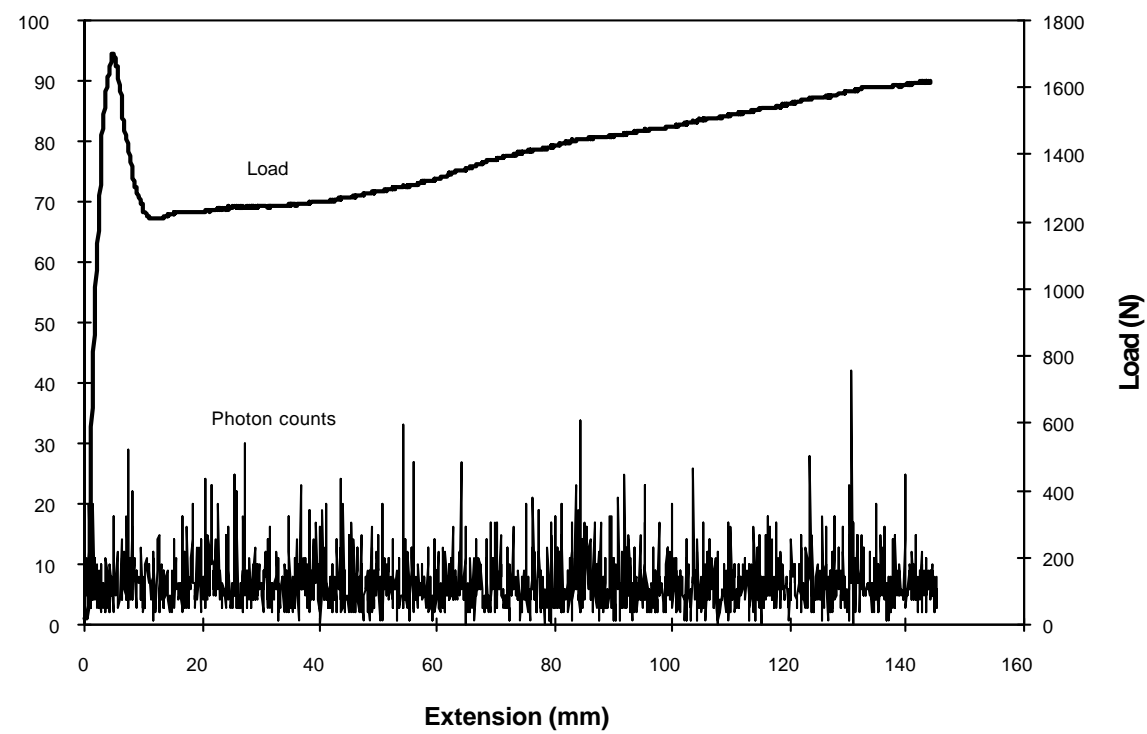

Figure 3.18a. Load and photon counts vs. extension for an unaged $\mathrm{SO}_{2}$ treated $\mathrm{PP}$ specimen showing ductile fracture. The elongation rate was $5 \mathrm{~mm} / \mathrm{min}$.

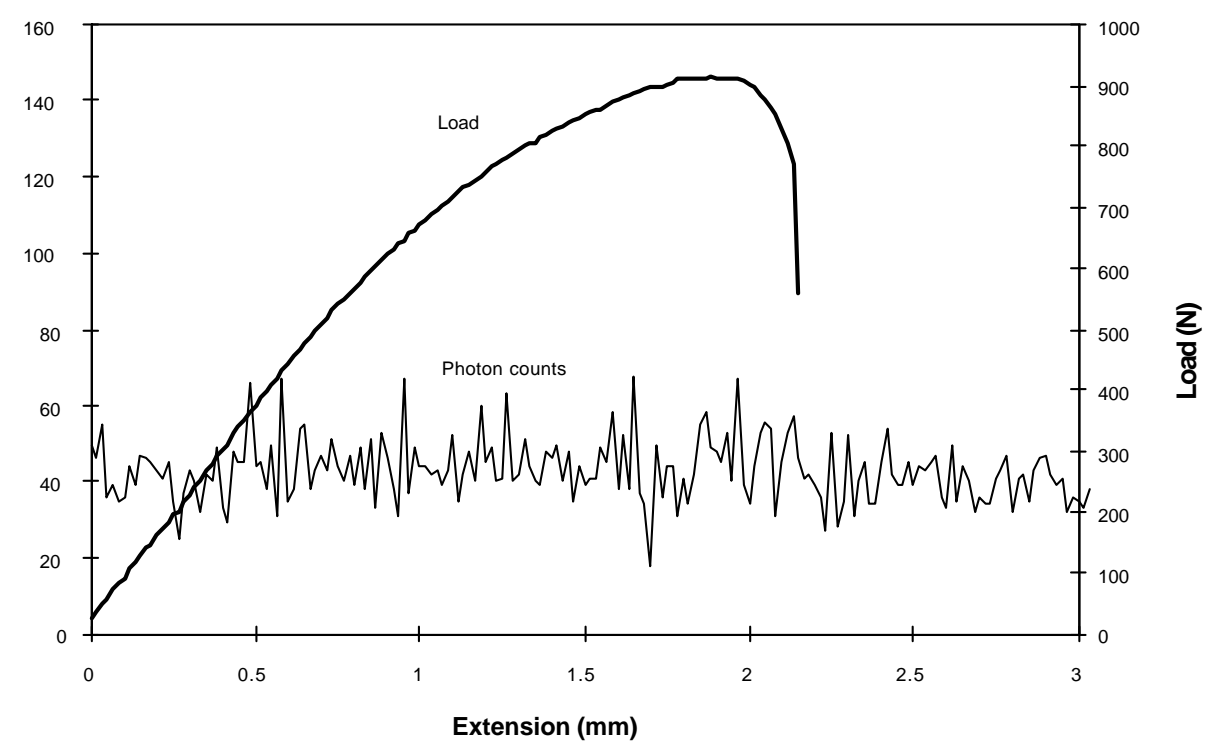

Figure 3.18b. Load and photon counts vs. extension for a pre-aged $\mathrm{SO}_{2}$ treated $\mathrm{PP}$ specimen showing brittle fracture. The elongation rate was $5 \mathrm{~mm} / \mathrm{min}$.

Summing up, it seems as if polyamide with its rigid structure produces radicals at both ductile and brittle fracture. HDPE only gives radical formation at fracture after the polymer has been transformed into a fibrous material. HDPE and PP which have not been sufficiently oriented to assume a fibrous structure does not yield radicals either at ductile or brittle fracture. 


\subsection{Influence of Thermoluminescence}

\section{[Paper IV]}

\subsubsection{Observations of Additional Luminescence During SCL Measurements}

In some of the measurements discussed in Section 3.1 the luminescence curve deviated from that which is normally observed. Curve (a) in Figure 3.19 represents the normally observed curve, which follows the temperature rise of the specimen. This has been attributed to thermal decomposition of hydroperoxides, i.e. chemiluminescence. However, the luminescence from the specimens represented by curves (b) and (c) does not follow the temperature increase but is substantional prior to necking, when the temperature is still low in the specimens. These specimens also produced slightly more light at necking than normally observed.

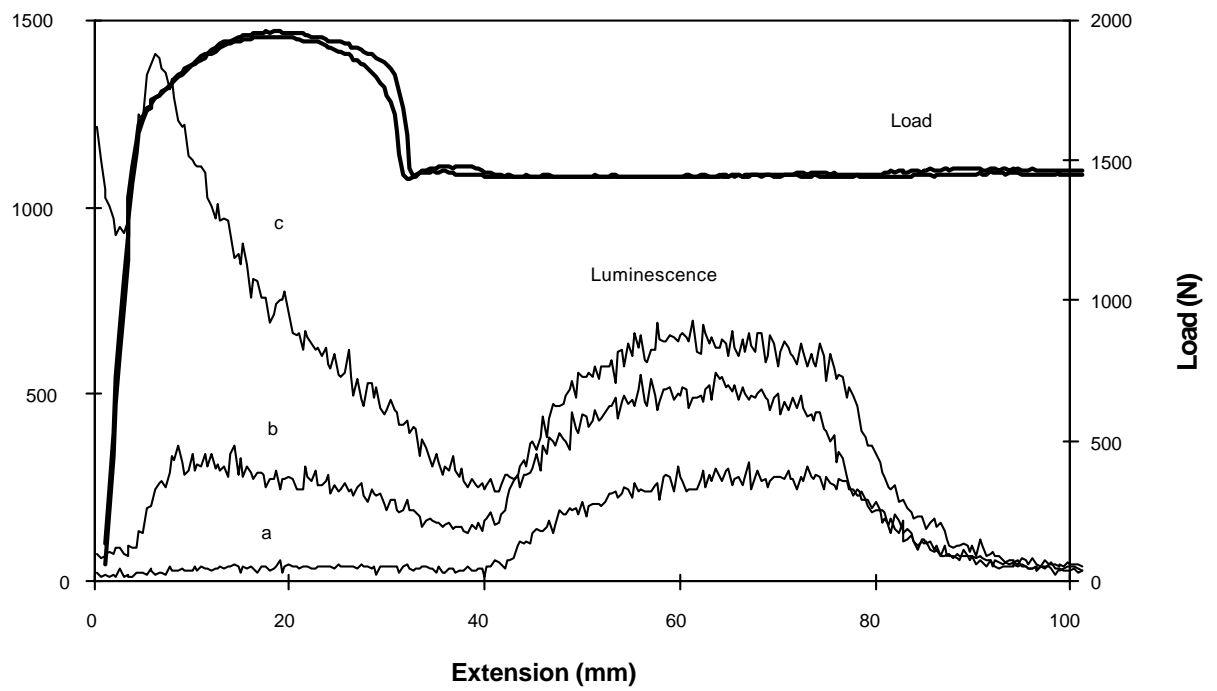

Figure 3.19. Curve (a) is the normally observed luminescence curve while curves (b) and (c) represent the luminescence curves from specimens which giving additional luminescence.

There was no obvious difference between the specimens represented in curves (a) (b) and (c). They were taken from the same injection moulded batch and had been stored together. The difference turned out to be the time spent in the laboratory outside the dark cupboard where they were usually stored. Specimens stored under or near a desk lamp, seated on the bench next to the instrument, emitted more light than the others. Both the desk lamp and the ceiling lamps in the laboratory were fitted with fluorescent light tubes.

\subsubsection{Investigation of the Origin of Additional Luminescence}

It was clear that the additional luminescence mentioned in Section 3.3.1 originated from irradiation of the specimens with light. In order to investigate the nature of the additional luminescence, specimens were irradiated with light of different wavelengths. Lamps which emitted light in the blue-UV region gave the highest response in luminescence emission. The time of irradiation did not affect the intensity, but the time from irradiation to the onset of the measurement was crucial. Since the photomultiplier is light sensitive, it cannot be turned on during 
irradiation. It also takes a few seconds to close the door to the light tight chamber after irradiation. Because of this photon detection cannot start much earlier than 7 seconds after irradiation has stopped. Figure 3.20a shows a typical luminescence intensity decay curve after irradiation with UV light. In Figure 3.20b the same curve is plotted in a log-log diagram. During the first 20 seconds of the measurement the decay is very fast. After these 20 seconds there is a bend in the curve, after which the decay is much slower. The duration of this particular experiment was 500 seconds. The decay down to the emission intensities of unirradiated specimens takes about $24 \mathrm{~h}$.

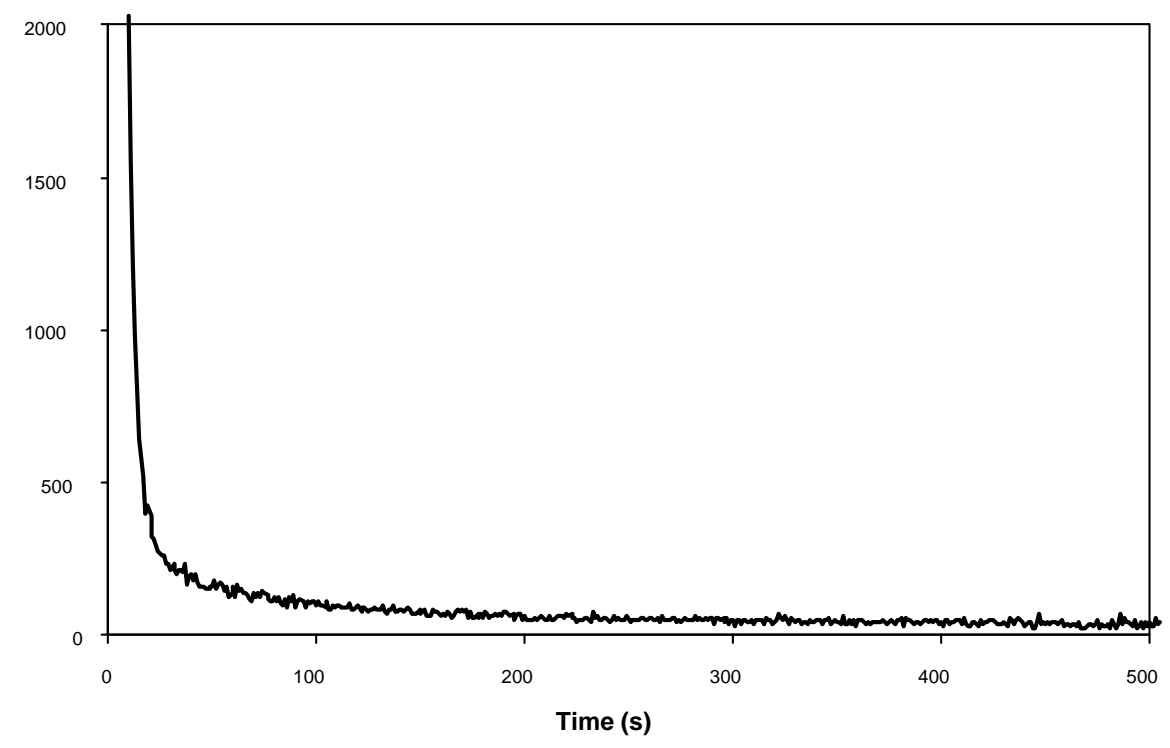

Figure 3.20a. Typical curve of the decay of luminescence after irradiation.

EMBED

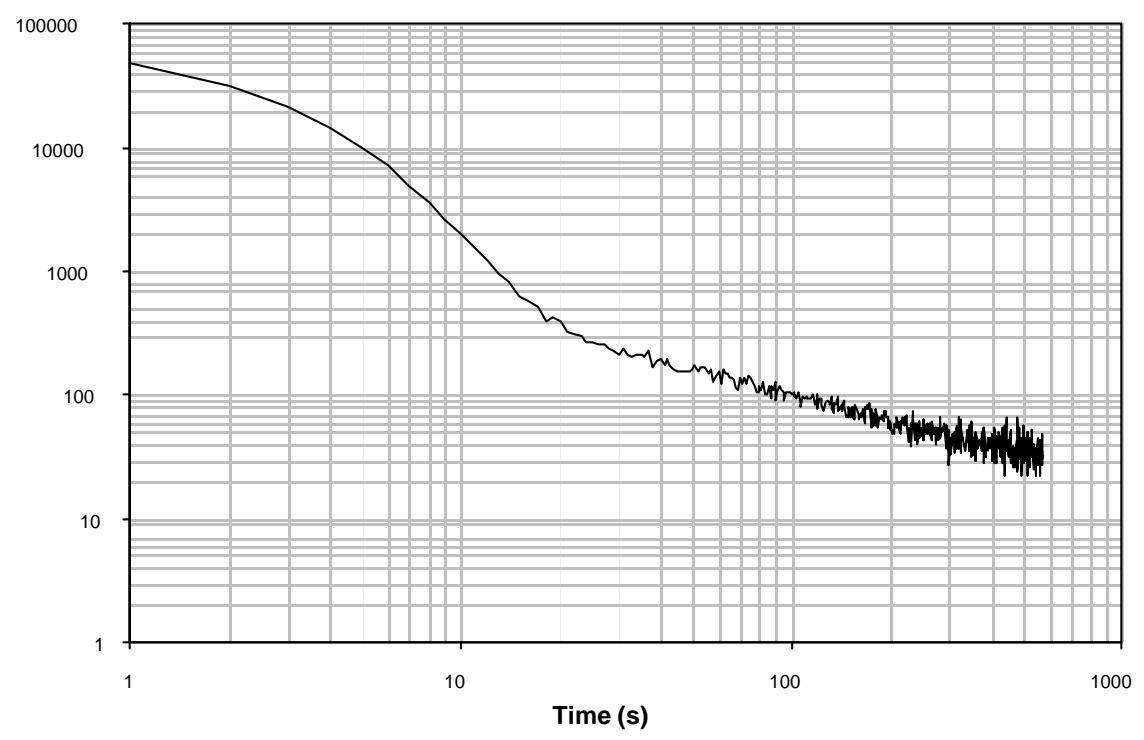

Figure $3.20 \mathrm{~b}$. The same curve as in $3.20 \mathrm{a}$ but plotted in a log-log diagram.

Figures 3.21a and $b$ show first and second order fits of the decay curves. The first part of the curve, i.e. the first 20 seconds could be fitted to first order kinetics, while the second part with very slow emission decay could neither be fitted to first nor to 
second order kinetics. There seem to be two different kinds of luminescence phenomena occurring after irradiation. The first order fit could be interpreted as luminescence by direct excitation, i.e. fluorescence or phosphorescence. Fluorescence has an emission time in the order of $10^{-8} \mathrm{~s}$ which makes it an improbable source of emission. Phosphorescence, however, has a longer emission time in the range of $10^{-4}$ to $10 \mathrm{~s}$ or more [Skoog and Leary, 1992]

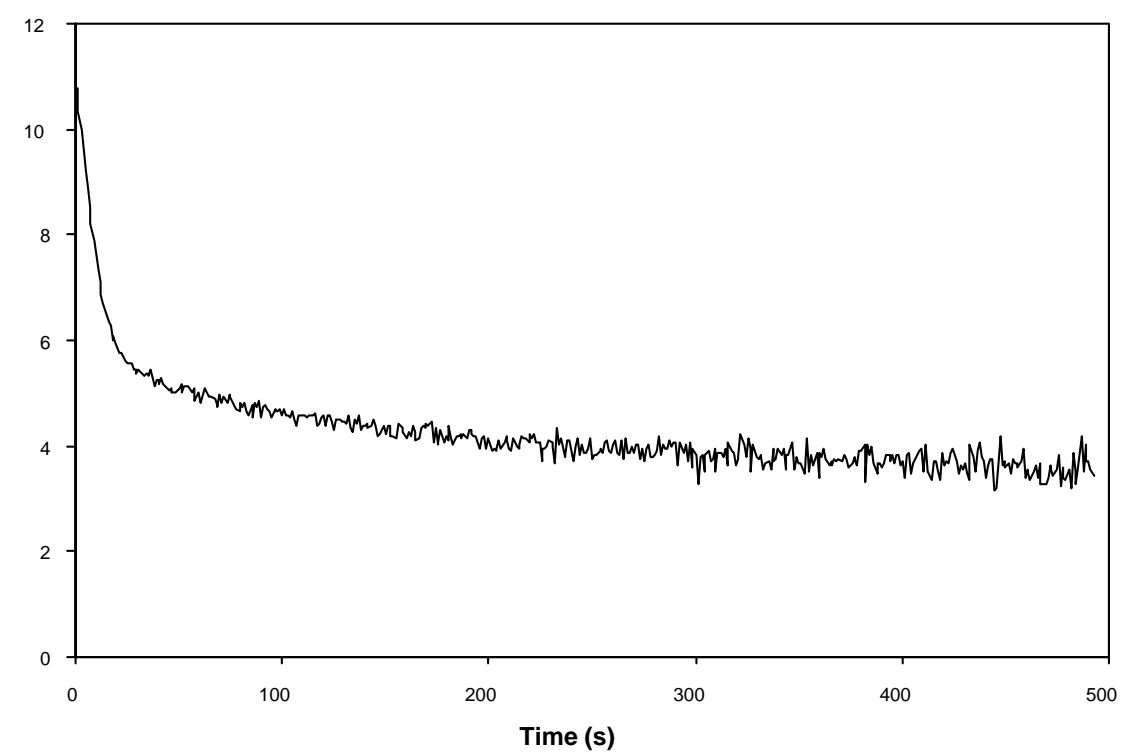

EMBED

Figure 3.21a. First order fit of the decay curve.

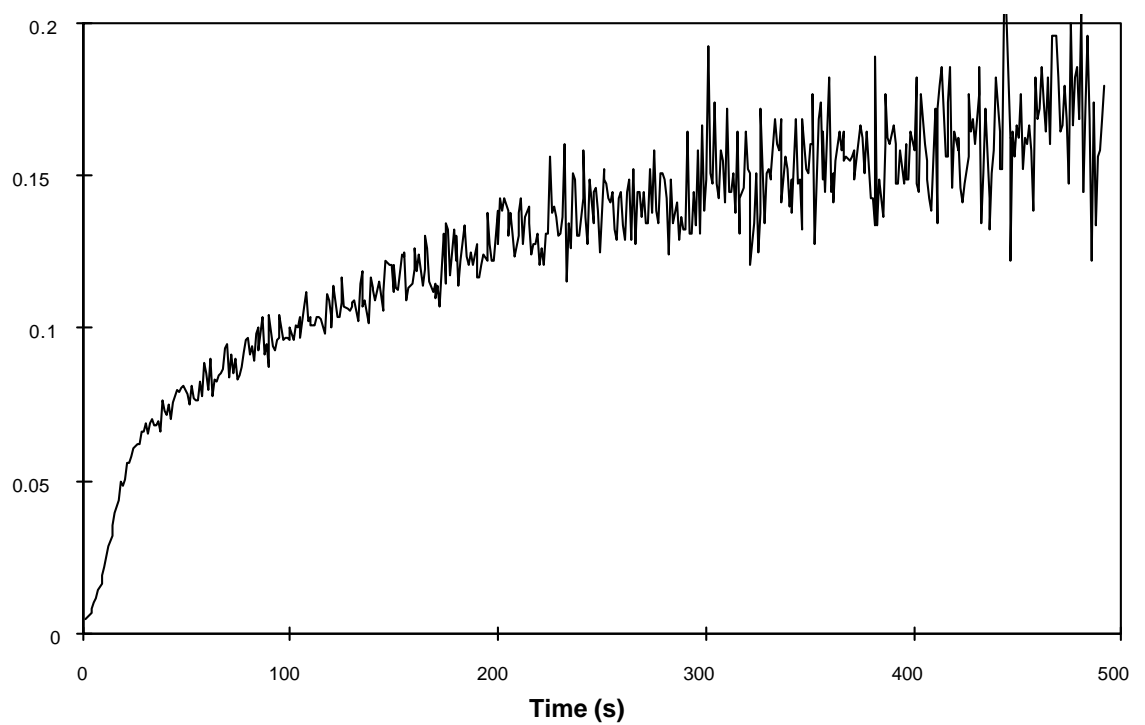

Figure 3.21b. Second order fit of the decay curve.

Experiments performed in both inert and oxidative atmosphere did not change the luminescence intensity and thus ruled out CL as a probable source of light emission. Moreover, CL should obey second order kinetics. However, thermoluminescence (TL), i.e. luminescence due to charge recombination (see Section 1.4.3) is not dependent on the atmosphere and does not conform to either first or second order kinetics [Fleming and Hagekyriakou, 1984]. Irradiation of stabilised polypropylene 
resulted in the same general luminescence decay curve as for polyamide. However, the intensity level was lower for PP than for PA. Since the unaged stabilised PP, as discussed in Section 3.1.6, did not contain any hydroperoxides, the luminescence could not be a result of UV induced degradation of hydroperoxides generating CL.

\subsubsection{Stress Induced Luminescence}

If load is applied to a specimen right after irradiation, the resulting luminescence curve will have the general appearance shown in curve (a) in Figure 3.22. Curve (b) represents a specimen which has been irradiated but not loaded and curve (c) is from an unirradiated specimen that has been loaded, i.e. only emits CL, as discussed in Section 3.1.6. As can be seen in the figure, curve (a) is obviously a superposition of curve (b) and (c).

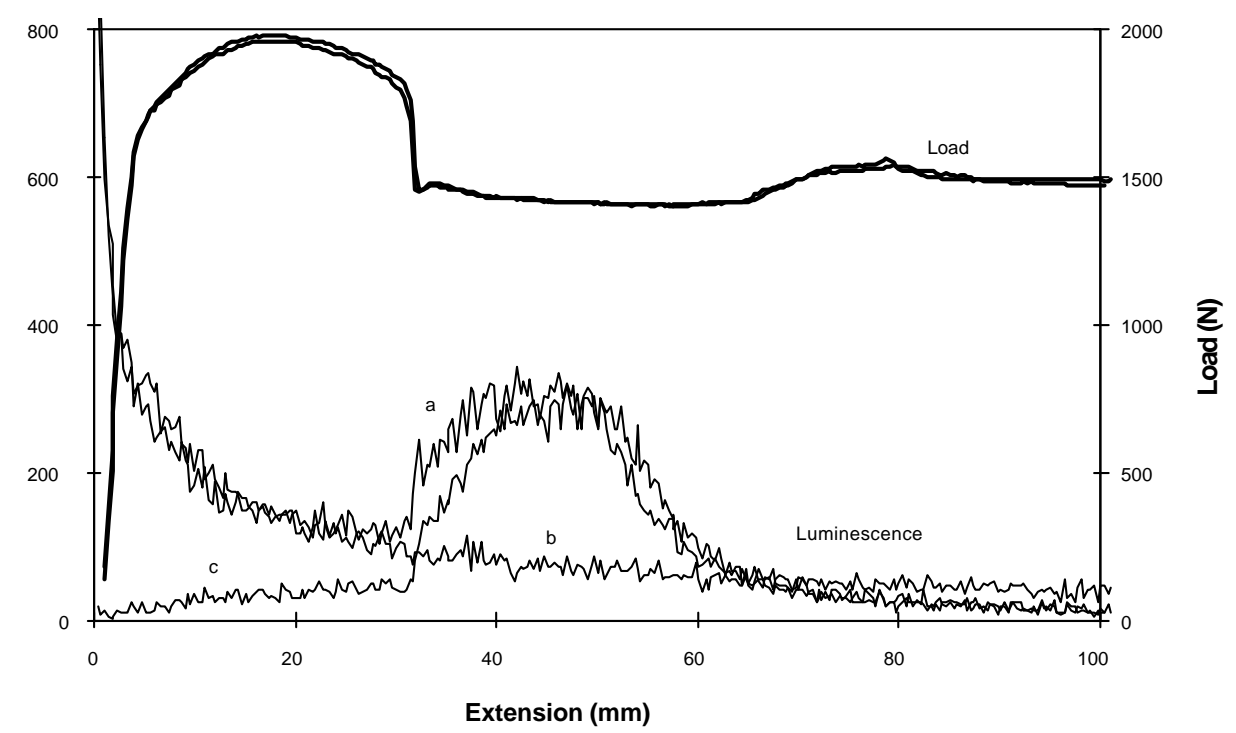

Figure 3.22. Curve (a) is the resulting luminescence from a PA66 specimen which has been irradiated and then stressed 7 seconds after the irradiation. Curve (b) represents a specimen which has been irradiated but not stressed and curve (c) represents a specimen which has not been irradiated but stressed.

If the load is not applied to the specimen until after the decay of the first type of luminescence, i.e., more than 20 seconds after the irradiation, the curve changes its appearance considerably, as can be seen in curve (a) in Figure 3.23. Curves (b) and (c) are from the same type of experiments as represented in Figure 3.22 above. Curve (a), i.e. the luminescence from the loaded and irradiated specimen, shows a peak near the yield point. However, the luminescence at necking is, just as in Figure 3.22, a superposition of curves (b) and (c). The first peak is not due to any thermal effect since the temperature is still low at this part of the tensile test. Neither is it just an apparent peak as the localised luminescence at necking (see Section 3.1.2) since the specimen is homogenous prior to neck formation. The levels of the photon counts, however, are not comparable in Figures 3.22 and 3.23 due to slightly different experimental conditions. When the two experiments are performed under exactly the same conditions, the level of the photon counts will be about 10 times higher in Figure 3.22 than what is now shown. The reson for not displaying that graph is that it does not show the phenomenon with the same clarity. 


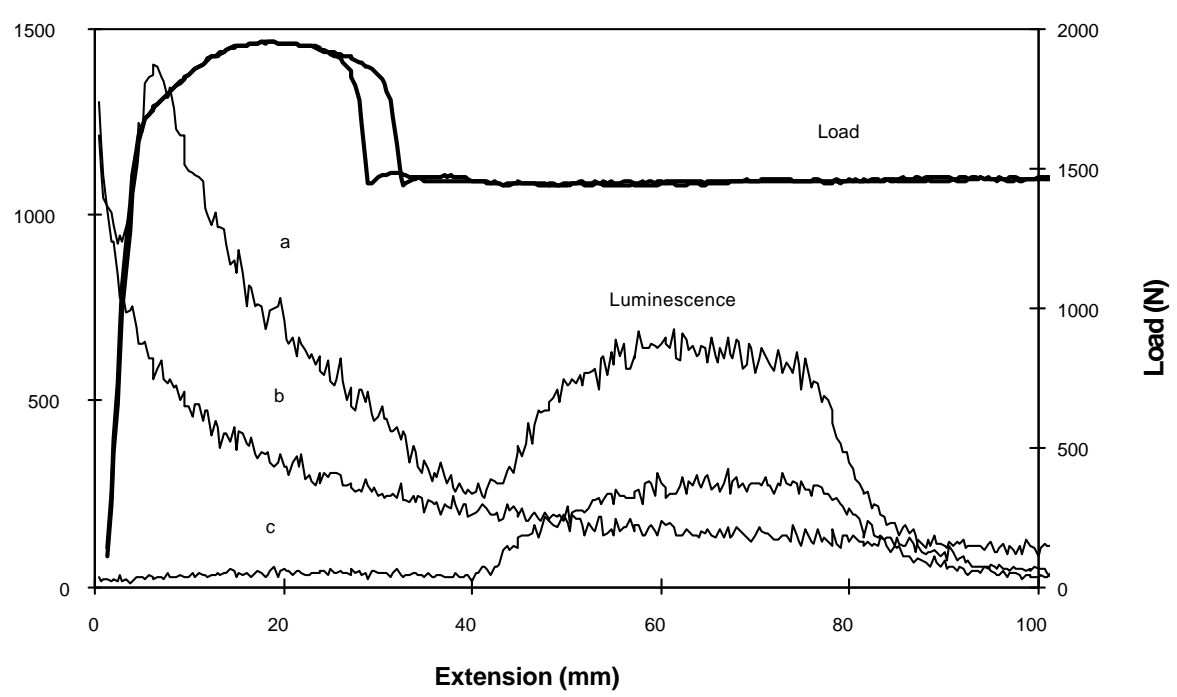

Figure 3.23. Curve (a) shows the resulting luminescence from a PA66 specimen which has been irradiated and then stressed 25 seconds after irradiation. Curve (b) represents a specimen which has been irradiated but not stressed and curve (c) a specimen which has not been irradiated but stressed.

It can be concluded that the first type of luminescence is unaffected by the application of mechanical energy, as can be expected from the decay of phosphorescence. The more slowly decaying luminescence is, however strongly affected by mechanical energy. This is in accordance with charge recombination luminescence, i.e. thermoluminescence, since the mechanical energy can, by an increased molecular motion, as in the case of molecular transitions, be enough to recombine separated charges. An interpretation of the results is outlined in Figure 3.24 .

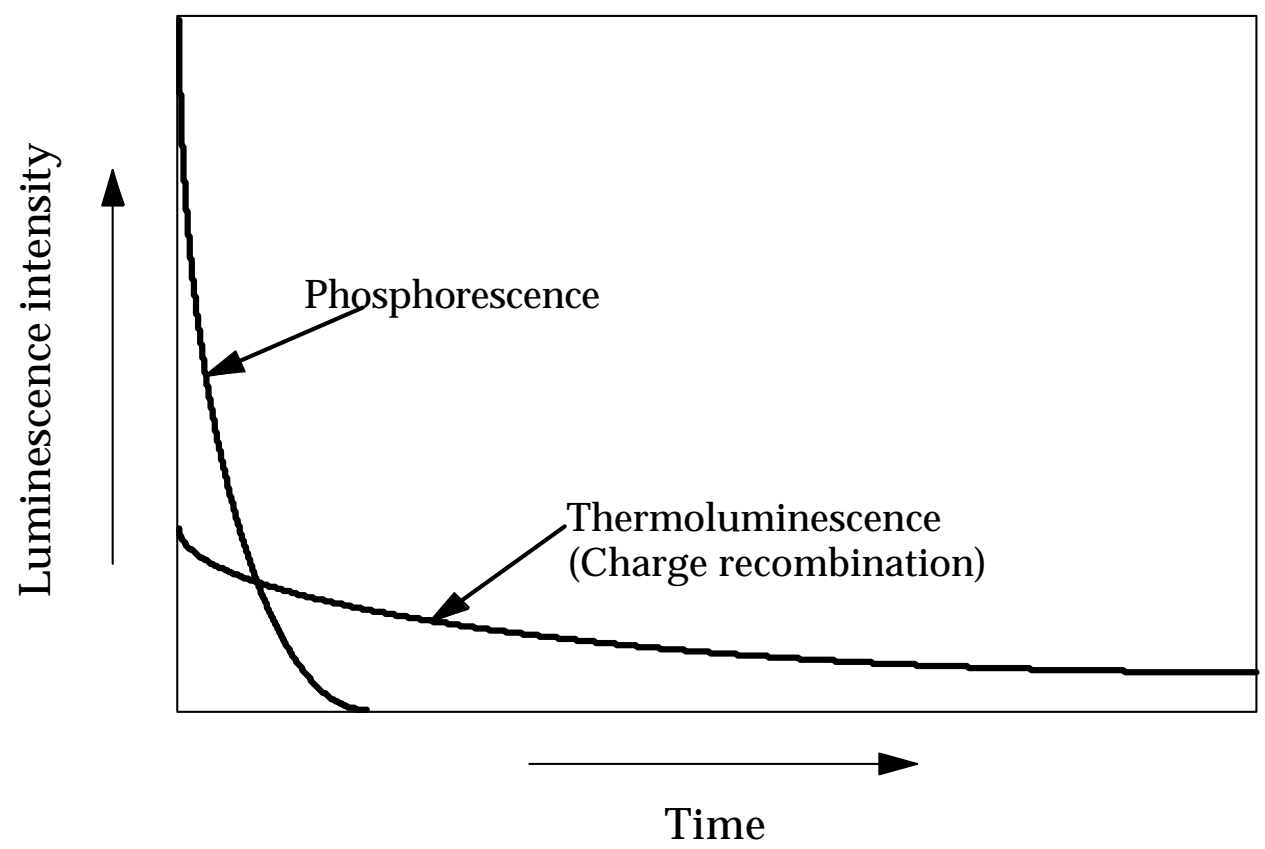

Figure 3.24. An interpretation of the observed luminescence phenomena. 
If luminescence from charge recombination is, as outlined in Figure 3.24, present right from the start of irradiation, the stress induced peak should still be present even when the specimen is stressed right after irradiation. However, as can be seen in Figure 3.25 the reason for its abscence is probably that it is drowned in the much more intense phosphorescence.

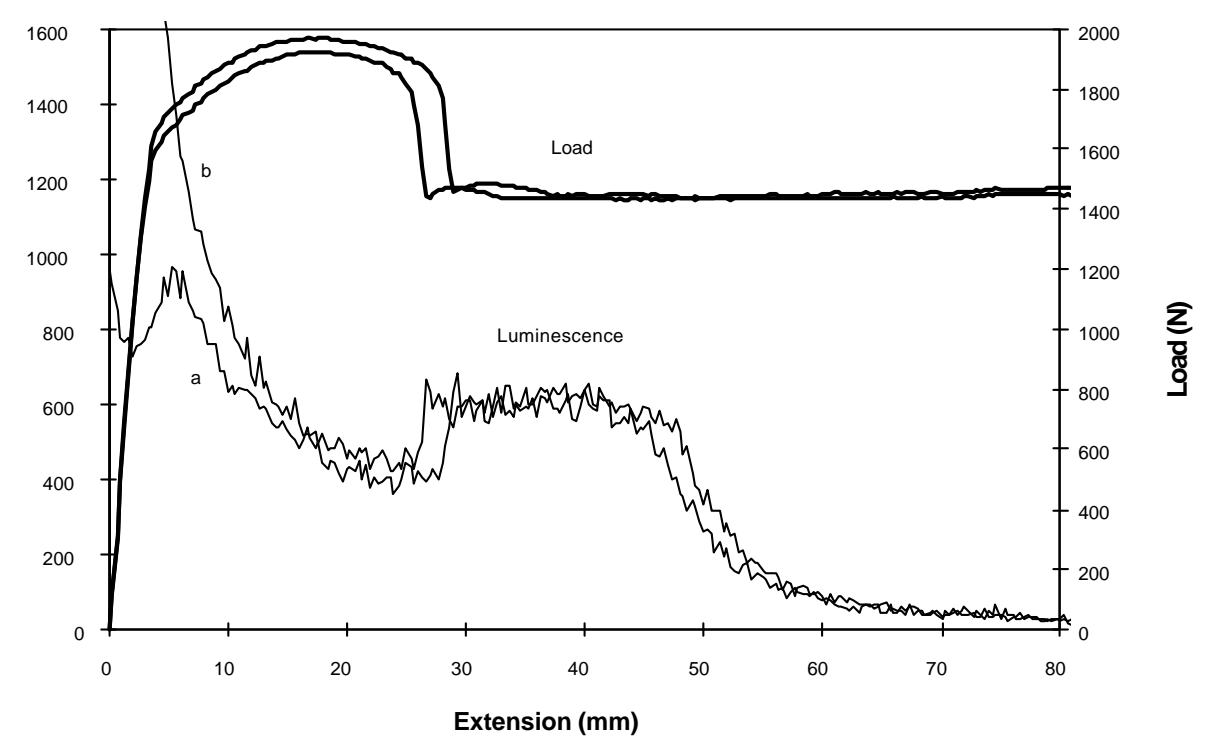

Figure 3.25. Curve (a) is the resulting luminescence from a PA66 specimen which has been irradiated and then stressed 25 seconds after irradiation. Curve (b) results from a specimen which has been stressed 7 seconds after irradiation.

\subsubsection{General Considerations of the Influence of TL on CL Measurements}

In the results outlined here it would be more accurate to refer to the type of luminescence observed as charge recombination luminescence rather than thermoluminescence. The concept thermoluminescence indicates that heat is the excitation mechanism (compare chemiluminescence from excitation by a chemical reaction and triboluminescence from mechanical excitation). Heat is, as shown in Figure 3.23, not the only means by which separated charges are recombined. The observed phenomena could also be referred to as triboluminescence since it is induced by stress (see Section 1.4.5).

All the results presented above were obtained at room temperature. However, CL measurements are generally performed at an elevated temperature. Since a higher temperature will increase the rate of recombination of the separated charges, the influence of TL is expected to be greater at room temperature where charges can be separated for a longer time. The effect of irradiation by ceiling lamps should thus not interfere with the results in the same detrimental way as in the results presented here. If, however, the oxidative degradation of UV irradiated specimens, from e.g. weather-O-meters or outdoor ageing, is to be investigated with CL, the contribution by TL could be significant.

The extent of TL emitted by a sample depends on the ability of the polymer to trap charges and on the quantum efficiency of the deexcitation associated with charge recombination. 


\subsection{Oxidation of Polymers During Constant Load}

[Papers V and VI]

In the previous three sections (3.1 to 3.3) the interest was focused on the origin of light observed during extension and fracture of some polymers. The investigation aimed more at explaining this and various similar observations made by other authors (see Section 1.4.6) than at solving a practical service life problem. In this section, however, the focus will be on how low levels of stress, i.e. constant sub-yield stresses, will influence the rate of oxidation. This is interesting from a service life point of view since a large number of polymeric products are used in load bearing constructions.

In load bearing constructions a polymeric product is very rarely subjected to stresses above $2 \%$ of load at yield. In this study, constant loads between $0 \%$ and up to $100 \%$ of load at yield have been applied to oxidising strips of PA6 film and injection moulded specimens of PP, HDPE, and PA6. The ageing study was performed at an elevated temperature in order to accelerate the oxidation.

\subsubsection{SCL Results}

Isothermal measurements under constant load were performed in the SCL instrument. The SCL curves follow the oxidation in situ in the specimens. In order to determine suitable loads for application to the specimens during oxidation, the loads at yield of the specimens were measured at the respective measuring temperatures of the materials involved. The loads at yield were determined using a very low elongation rate in order to as closely as possible match the creep rate. The measuring temperatures chosen were $95^{\circ} \mathrm{C}$ for PP, $110^{\circ}$ for $\mathrm{HDPE}, 120^{\circ} \mathrm{C}$ for PA6 film and $130^{\circ} \mathrm{C}$ for injection moulded PA6. These measuring temperatures were intended to give a significant oxidation of the specimens within a feasible time frame. The loads at yield were $175 \mathrm{~N}(4.38 \mathrm{MPa})$ for PP, $110 \mathrm{~N}(2.75 \mathrm{MPa})$ for HDPE, $995 \mathrm{~N}$ (24.9 MPa) for injection moulded PA6, and 26.9 N (20.4 MPa) for PA6 film at these temperatures.

Figures 3.26 to 3.29 show the SCL curves for PA6 film and injection moulded PP, HDPE and PA6 specimens, respectively. As can be seen in the figures, there is quite a large data scatter, but no acceleration of oxidation due to stress can be distinguished. The variation in appearance of the CL curves for the different materials should also be noted. It indicates the different oxidative behaviour of the polymers studied (see Section 1.3.1 Oxidation of Polyolefins and Oxidation of Polyamides). 


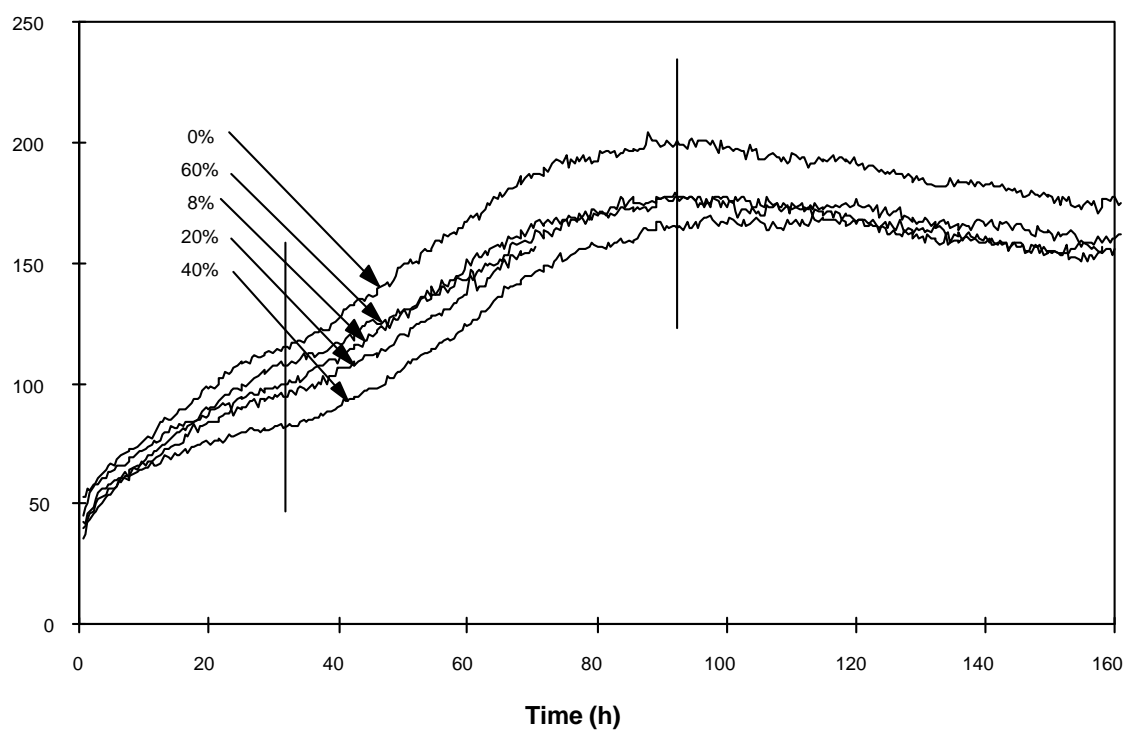

EMBED

Figure 3.26. SCL curves of five PA6 film stripes loaded with $0 \%, 8 \%, 20 \%, 40 \%$ and $60 \%$ of load at yield, respectively, at $120^{\circ} \mathrm{C}$. The vertical lines represent the end of the "induction period" and the maximum intensity, respectively. They are the same for all specimens.

The apparent decrease in CL intensity with load which can be found in Figure 3.26 for PA6 film is not statistically significant but purely coincidental. The vertical lines in the figure show the end of the "induction period" and the time to maximum. They are the same for all specimens.

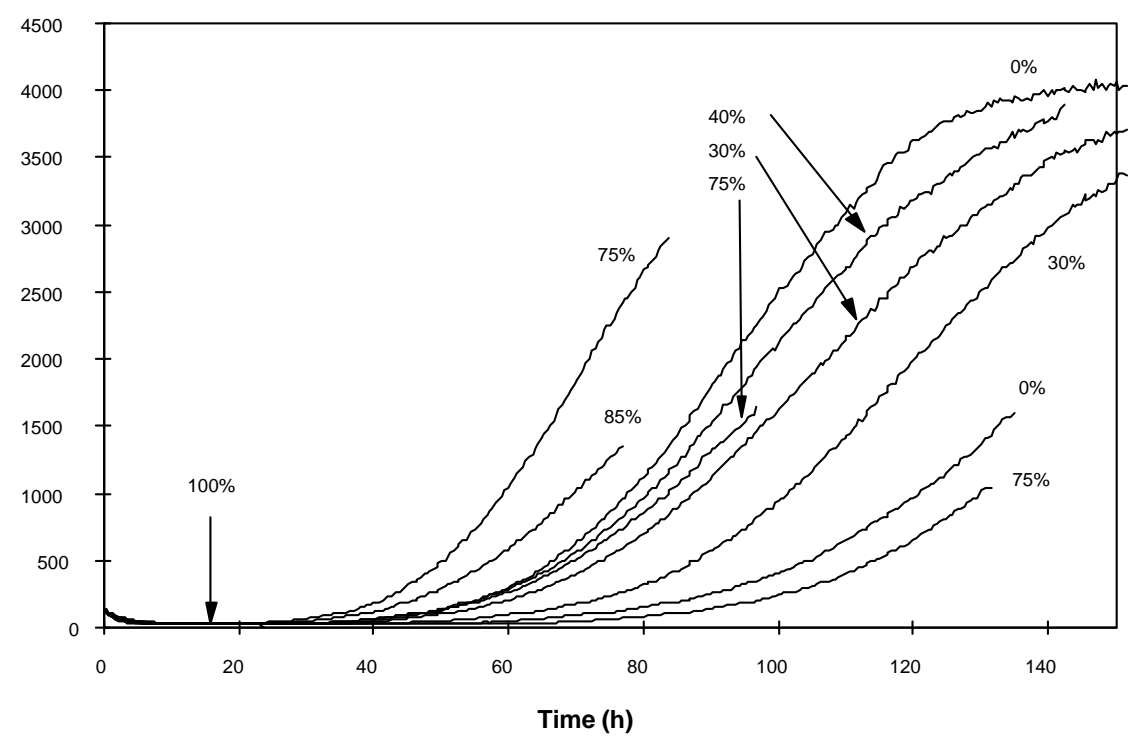

Figure 3.27. SCL curves of injection moulded PP specimens loaded with 0\%, 30\%, 40\%, 75\%, 85\% and $100 \%$ of load at yield, respectively, at $95^{\circ} \mathrm{C}$. 


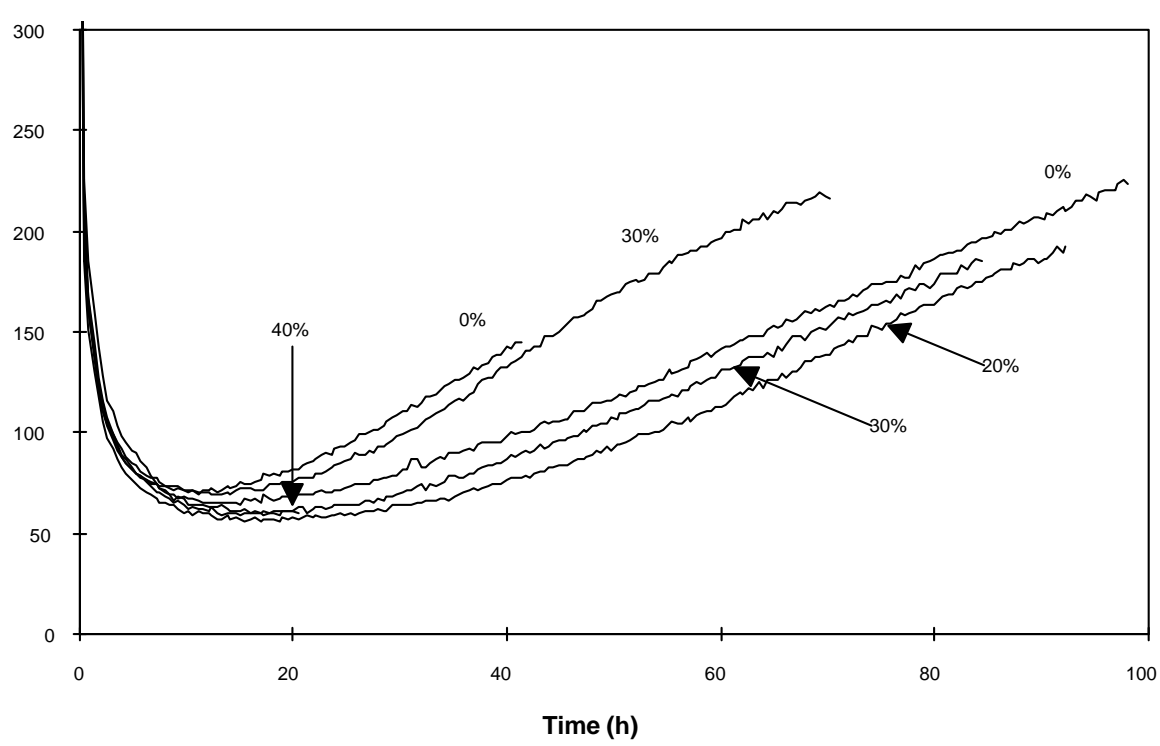

Figure 3.28. SCL curves of injection moulded HDPE specimens loaded with $0 \%, 20 \%, 30 \%$ and $40 \%$ of load at yield, respectively, at $110^{\circ} \mathrm{C}$.

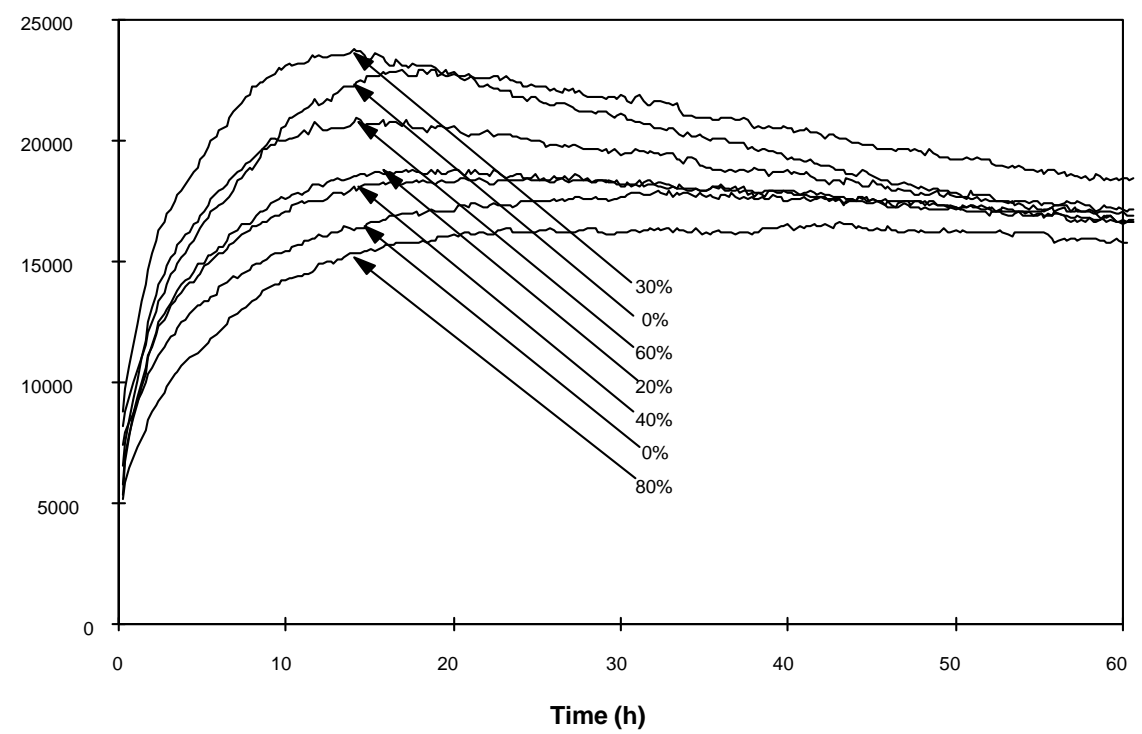

Figure 3.29. SCL curves of injection moulded PA6 specimens loaded with $0 \%, 20 \%, 30 \%, 40 \%, 60 \%$ and $80 \%$ of load at yield, respectively, at $130^{\circ} \mathrm{C}$.

The data scatter, seen in the figures, has been attributed to variation in oxidative stability. This variation was especially pronounced for the injection moulded PP specimens. Figure 3.30a shows the CL from six oxidising PP samples measured simultaneously in the ICL instrument. The samples were taken from six different injection moulded bars. Figure $3.30 \mathrm{~b}$ shows one of the ICL images, which was taken after 50 hours of oxidative degradation at $95^{\circ} \mathrm{C}$. It is obvious that the oxidation does not start simultaneously in all specimens but that there is a fairly large scattering in oxidation rate between them. 


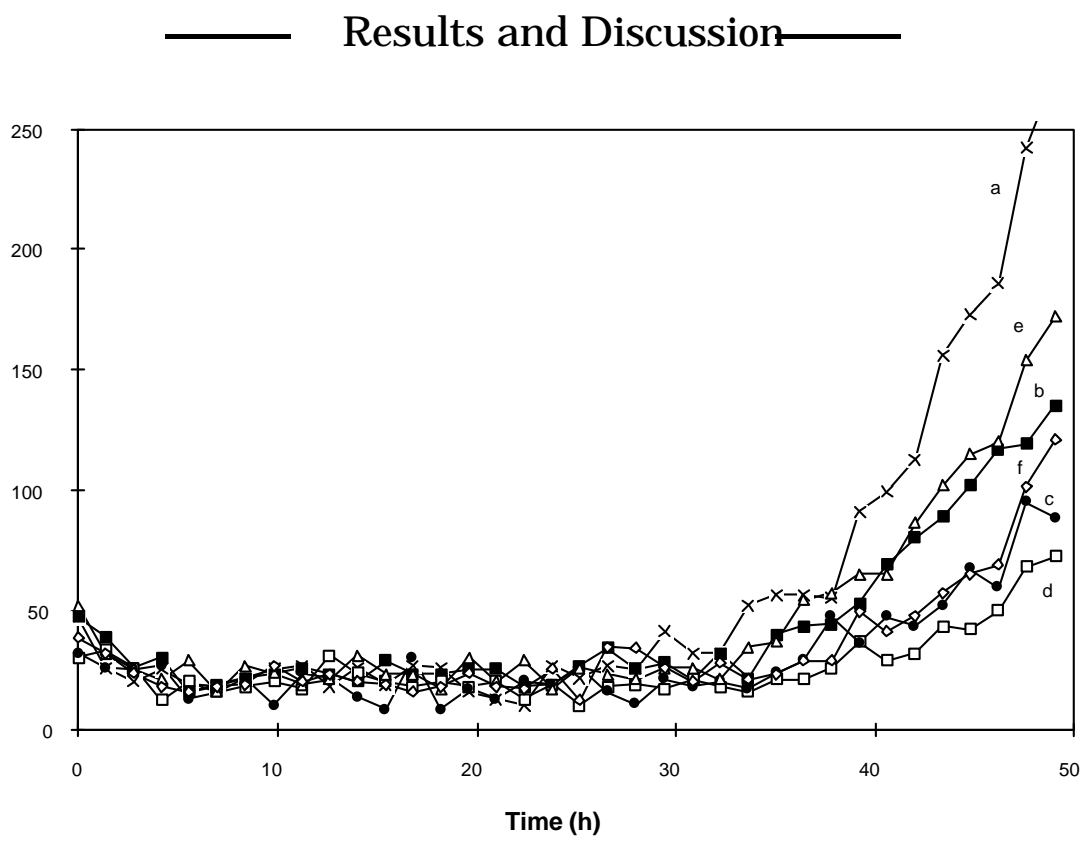

Figure 3.30a. CL graphs calculated from ICL data of six oxidising PP samples. Each sample was taken from a different injection moulded specimen.

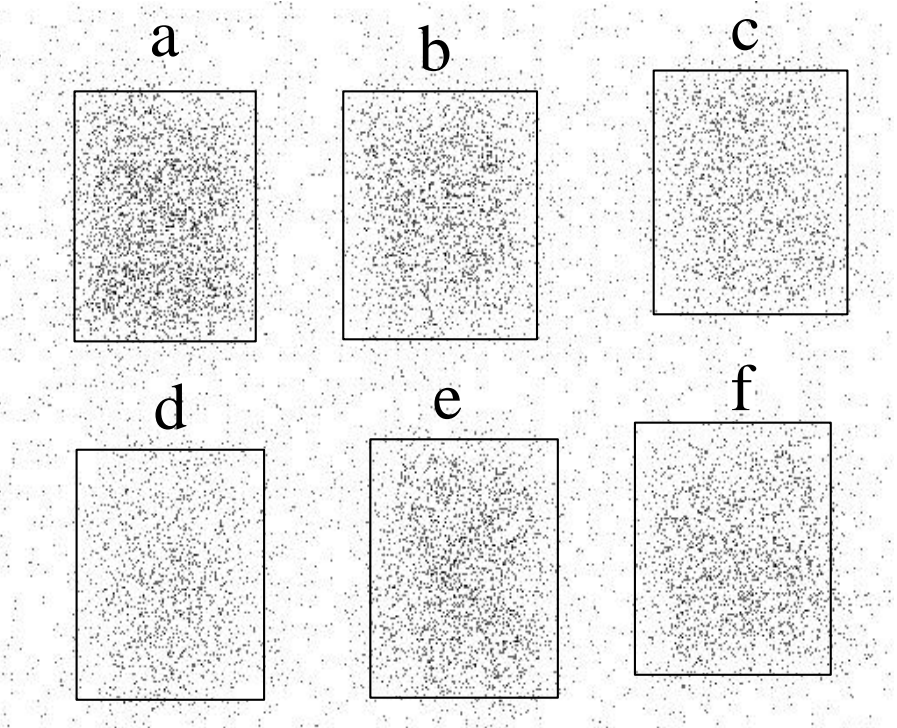

Figure $3.30 \mathrm{~b}$ ICL image of the six PP samples after 50 hours of oxidation in air at $95^{\circ} \mathrm{C}$.

The period of constant CL intensity seen in Figure 3.27 for PP specimens should not be interpreted as a period free from oxidation of the material. The emitted light during this period is well above the level of backgound noise. This is clearly seen in Figure 3.31, which depicts the luminescence from two PP specimens loaded with $100 \%$ of load at yield. Curve (a) shows luminescence data from a specimen in nitrogen and curve (b) the corresponding luminescence data in air. This means that the specimen that was loaded with $100 \%$ of load at yield, shown in Figure 3.27, was slightly oxidised at fracture and could have fractured as a result of this. However, of the specimens shown in Figure 3.31 the unoxidised specimen fractured first, indicating an oxygen independent creep fracture. 


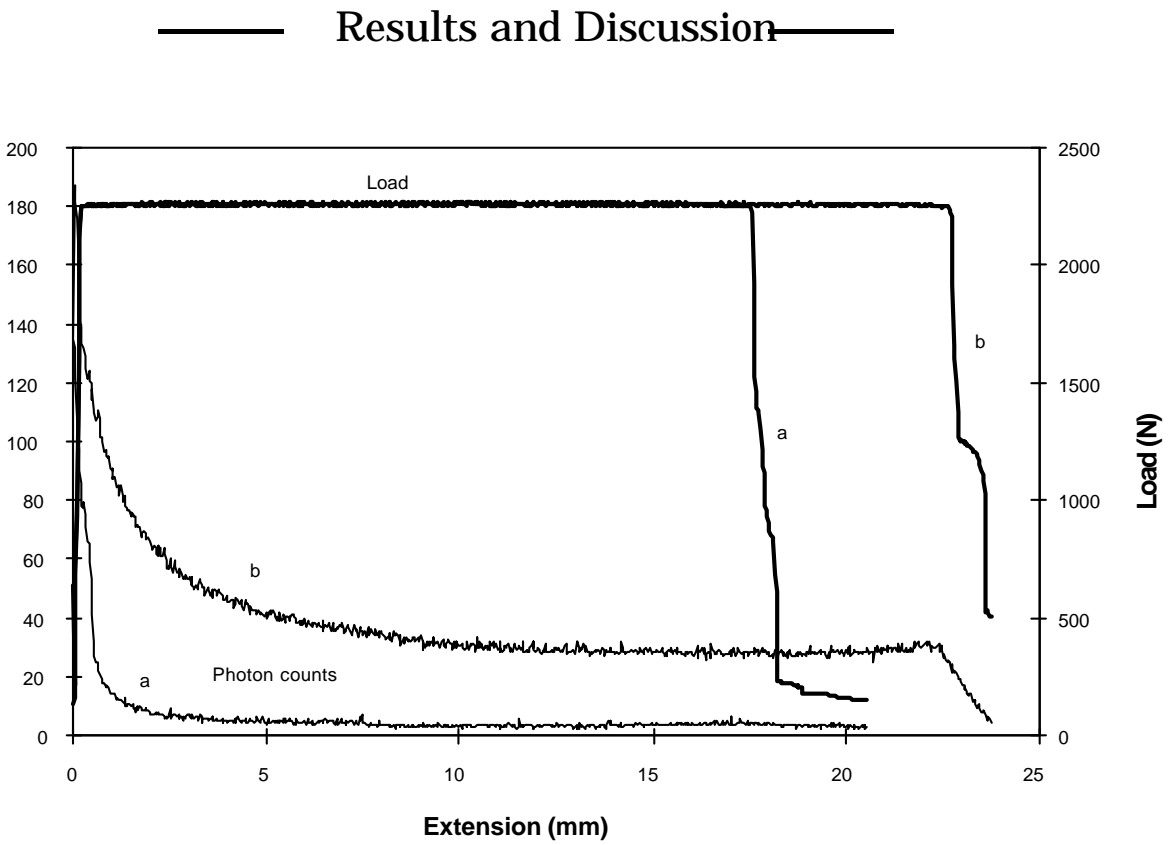

Figure 3.31. SCL curves from two PP specimens loaded with $100 \%$ of load at yield measured (a) in nitrogen and (b) in air at $95^{\circ} \mathrm{C}$.

For specimens stressed with lower loads, where the oxidation had started to accelerate prior to fracture, there was a difference in the time of fracture between specimens aged in an inert or oxidative atmosphere. The oxidated specimens fractured well before the unoxidised ones.

Note also that the PP specimens represented in Figure 3.31 do not give any burst of luminescence at fracture, as discussed in Section 3.2.

All of the loaded specimens in this study were elongated during ageing. The largest creep (10\%) was observed for the PA6 specimen loaded with $80 \%$ of load at yield. However, as mentioned in Section 2.3.9, no orientation due to creep was observed for any of the specimens. The physical properties of the material were thus unchanged by the creep.

\subsubsection{Chemical, Physical and Mechanical Properties of Creep-Aged Specimens}

Specimens of injection moulded PP and strips of PA6 film were aged in a special creep-ageing oven, in which specimens can be aged under constant load at different temperatures. This was made in order to compare the results from the SCL experiments with measurements where other more conventional techniques were used to assess the effect of oxidation. The chemical changes in the specimens were then measured with FTIR (carbonyl index), CL (TLI value), DSC (mass crystallinity for PA6 film and melt temperature for PP specimens) and UV absorption (only for PA6 film), and the change in fracture properties was assessed by measuring the elongation at break. The presented carbonyl index is based on an average of three measurements, the TLI value, the DSC data and the UV absorption on two. The elongation at break was calculated from an average of five measurements for PA6 strips and of three for PP specimens. 
Figures 3.32 to 3.34 display the results as a function of \% of load at yield for PA6 strips aged for 48,96 , and 168 hours, respectively. In the same way Figures 3.35 to 3.37 show the results for PP specimens.

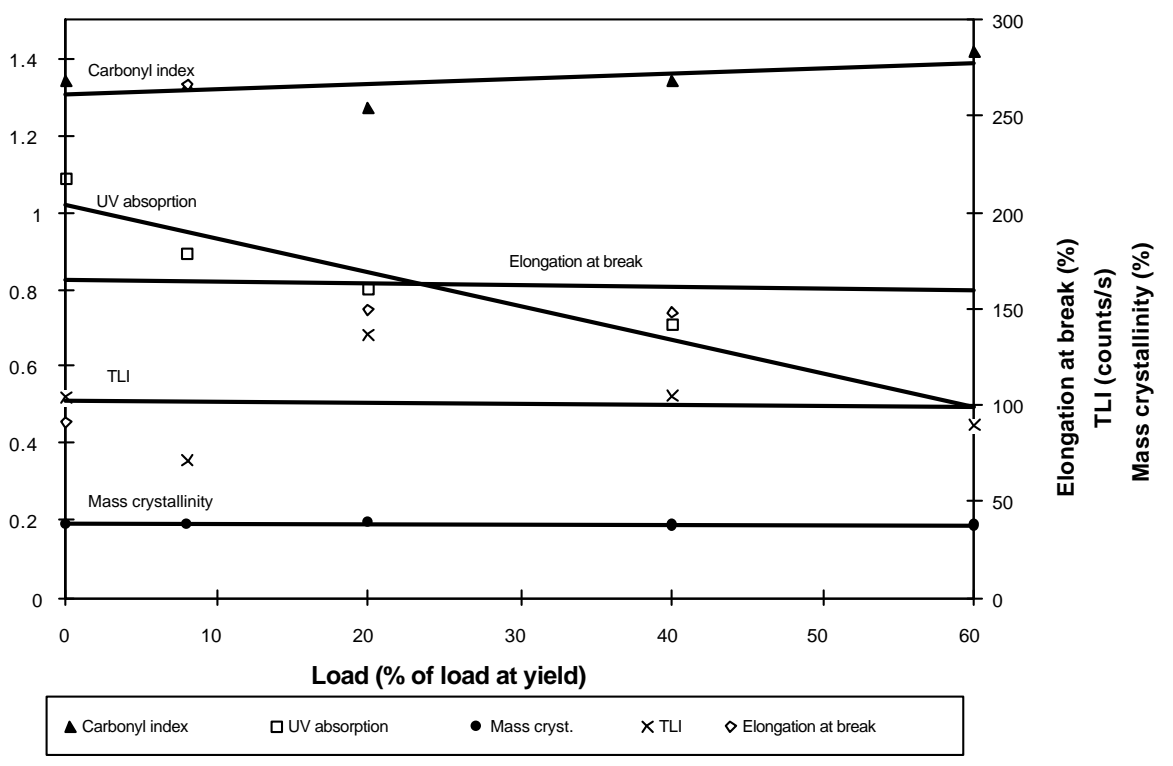

Figure 3.32. Elongation at break, carbonyl index, UV absorption, TLI value and mass crystallinity for PA6 film specimens aged for $48 \mathrm{~h}$ at $120^{\circ} \mathrm{C}$ with $0 \%, 8 \%, 20 \%, 40 \%$, and $60 \%$ of load at yield, respectively.

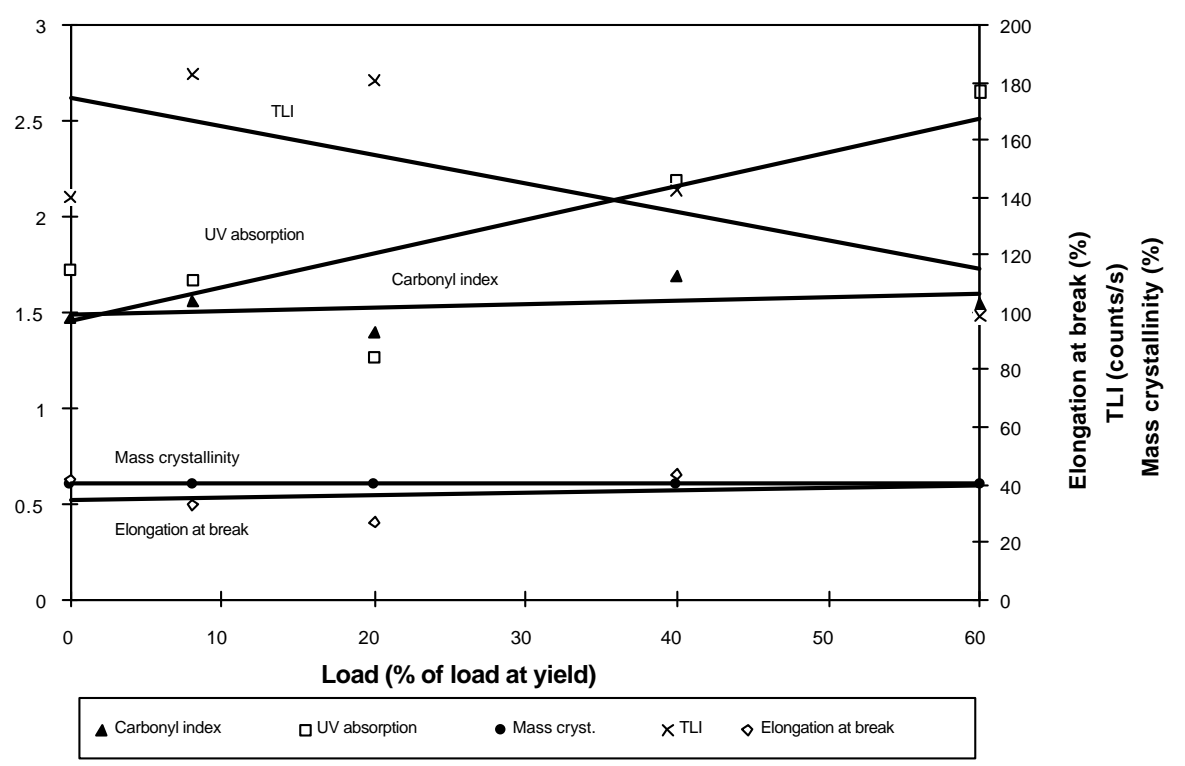

Figure 3.33. Elongation at break, carbonyl index, UV absorption, TLI value and mass crystallinity for PA6 film specimens aged for $96 \mathrm{~h}$ at $120^{\circ} \mathrm{C}$ with $0 \%, 8 \%, 20 \%, 40 \%$, and $60 \%$ of load at yield, respectively. 

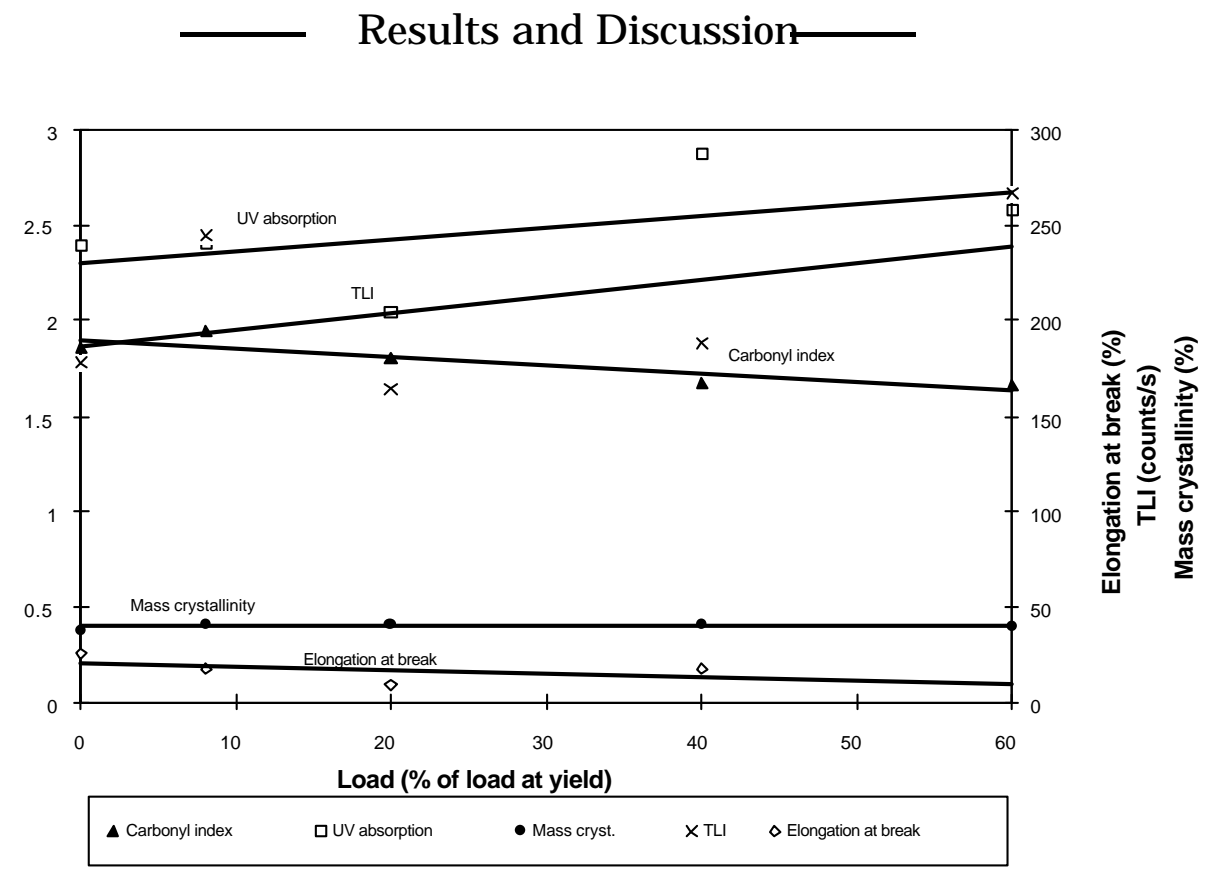

Figure 3.34. Elongation at break, carbonyl index, UV absorption, TLI value and mass crystallinity for PA6 film specimens aged for $144 \mathrm{~h}$ at $120^{\circ} \mathrm{C}$ with $0 \%, 8 \%, 20 \%, 40 \%$, and $60 \%$ of load at yield, respectively.

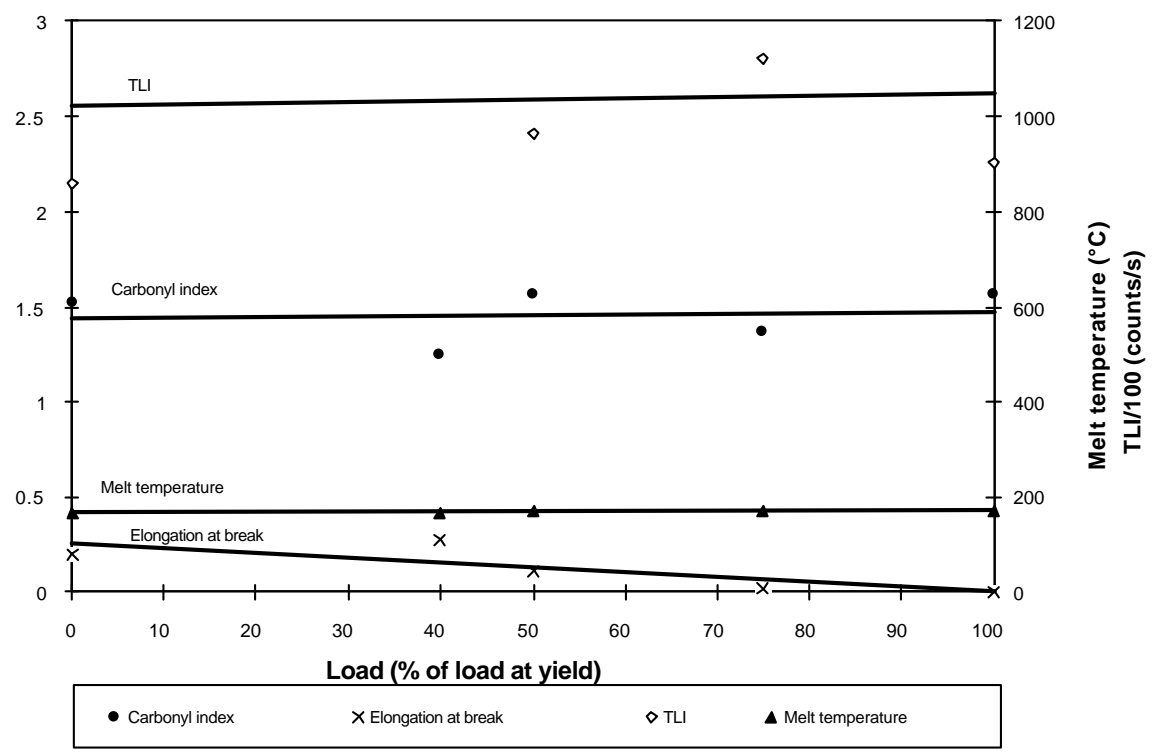

Figure 3.35. Elongation at break, carbonyl index, TLI value and melt temperature for PP specimens aged for $48 \mathrm{~h}$ at $95^{\circ} \mathrm{C}$ with $0 \%, 40 \%, 50 \%, 75 \%$, and $100 \%$ of load at yield, respectively. 


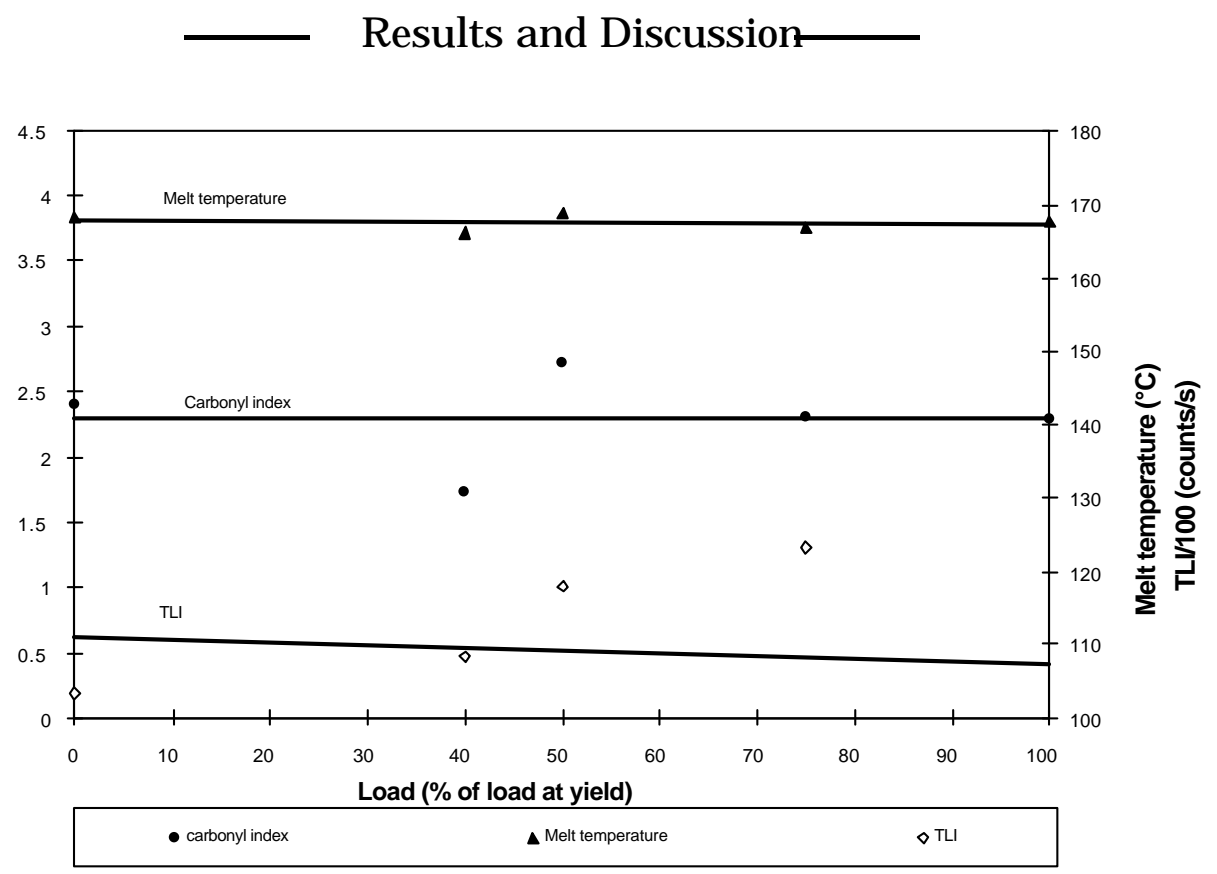

Figure 3.36. Carbonyl index, TLI value and melt temperature for PP specimens aged for $96 \mathrm{~h}$ at $95^{\circ} \mathrm{C}$ with $0 \%, 40 \%, 50 \%, 75 \%$, and $100 \%$ of load at yield, respectively.

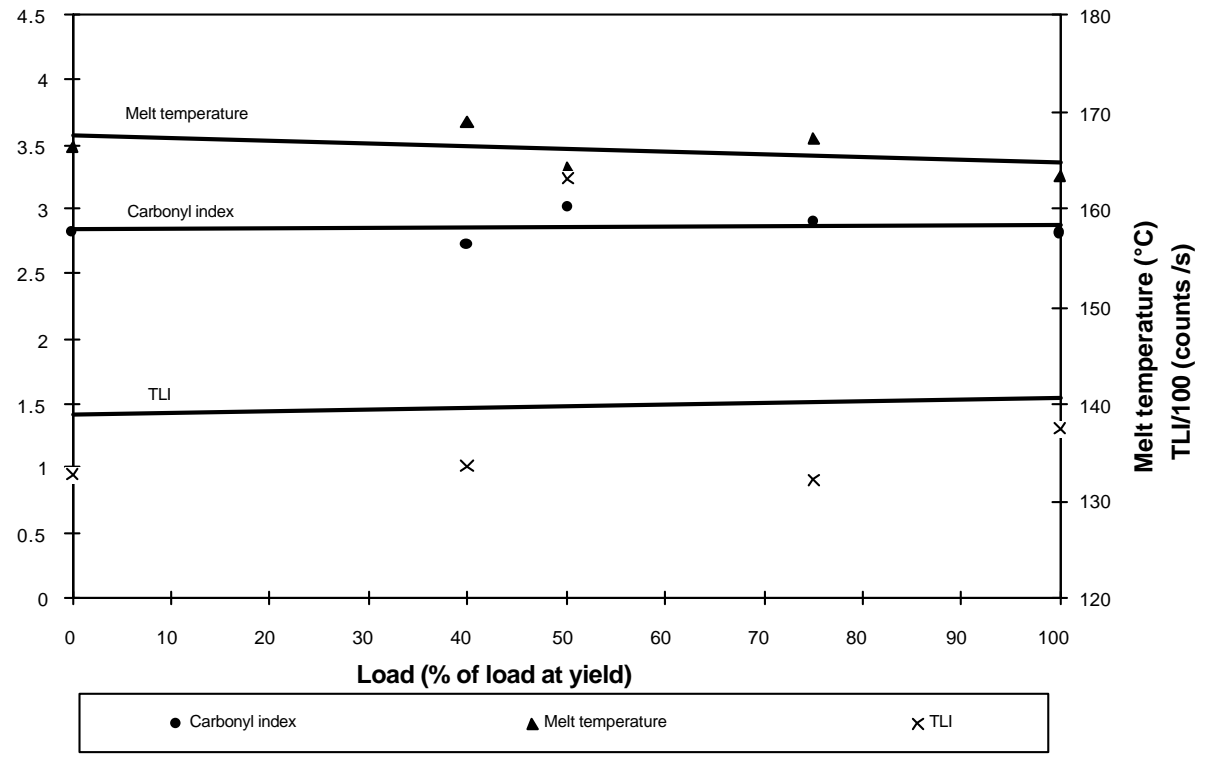

EMBEDEMBEDEMBEDEMBEDEMBEDEMBEDFigure 3.37. Carbonyl index, TLI value and melt temperature for PP specimens aged for $144 \mathrm{~h}$ at $95^{\circ} \mathrm{C}$ with $0 \%, 40 \%, 50 \%, 75 \%$, and $100 \%$ of load at yield, respectively.

For legiability there are no error bars presented in the figures. There was, however, a fairly large data scattering in the results, especially for the PA6 film (up to $\pm 30 \%$ for the UV absorption measurements). The lines in the figures represent linear regression curves from the data points. If the rate of oxidation were increased as a result of load, all the properties would be expected to increase, except for the elongation at break, which would decrease. As can be seen in the figures, this is not the case, except for the elongation at break which for the PP specimens did decrease 
with load. From both the 50\% and $75 \%$ test series there are no data for the most aged specimens since they failed during ageing. The mechanical properties of specimens with $100 \%$ of load at yield could not be measured at all since they all failed during the first 24 hours of ageing.

Accelerated ageing tests have the drawback that the reactions at the ageing temperature are not the same as at the use temperature (see Section 1.3.1, Accelerated Ageing). In order to see if lowering the temperature from $120^{\circ} \mathrm{C}$ to $90^{\circ} \mathrm{C}$ would affect the results, PA6 film strips were aged for four weeks at $90^{\circ} \mathrm{C}$ with six different loads: $0 \%, 40 \%, 50 \%, 60 \%, 70 \%$ and $80 \%$ of load at yield, respectively. Figure 3.38 shows the carbonyl index, elongation at break, and UV absorption, TLI, and mass crystallinity as a function of load. As can be seen in the figure, the strips aged with $40 \%$ of load at yield seemed to have the highest degree of oxidation, and it then decreased even when the load was increased up to $80 \%$ of load at yield. However, it turned out that this was most probably not an effect of load but was instead an effect of a temperature gradient in the creep-ageing oven. The temperature was highest at the position of the specimen loaded with $40 \%$ of load at yield and then decreased towards the position of the specimen loaded with $80 \%$ of load at yield. The unloaded specimen was aged in a separate oven. The temperature variation between the different specimens was not more than $\pm 1^{\circ} \mathrm{C}$. This shows how decisive the ageing temperature is during oxidation, especially at ageing times as long as this.

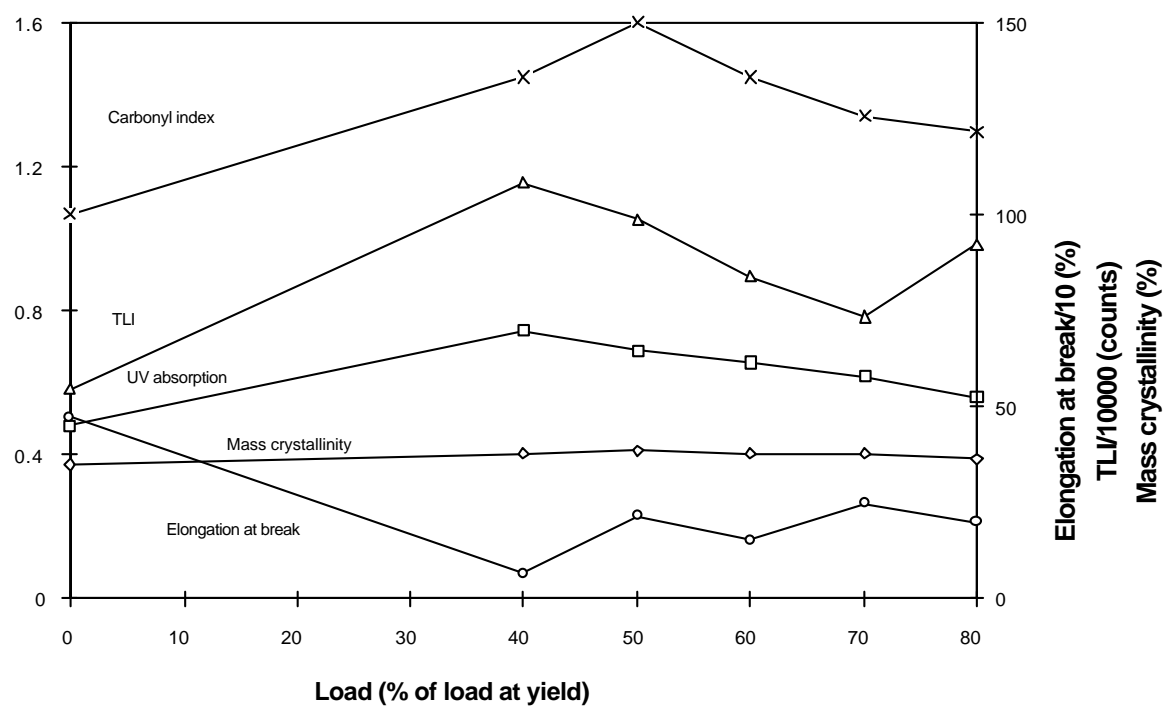

Figure 3.38. Elongation at break, carbonyl index, UV absorption, TLI and mass crystallinity for PA6 film specimens aged for four weeks at $90^{\circ} \mathrm{C}$ with $0 \%, 40 \%, 50 \%, 60 \%, 70 \%$ and $80 \%$ of load at yield, respectively.

\subsubsection{ICL Images of Creep-Aged Specimens}

Imaging chemiluminescence can, as in Section 3.1.3, be used to study a number of samples at the same time. This increases the efficiency since it decreases the number of measurements as compared with conventional $\mathrm{CL}$, in which only one sample at a time can be measured (see Section 1.4.3). It can, however, also be used 
to monitor the spatial distribution of oxidation. Figure 3.39 shows a schematic drawing of the tensile specimen specially designed for the SCL instrument. It was originally designed to give a well defined neck and a short cold drawing region. The design did, however, also result in a stress gradient where the stress is twice as high at the centre of the specimen as compared to a position $20 \mathrm{~mm}$ to the sides; see the shaded area in Figure 3.39.

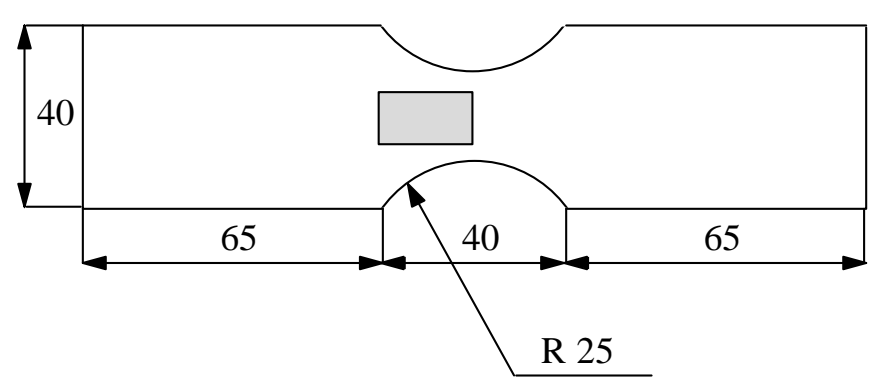

Figure 3.39. Schematic drawing of the specially designed tensile specimen. The shaded area shows how the piece for ICL measurements was cut out.

Specimens of $\mathrm{PP}, \mathrm{HDPE}$, and PA6 were creep-aged at $95^{\circ}, 110^{\circ}$, and $130^{\circ} \mathrm{C}$ for 48 , 52 , and 24 hours, respectively. Pieces, represented by the shaded area in Figure 3.42 were then cut out, and the spatial distribution of accumulated hydroperoxides was measured under nitrogen in the ICL instrument. Figures 3.40 to 3.42 show the resulting images and luminescence profiles calculated from the images. The darker the image the more light emission. The light gray area (low CL emission) on the sides of the pieces is the background noise. The stress was twice as high to the far left as at to the far right, but no change in the degree of oxidation can be found across the samples. Thus, the ICL images very clearly illustrate the same result as the other measuring techniques, i.e. that stresses below the yield point do not change the rate of oxidation, at least not at the temperatures used in this study.

$2 \sigma$

$\sigma$

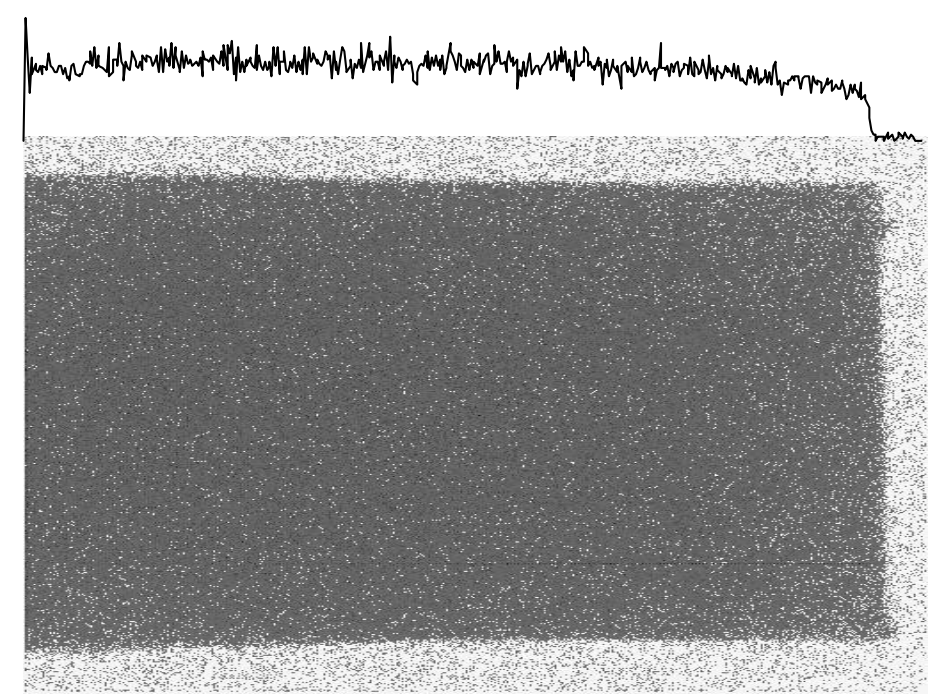


Figure 3.40. ICL image of a PP specimen creep-aged with $75 \%$ of load at yield at $95^{\circ} \mathrm{C}$ for 48 hours. The stress was twice as high to the left in the image as to the right.
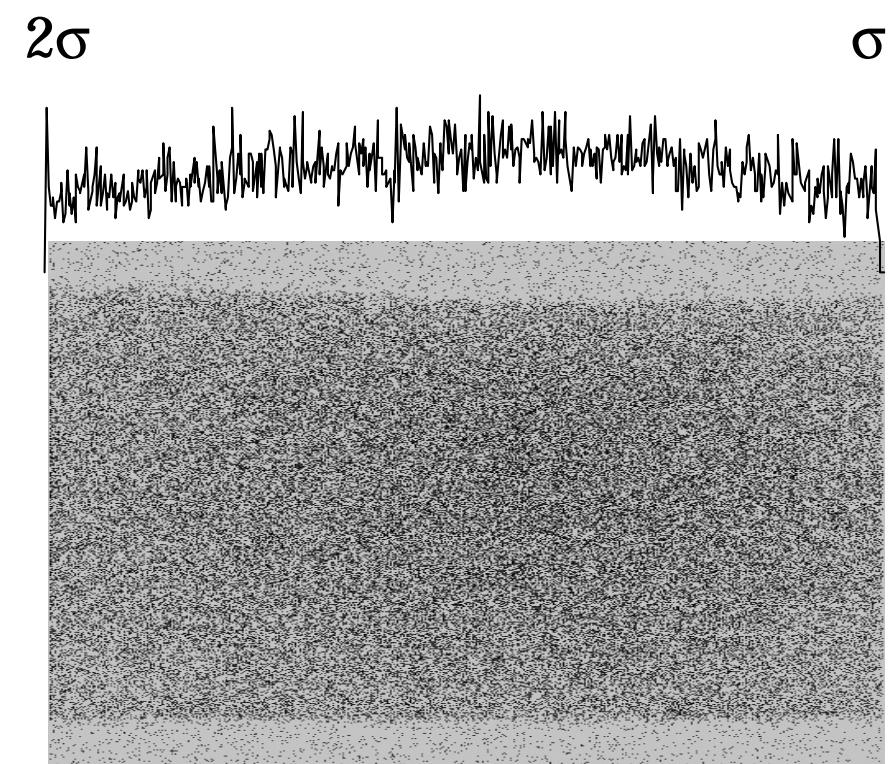

Figure 3.41. ICL image of a HDPE specimen creep-aged with $75 \%$ of load at yield at $110^{\circ} \mathrm{C}$ for 52 hours. The stress was twice as high to the left in the image as to the right.

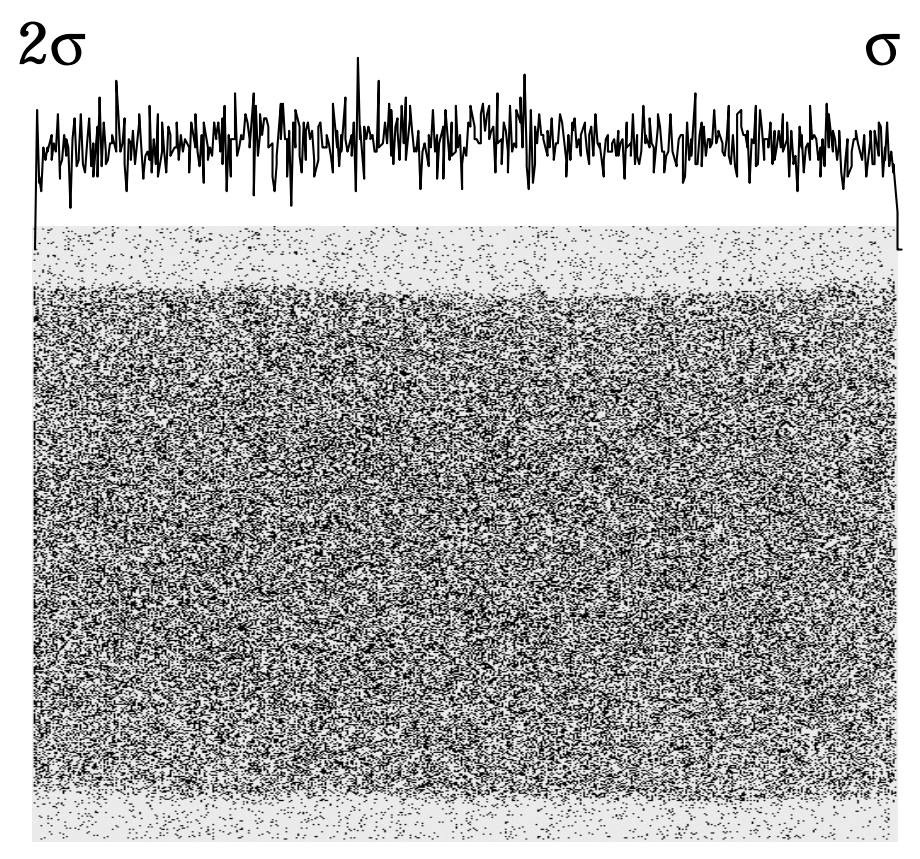

Figure 3.42. ICL image of a PA6 specimen creep-aged with $75 \%$ of load at yield at $130^{\circ} \mathrm{C}$ for 24 hours. The stress was twice as high to the left in the image as to the right.

\subsubsection{General Remarks to the Study}

The present study involves three different polymers, polypropylene, polyethylene and polyamide. These polymers degrade by different reaction pathways (see Section 1.3.1 Oxidation of Polyolefins and Oxidation of Polyamides). Polyamide was investigated both as film and as injection moulded samples. Film can have a 
different oxidative behaviour as compared with thicker injection moulded parts, since it is not limited by oxygen diffusion (see Section 1.3.1 Specific Features of Solid State Oxidation). In none of the materials, including the two different forms of polyamide, was any indication of enhanced oxidation due to an applied load observed.

For a comparison between the results from oxidation of stressed polyamide 6 films and the results from oxidation of films made from other polymers, similar measurements on polypropylene film were performed. However, the PP film oxidised very heterogenously, making any interpretation of the results impossible. In some cases the specimen lost all its mechanical properties due to very localised oxidation in one part, while it was more or less unaffected at the spot where the chemical changes were measured (see Section 1.3.1, Specific Features of Solid State Oxidation).

At room temperature bulky samples, such as the injection moulded specimens used in this study, are expected to oxidise to a depth of the order of a few centimetres, i.e. the $2 \mathrm{~mm}$ thick specimens used here should be homogeneously oxidised (see Section 1.3.1 Specific Features of Solid State Oxidation). However, in order to accelerate the oxidation of the specimens to a feasible time scale, the ageing temperatures were fairly high. This resulted in higher oxidation at the surface than at the core due to diffusion limitation. The nature of the resulting oxidised surface layer differs between the different materials. In PP the surface layer is crumbly and loses all its mechanical properties at an early stage. In HDPE cracks which are formed in the embrittled surface layer will work as fracture initiators. However, the oxidised surface layer in PA6, though very discoloured, still maintains its mechanical properties and does not initiate fracture processes such as those in HDPE. Thus most of the stressed PP and some of the stressed HDPE specimens broke before the maximum in luminescence intensity was reached. The time to fracture thus decreased with load for PP and HDPE specimens. However, as can be seen in Figures 3.27 and 3.28 this was not due to accelerated oxidation but was a result of mechanical degradation of the material. The PA6 specimens, on the other hand, could withstand the mechanical load even though they were highly oxidised. 


\section{CONCLUSIONS}

The most important conclusion that can be drawn from this work is that stress does not accelerate the oxidation of polymers. This conclusion is valid for all the three polymers studied, namely polyamide, polyethylene and polypropylene, which are among the most important engineering polymers. The conclusion applies both to film, in which there is no restricted oxygen diffusion, and to injection moulded parts. The discovery is very important for the design of polymer products in that it gives a better understanding of the degradation mechanisms involved in ageing.

It has also been demonstrated that stress induced chemiluminescence (SCL) can be used to study radical formation at fracture of injection moulded polymers. This has so far only been possible for highly oriented fibres. Polyamide shows radical formation at both ductile and brittle fracture but polyethylene only at ductile fracture after a substantial orientation yielding a fibrous structure. Polypropylene, finally, does not yield any radicals either at ductile or at brittle fracture.

The two abovementioned findings would not have been possible without a penetrating analysis of the different sources responsible for light emission from stressed polymers. This work also helps to explain some of the ambiguous results earlier SCL reports. The emitted light was found to be chemiluminescence, thermoluminescence, triboluminescence or a combination of them. The chemiluminescence was shown to originate mainly from hydroperoxide decomposition due to stress-induced adiabatic heating, which after necking is localised in the travelling neck shoulders. It can be eliminated by treating the specimens with sulphur dioxide and/or heat treatment in inert atmosphere. CL was also found to be due to the abovementioned radical formation at fracture and to oxidation at an elevated temperature. The thermoluminescence was a result of radiation from fluorescent light tubes and could be eliminated by keeping the specimens in the dark prior to a measurement. The triboluminescence was emitted from irradiated specimens in which stress helped to recombine separated charges.

Some of the fields in which the SCL method and the findings reported in this thesis can be used to obtain new knowledge are enumerated in the chapter Suggestions for Future Work.

Summing up it can be concluded that SCL can be a very potent tool for investigating oxidation related properties of stressed polymers. 


\section{SUGGESTIONS FOR FUTURE WORK}

One of the main conclusions that can be drawn from this work is that stress does not have any effect in itself on the oxidation studied. This is, however, not necessarily true for all oxidising systems and there are still a large number of unanswered question in this area. Some suggestions for future work are:

- Continuing the investigation of oxidation under constant load by testing other materials, such as amorphous polyamide and cross-linked systems, e.g. epoxies and rubbers. It would also be informative to repeat this study using lower measuring temperatures in order to verify that the observations are not only valid during accelerated ageing.

- Continuing the work on chemiluminescence at fracture. SCL is the most sensitive existing method for studying the possible radical formation at fracture of polymers. New knowledge of the mechano-chemical degradation of polymers could be obtained.

- Investigating the relative influence of stress and ozone on the degradation of unsaturated rubber materials. Ozone cracks in stressed rubbers is believed to be the first step in the fatigue process. Fatigue is a great practical problem for users of rubber materials. No unambiguous results in this field can be found in the literature, and SCL is probably the most practical and sensitive technique there is for a study of this phenomenon.

- Modifying the SCL instrument by attaching a UV lamp and investigating the effect of both UV light and stress on oxidation. A number of observations are reported in the literature which indicate that stress does have an effect on UV induced oxidative degradation. This type of modification could be possible using cut-off filters protecting the photomultiplier from direct light emitted by the UV lamp. 


\section{ACKNOWLEDGEMENTS}

I would like to start by thanking my head supervisor Associate Professor Bengt Stenberg who sent me to Australia to do my diploma work on stress-induced chemiluminescence and who, upon my return, took me on as his $\mathrm{PhD}$ student on the same subject. I thank him for the very stimulating atmosphere that we have in the "CL group" under his leadership. I am also indebted to Professor Graeme George who was my supervised in Australia and who really awakened my interest in research work.

I owe a debt of gratitude to my assistant supervisors Associate Professor Torbjörn Reitberger and Associate Professor Björn Terselius. I thank Torbjörn especially for his enthusiasm, his constant interest in my work and for all his valuable ideas and Björn for his careful and professional comments on my papers and on this thesis.

I am very thankful to Gunnar Färnert for all his help with the SCL instrument. Rome wasn't built in a day either....

To Professor Ann-Christine Albertsson, Professor Ulf Gedde, Professor Anders Hult, Professor Sigbritt Karlsson, the late Professor Jan-Fredrik Jansson, and Professor Emeritus Bengt Rånby I am grateful for their work on organising and leading the research of the Department of Polymer Technology. I thank Ulf Gedde also for his valuable scientific help and interesting lunch discussions throughout my time at the department.

My thanks are further due to the administrative personnel of the department, Margareta Andersson, Maria Bozena Anderz, Charlotte Warding and Birgitta Asker, for their great work and all the help they have given me over the years. A person at the department who deserves to be specially mentioned is Ove Källberg whose help has been invaluable to me.

Financial support from the Swedish Research Council for Engineering Sciences (TFR), the Axel and Margret Ax:son Johnson Foundation and the Swedish Defence Materiel Administration (FMV) has made this work possible and is gratefully acknowledged.

I am very grateful to Dr. Chris DeArmitt, Dr. Pieter Gijsman, Professor Lyda Rychla and Professor Norman Billingham for their interest in my work and for valuable discussions.

The list of graduate and undergraduate students at the department to whom I am indebted is very long. The ones I would especially like to mention are former and present members of the "rubber group" the super hero Martin Bellander, the crazy king of weird music and horror cooking Gustav Ahlblad, not always acting his age Dan Forsström, the lambada king Tomas Forss, the queen of CL Anna Kron, the politically incorrect Pontus Nordberg and not as innocent as he is looking, Mr power cut Petter Eriksson. Former and present members of "ABB" who have given me a lot of memorable moments (and a sore shoulder) are, among others, the crazy Swiss 


\section{- Acknowledgements -}

sailor Thierry Glauser, Tiger Woods Ronnie Palmgren, party-specialist Kajsa Stridsberg, blondie Maria Ryner, Mr pepparkaka Phillipe Busson, song bird Mikael Krook and squash player Mats Johansson. To my room mates I don't know where he is and I don't know when he'll be back Johan Haasum and the language whiz Walker Camacho I am grateful for many enjoyable and fruitful conversations and their help with all sorts of things from injection moulding to translating Russian articles. Some of my former undergraduate students who deserve special thanks are Fredrik Hyllengren for all the fantastic skiing in Chamonix, Birgitta Westerlund and Roman Ekelöf for continuing the Swedish traditions at QUT and Mathias Puide for all his help with the injection moulding machine.

I have also a number of great friends outside the department who have supported me over the years by being there. Thank you all for your true, or at least well acted, interest in my research and all the fun times we have had.

Finally, I would like to thank my dear family, Sven, Evy, Hans Erik and Bengt, for their endless support and for many dinners with delicious food and interesting discussions and for all the good times we have spent together sailing and skiing. I also thank my father for revising my English. His help has been invaluable to me and I dedicate this thesis to him. 


\section{REFERENCES}

Adams, 1970

Ahlblad et al, 1997

Ahlblad, 1998

Albertsson and Huang, 1995

Albertsson et al, 1992

Allen, 1983

Al-Malaika, 1993

Ashby, 1961

Audouin-Jirackova and Verdu, 1987

Bacon, 1605

Bair, 1973

Barenstedt, 1994

Bateman et al, 1952

Bateman et al, 1953

Bateman, 1954

Billingham, 1989

Billingham and Calvert, 1982

Billingham and Calvert,
Adams, J.H., J. Polym. Sci., A-1, 1970, 8, 1077.

Ahlblad, G., Stenberg, B., Terselius, B. \& Reitberger, T., Polymer Testing, 1997, 16, 59.

Ahlblad, G., PhD thesis "Imaging chemiluminescence Applied to Oxidation of Rubber Materials and Polyamide", Royal Institute of Technology, Stockholm, Sweden, 1998.

Albertsson, A-C. \& Huang, S.J., "Degradable Polymers, Recycling and Plastics Waste Management", Marcel Dekker Inc., New York, 1995.

Albertsson, A-C., Barenstedt, C. \& Karlsson, S., Polym. Deg. Stab., 1992, 37, 163.

Allen, N.S. "Degradation and Stabilisation of Poleolefins", Applied Science Publishers Ltd., London and New York, 1983.

Al-Malaika, S., in "Atmospheric Oxidation and Antioxidants", Ed. Scott, G., Vol.I, Elsevier Publishing Company, Amsterdam, 1993, Ch. 2

Ashby G. E., J. Polym. Sci., 1961, 50, 99.

Audouin-Jirackova, L. \& Verdu, J., J. Polym. Sci., Polym. Chem., 1987, 25, 1205.

Bacon, F., "The Advancement of Learning", 1605

Ed. Kitchin, G.W., Rowman and Littlefield University Library, London 1978.

Bair, H.E., Technical Papers / Soc. Plast. Eng., 1973, 19, 106.

Barenstedt, C., PhD thesis "Environmental Degradation of Starch-modified Polyethylene: Degradation Products and Longterm Properties", Royal Institute of Technology, Stockholm, Sweden, 1994.

Bateman, L. \& Hughes, H., J. Chem. Soc., 1952, 4594.

Bateman, L., Hughes, H. \& Morris, A.L., Discuss. Faraday Soc., 1953, 14, 190.

Bateman, L., Quart. Rev. Chem. Soc., 1954, 8, 147.

Billingham, N.C., Macromol. Chem., Macromol. Symp., 1989, 28, 145.

Billingham N.C., Calvert, P.D., in "Developments in Polymer Stabilisation-5", Ed. Scott, G., Applied Science Publishers Ltd, 1982, Oxford, Ch. 5

Billingham, N.C., Calvert, P.D., in "Degradation and 


\section{References}

1983

Billingham et al, 1976

Billingham et al, 1988

Billingham et al, 1991

Billmeyer, 1984

Bolland, 1949

Bolland and Gee, 1946

Boustead and Charlesby, 1970

Brolin and Wettermark, 1992

Bresler et al, 1959

Brydson, 1995

Buchachenko,1976

Bueche, 1955

Bueche, 1957

Bueche, 1958

Butyagin et al, 1965

Butyagin et al, 1970

Carlsson and Wiles, 1976

Carothers, 1929

Casale and Porter, 1978

Ceresa and Watson, 1959

Chakraborty and Scott,
Stabilisation of Polyolefines", Ed. Allen, N.S., Applied Science Publishers Ltd, London and New York, 1983

Billingham, N.C., Prentice, P. \& Walker, T.J., J. Polym. Sci., Symp., 1976, 57, 287.

Billingham, N.C., Burdon, J.W., Kakulska, I. W., O'Keefe, E.S. \& Then, E.T.H., Proc. Int. Symp. Lucerne, 1988, $2,11$.

Billingham, N.C., Then, E.T.H \& Gijsman, P.J., Polym. Deg. Stab., 1991, 34, 263.

Billmeyer, F.W., Textbook of Polymer Science, 3:rd ed. John Wiley \& Sons, Inc., Singapore, 1984

Bolland, J.L., Quart. Rev. Chem. Soc., 1949, 3, 1.

Bolland, J.L. \& Gee, G., Trans. Farraday Soc., 1946, 42, 236.

Boustead, I. \& Charlesby, A., Proc. Roy. Soc. Lond., A 316 (1970) 291.

Brolin, S., Wettermark, G., "Bioluminescence Analysis", VCH, Weinheim, 1992

Bresler, S.E., Zhurkov, S.N., Kazbekov, E.N., Saminskii, E.M. \& Tomashevskii, F.E., Zh. Tekh. Fiz., 1959, 29, 358.

Brydson, J.A., "Plastics Material", 6:th ed., ButterworthHeinemann Ltd, Oxford, 1995

Buchachenko, A.L, J. Polym. Sci., Symp., 1976, 57, 299.

Bueche, J.J. Appl. Phys., 1955, 26, 1133.

Bueche, J. J. Appl. Phys., 1957, 28, 784.

Bueche, J. J. Appl. Phys., 1958, 29, 1231.

Butyagin, P.Yu., Drozdovskii, V.F., Razgon, D.R. \& Kolbanov, I.V., Fiz. Tverd. Tela, 1965, 7, 941.

Butyagin P.Yu, Yerofeyev V.S., Musalyelyan I.N., Patrikeyev G.A., Streletskii A.N. and Shulyak A.D., Polym. Sci. USSR, 1970, 12330.

Carlsson, D.J., Wiles, D.M., J. Macromol.Sci., Rev. Macromol. Chem., 1976, C14, 65

Carothers, W.H., J. Am. Chem. Soc., 1929, 51, 2548.

Casale, A. \& Porter, R.S., "Polymer Stress Reactions", Academic Press, New York, 1978.

Ceresa, R.J. \& Watson, W.F., J. Appl. Polym. Sci., 1959, 1, 101.

Chakraborty, K.B. \& Scott, G., Europ. Polym. Press, 1977, 13, 
1977

Charlesby, 1991

Charlesby and Partrige, 1963

Chien and Jabloner, 1968

Clough et al 1996

Czerny, 1972

Dickinson, 1990

Dickinson et al, 1993

Dickinson et al, 1994

Fanter and Levy, 1979

Fleming, 1990

Fleming and Craig, 1992

Fleming and Hagekyriakou, 1984

Forsström, 1999

Forsström et al, 1999

George, 1989a

George, $1989 b$

George et al, 1982

George et al, 1983

George and O'Shea, 1989
731.

Charlesby, A., in "Irradaition effects on Polymers", Eds. Clegg, D.W. \& Collyer, A.A., Elsevier Applied Science, London and New York, 1991, Ch 2.

Charlesby, A. \& Partridge, R. H., Proc. Roy. Soc. Lond., A 271 (1963) $170,188$.

Chien, J.C. \& Jabloner, H., J. Polym. Sci., A-1, 1968, $6,393$.

Clough, R.L., Billingham, N.C. and Gillen, K.T. (Eds.) "Polymer Durability", ASC Adv. Chem. Ser.,1996

Czerny, J., J. Appl. Polym. Sci., 1972, 16, 2623.

Dickinson, J. T., Non-destructive Testing of Fibre-reinforced Plastics Composites, Vol. 2, Ed. Summerscales, Elsevier Applied Science, London, 1990, p 429.

Zimmerman, K.A., Langford, S.C., Dickinson, J.T. \& Dion, R.P., J. Polym. Sci. Part B: Polym. Phys., 1993, 31, 1229.

Dickinson, J.T., Jensen, L.C., Langford, S.C. \& Dion, R.P., J. Polym. Sci., Part B Polym. Phys., 1994, 32,

Fanter D. L. and Levy R. L., ACS Symp. Ser., 1979, 95, 211.

Fleming, R.J., Radiat. Phys. Chem., 36 (1990) 59.

Fleming, R.H \& Craig, A.Y., Polym. Deg. Stab., 1992, 37, 173.

Fleming, R.J. \& Hagekyriakou, ?, Radiat. Protect Dosim., 8 (1984) 99.

Forsström, D., PhD thesis "Novel Techniques for Characterisation of the Oxidative Stability of Polyamides", Royal Institute of Technology, Stockholm, Sweden, 1999

Forsström, D., Terselius, B., Svensson, L-G. \& Paulsson, L-E., submitted to Polym. Deg. Stab., 1999.

George, G.A., in "Luminescence Techniques in Solid State Polymer Research", Ed. Zlatkevich, L., Marcel Dekker Inc., New York, 1989, Ch. 1

George, G.A., in "Luminescence Techniques in Solid State Polymer Research", Ed. Zlatkevich, L., Marcel Dekker Inc., New York, 1989, Ch. 3

George G. A., Egglestone G. T. and Riddell S. Z., J. Appl. Polym. Sci., 1982, 27, 3990.

George, G. A., Egglestone, G. T. \& Riddell, S. Z., Polym. Eng. Sci., 1983, 23, 412 .

George, G.A. \& O’Shea, M.S., Materials Forum, 1989, 13, 11 
George and O’Shea, 1990

Gijsman, 1994

Gijsman et al, 1993

Gillen and Clough, 1989

Glasstone et al, 1941

Gugumus, 1987

Hakkarinen, 1996

Hendry and Russell, 1964

Hiatt et al, 1968

Hoffman, 1861

Holmström and Sörvik, 1976

Hosoda et al, 1993

Ingold, 1967

Jellinek, 1978

Kamiya, 1966

Kamiya and Niki, 1978

Karstens and Rossbach, 1989

Kausch, 1978

Kauzmann and Eyring,
George, G.A. \& O'Shea, M.S., Polym. Deg. Stab., 1990, 28, 289.

Gijsman, P. PhD thesis "The Long-Term Stability of Poleolefins", University of Eindhoven, Holland, 1994

Gijsman, P., Hennekens, J. \& Vincent, J., Polym. Deg. Stab., 1993, 42, 95

Gillen, K.T. \& Clough, R.L., in "Handbook of Polymer Science and Technology Vol. 2: Performance Properties of Plastics and Elastomers", Ed. Cheremisinoff, N.P., Marcel Dekker, 1989, Ch. 6.

Glasstone, S., Laider, K.J. \& Eyring, H., "The theory of Rate Processes", McGraw Hill, New York, 1941.

Gugumus, F., in "Developments in Polymert Stabilisation", Vol. 8, Ed Scott, G., Elsevier Applied Science Publishers, London, 1987, Ch 6.

Hakkarinen, M. PhD thesis "Degradation Products and Mechanisms in Hydrolysable and Oxidisable Environmentally Adaptable Polymers", Royal Institute of Technology, Stockholm, Sweden, 1996

Hendry, D.G. \& Russell, G.A., J. Am. Chem. Soc., 1964, 86, 2371.

Hiatt, R., Mill, T. \& Mayo, F.R., J. Org. Chem., 1968, 33, 1416.

Hoffman, A.W., J. Chem. Soc., 1861, 13, 87.

Holmström, A. \& Sörvik, E.G..M, J. Polym. Sci., Symp., 1976, $\mathbf{5 7}, 33$.

Hosoda S., Seki Y. and Kihara H., Polym., 1993, 34, 22.

Ingold, K.U., Pure Appl. Chem., 1967, 15, 49.

Jellinek, H.H.G., "Aspects of Degradation and Stabilistation of Polymers", Elsevier Scientific Publishing Company, Amsterdam, 1978,

Kamiya, Y., J. Polym. Sci., 1966, B-4, 999.

Kamiya, Y. \& Niki, E.G., in "Aspects of Degradation and Stabilistation of Polymers", Ed. Jellinek, H.H.G., Elsevier Scientific Publishing Company, Amsterdam, 1978, Ch. 3.

Karstens, T. \& Rossbach, V., Makromol. Chem., 1989, 190, 3033.

Kausch, H.H., "Polymer Fracture", Springer-Verlag, Heidelberg, 1978

Kauzmann, W. \& Eyring, H., J. Am. Chem. Soc., 1940, 62, 3113. 
1940

Klason and Kubat, 1997

Knight et al, 1985

Kron, 1996

Kron et al, 1996

Kron et al, 1997

Lacey and Dudler, 1996a

Lacey and Dudler, $1996 b$

Lacey and Dudler, 1996c

Lánská et al, 1998

Lemair et al, 1991

Lemair et al, 1996

Levantovskaya et al, 1964

Lloyd et al, 1972

Lloyd et al, 1974

Malmström et al, 1998

Markiewicz and Fleming, 1988

Matisová-Rychlá and Rychly, 1996

Matisová-Rychlá et al, 1978
Klason, C., Kubat, J., "Plaster - Materialval och Materialdata, 4:th ed., Sveriges Verkstadsindustrier", Förlags AB Industrilitteratur, 1997

Knight, J.B., Calvert, P.D. \& Billingham, N.C., Polymer, 1985, 26, 1713.

Kron, A., $\mathrm{PhD}$ thesis "Chemiluminescence Applied to Oxidation of Polyolefins", Royal Institute of Technology, Stockholm, Sweden, 1996

Kron, A., Stenberg, B., Reitberger, T. \& Billingham, N.C., Polym. Deg. Stab., 1996, 53, 119.

Kron, A., Stenberg, B. \& Reitberger, T.,Polym. International, 42 (1997) 131.

Lacey, D. \& Dudler, V., Polym. Deg. Stab., 1996, 51, 101.

Lacey, D. \& Dudler, V., Polym. Deg. Stab., 1996, 51, 109.

Lacey, D. \& Dudler, V., Polym. Deg. Stab., 1996, 51, 115.

Lánská B., Matisová-Rychlá L. \& Rychly J., Polym. Deg. Stab., 1998, 61, 119.

Lemaire, J., Arnaud, R. \& Gardette, J. L., Polym. Deg. Stab., 1991, 33, 277.

Lemaire, J., Gardette, J.L., Lacoste, J., Delprat, P. \& Vaillant, D., in "Polymer Durability", eds. Clough, R.L., Billingham, N.C. \& Gillen, K.T., ACS Adv. Chem. Ser., 1996, p. 577.

Levantovskaya, I.I., Kovarskaya, B.M., Dralyuk, G.V. \& Neiman, M.B., Vysokomol. Soed., 1964, 6, 1885.

Lloyd, B.A., DeVries, K.L. \& Williams, M.L., J. Polym. Sci., A-2, 1972, 10, 1415.

Lloyd, B.A., DeVries, K.L. \& Williams, M.L., Rheol. Acta, 1974, 13, 352 .

Malmström, J., Engman, L., Bellander, M., Jacobson, K., Stenberg, B., Lönnberg V., J. Appl. Polym. Sci., 1998, 70, 449.

Markiewicz, A. \& Fleming, R.J., J. Phys. D: Appl. Phys. 1988, 21, 349

Matisová-Rychlá, L. \& Rychly, J., in "Polymer Durability", eds. Clough, R.L., Billingham, N.C. \& Gillen, K.T., ACS Adv. Chem. Ser., 1996, Ch. 12

Matisová-Rychlá, L., Rychly, J. \& Vavrekova, M., Eur. Polym. J., 1978, 14, 1033. 


\section{References}

Matisová-Rychlá et al, 1980 Matisová-Rychlá, L., Fodor, Zs., Rychly, J. \& Iring, M., Polym. Deg. Stab., 1980-81, 3, 371.

Mattson, 1993

Mattson, B., PhD thesis "Thermo-oxidative Degradation and Stabilisation of Rubber Materials", Royal Institute of Technology, Stockholm, Sweden, 1993

Mayo, 1978

McKeever, 1985

Mayo, F.R., Macromolecules, 1978, 11, 942.

McKeever, S.W.S., in "Thermoluminescence of solids", Cambridge Uni. Press, Cambridge, 1985, Ch. 1.

Mendenhall, 1977

Mendenhall et al, 1978

Mendenhall G. D., Angew. Chem. Int. Ed. Engl., 1977, 16, 225.

Mendenhall, G.D., Nathan, R.A. \& Golub, M.A., in "Applications of Polymer Spectroscopy", Ed Brame, E.G., Academic Press, New York, 1978, Ch. 8.

Miller and Mayo, 1956

Miller, A.A. \& Mayo, F.R., J. Am. Chem. Soc., 1956, 78, 1017.

Monaco and Richardson, 1989

Monaco S. B. and Richardson J. H., in Luminescence Techniques in Solid State Polymer Research, Zlatkevich L. (ed.) Marcel Dekker, Inc., New York, 1989, p. 237.

Natta et al, 1955

Natta, G., Pino, P., Corradini, P., Danusso, F., Mantica, E., Mazzanti, G. \& Moraglio, G., J. Am. Chem. Soc., 1955, 77, 1708.

Niki et al, 1973

Niki, E., Decker, C, Mayo, F.R., J. Polym. Sci., Polym. Chem. Ed., 1973, 11, 2813

O'Shea, 1987

O'Shea, M.S., M. App. Sc. thesis "Studies of the Degradation of Stressed Polyamides" Queensland University of Technology, Australia, 1987.

Palmgren, 1997

Palmgren, R. PhD thesis "Degradable Elastomers", Royal Institute of Technology, Stockholm, Sweden, 1997

Peterlin, 1969

Peterlin, A., J. Polym. Sci., A-2., 1969, 7, 1151.

Peterlin, 1971

Peterlin, A., Polym. Sci. Symp., 1971, 32, 297.

Peterlin, 1981

Peterlin, A., J. Macromol. Sci. Phys., 1981, B19, 401.

Pike and Watson, 1952

Pike, M. \& Watson, W.F., J. Polym. Sci., 1952, 9, 229

Polymer Handbook, 1989

Popov et al, 1984

Polymer Handbook - 3rd ed., Eds. Bandrup, J. \& Immergut, E. H., John Wiley \& Sons, 1989.

Popov, A.A., Blinov, N.N., Krisyuk, B.E: \& Zaikov, G.E., Polym. Deg. Stab., 1984, 7, 33.

Popov et al, 1991

Popov, A., Rapoport, N.Ya. \& Zaikov, G.E., "Oxidation of Stressed Polymers", Gordon \& Breach, 1991 [Translation of Okislenie orientirovannykh i napryazhennykh polimerov, Khimiya, Moscow, 1987]

Quinga and Mendenhall, Quinga, E.M.Y. \& Mendenhall, G.D., J. Am. Chem. Soc., 1983, 
1983

Rabello and White, 1997

Rapoport and Zaikov, 1985

Reich and Stivala, 1969

Reich et al, 1971

Renschler, 1985

Renschler et al, 1984

Richters, 1970

Roylance, 1978

Russell, 1957

Rust, 1957

Rånby and Rabek, 1975

Rånby and Rabek, 1977

Schard and Rusell, 1964

Scott, 1965

Scott, 1984

Scott, 1993

Sharkey and Moechel, 1959

Skoog and Leary, 1992

Staudinger, 1929

Terselius et al, 1986
105,6520 .

Rabello, M.S. \& White, J.R., Polym. Deg. Stab., 1997, 56, 55.

Rapoport, N.Ya \& Zaikov, G.E., in "Developments in Polymer Degradation-6", Ed. Grassie, N., Elsevier Applied Science Publishers, London, 1985, p. 207.

Reich, L., Stivala, S.S., "Autooxidation of Hydrocarbons and Polyolefins", Dekker, New York, 1969

Reich, L., Jadrnicek, B.R. \& Stivala, S.S., Polym. Eng. Sci., 1971, 11, 265.

Renschler, C. L., J. Mater. Sci. Letters, 1985, 4, 707.

Renschler, C. L. \& Burns, F. B., J. Appl. Polym. Sci., 1984, 29, 1125 .

Richters, P., Macromolecules, 1970, 3, 262.

Roylance, D.K., in "Applications of Polymer Spectroscopy", Ed Brame, E.G., Academic Press, New York, 1978, Ch. 13.

Russell, G.A., J. Am. Chem. Soc., 1957, 79, 3871.

Rust, F.F., J. Am. Chem. Soc., 1957, 79, 4000.

Rånby, B., Rabek, J.F., "Photodegradation, Photo-oxidation and Photostabilization of Polymers", John Wiley \& Sons, London, 1975

Rånby, B. \& Rabek, J.F., "ESR Spectroscopy in Polymer Research", Springer, Berlin Heidelberg, 1977.

Schard M.P. and Russell C.A., J. Appl. Polym. Sci., 1964, 8, 985.

Scott, G., "Atmospheric Oxidation and Antioxidants", Elsevier Publishing Company, Amsterdam, 1965

Scott, G.,Polym. Eng. Sci., 1984, 24, 1007.

Scott, G., in "Atmospheric Oxidation and Antioxidants", Ed. Scott, G., Vol. I, Elsevier Publishing Company, Amsterdam, 1993, Ch. 1

Sharkey, W.H. \& Moechel, W.E., J. Am. Chem. Soc., 1959, 81, 3000 .

Skoog, D.A. \& Leary, J.J, " Principles of Instrumental Analysis", 4 ed., Sauders College Publishing, Fort Worth, 1992, Ch. 9.

Staudinger, H., Kautschuk, 1929, 5, 128.

Terselius, B., Gedde, U.W. \& Jansson, J.F., in "Failure of 
Plastics”, Eds. Brostow, W. \& Corneliussen, R.D., Hanser Publishers, Munich, 1986, Ch. 14

Tobolsky and Eyring, 1943

Van Sickle, 1972

Van Sickle et al, 1973

Vasil'ev, 1970

Viebke, 1996

White and Rapoport, 1994

White and Turnbull, 1994

Zhurkov et al, 1953

Zhurkov et al, $1955 a$

Zhurkov et al, $1955 b$

Zhurkov et al, 1964

Zhurkov et al, 1972

Zink, 1978

Zlatkevich, 1985

Zlatkevich, 1989

Zlatkevich, 1997

Ziegler et al, 1955

Zolotova and Denisov, 1971
Tobolsky, A. \& Eyring, H., J. Chem. Phys., 1943, 11, 125

Van Sickle, D.E., J. Org. Chem., 1972, 37, 755.

Van Sickle, D.E., Mill, T., Mayo, F.R., Richardson, H. \& Gould, C., J. Org. Chem., 1973, 38, 4435.

Vasil'ev, R.F., Russ. Chem. Rev., 1970, 39, 529.

Viebke, J., PhD thesis "Theoretical Asbects and Experimental Data on the Detoriation of Polyolefin Hot-Water Pipes", Royal Institute of Technology, Stockholm, Sweden, 1996

White, J.R. \& Rapoport, N.Ya.,Trends in Polymer Science, 1994, 6, 197.

White J. R. and Turnbull A., J. Mater. Sci.,1994, 29, 584-613.

Zhurkov, S.N. \& Narzullayev, B.N., Zhur. Techn. Fiz, 1953, 23, 1677

Zhurkov, S.N. \& Tomashevskii, E.Ye., Zhur. Techn. Fiz., 1955, 25, 66

Zhurkov, S.N. \& Sanfirova, T.P., Dokl. Akad. Nauk SSSR, 1955, 237, 101

Zhurkov, S.N., Savostin, A.Y. \& Tomashevskii, E.E, Dokl. Akad. Nauk SSR, 1964, 159, 303..

Zhurkov, S.N., Zakrevskii, V.A. , Korsukov, V.E. \& Kuksenko, V.S., Soviet Physics - Solid State, 1972, 13, 1680

Zink, J.I., Accts. Chem. Res., 1978, 11, 289

Zlatkevich, L., J. Polym. Sci., Polym. Phys. Ed., 1985, 23, 1691.

Zlatkevich, L., in "Luminescence Techniques in Solid State Polymer Research", ed. Zlatkevich, L., Marcel Dekker, Inc., New York, 1989, Ch. 7.

Zlatkevich, 1., Die Angew. Mak. Chem., 1997, 252, 257

Ziegler, K., Holzkamp, E.G., Breil, H. \& Martin, H., Angew. Chem., 1955, 67, 426

Zolotova, N.V. \& Denisov, E.T., J. Polym. Sci., A-1, 1971, 9, 3311. 
1.1 Purpose of Study....................................................................................... 1

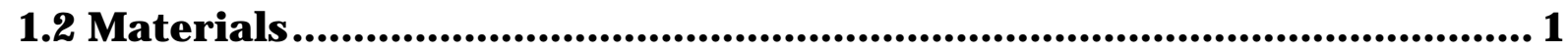

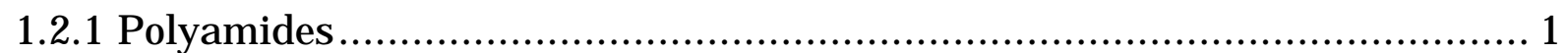

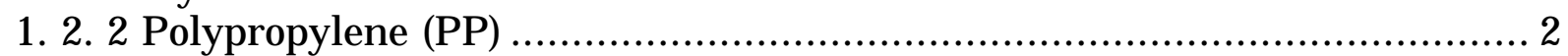

1.2.3 High Density Polyethylene (HDPE) ........................................................ 3

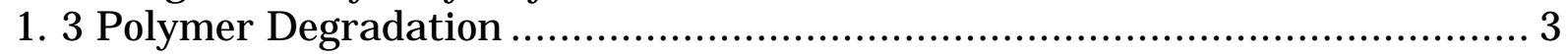

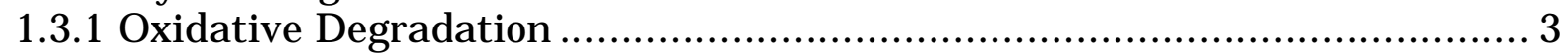

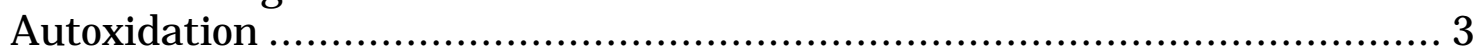

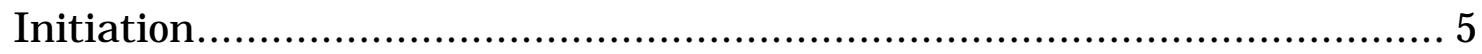

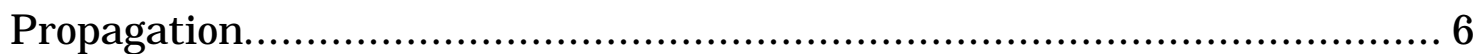

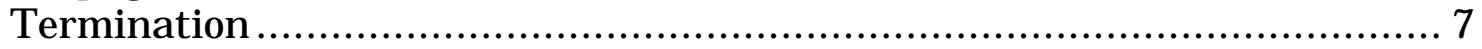

Specific Features of Solid State Oxidation............................................ 7

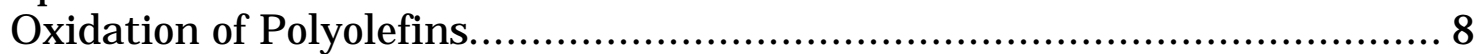

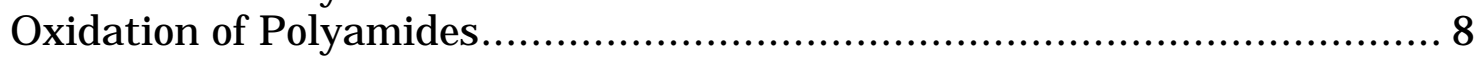

Embrittlement due to Oxidation......................................................... 9

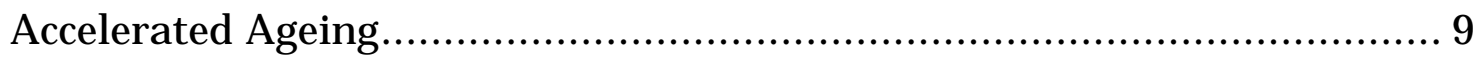

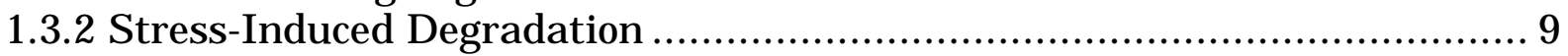

1.3.3 Stress-Induced Oxidative Degradation .................................................... 11

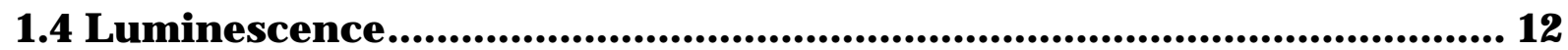

1.4.1 Luminescence Phenomena................................................................ 12

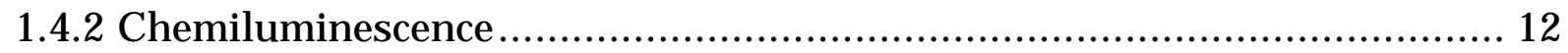

Chemiluminescence in Oxidative Atmosphere ......................................... 14

Chemiluminescence in Inert Atmosphere ............................................. 14

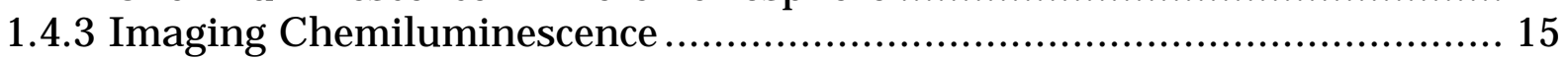

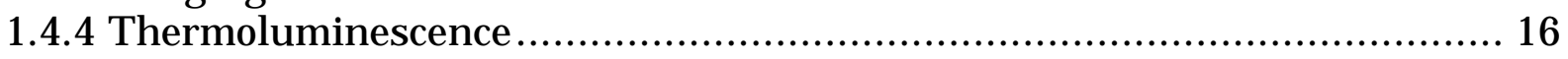

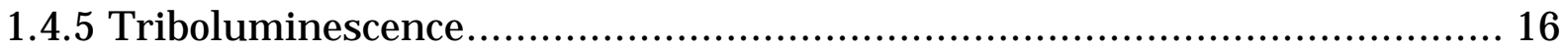

1.4.6 Stress-Induced Chemiluminescence ................................................... 17

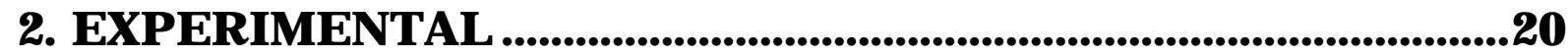

2.1 Materials and Processing............................................................................ 20

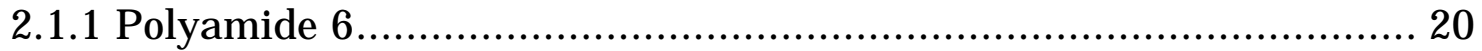

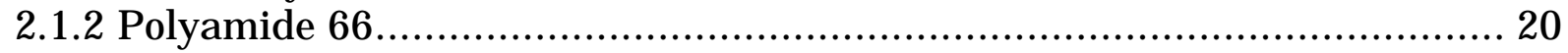

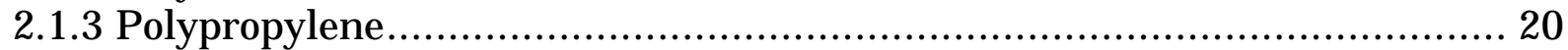

2.1.4 High Density Polyethylene ............................................................... 20

2.1.5 Injection Moulded Tensile Specimens ……......................................... 20

2.2 Ageing Conditions and Treatments ................................................... 21

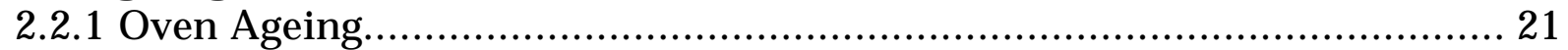

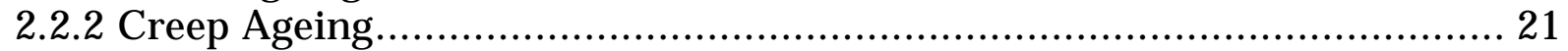

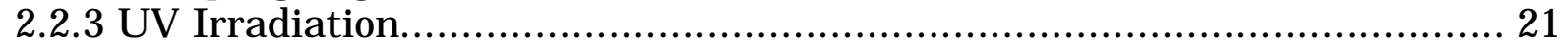

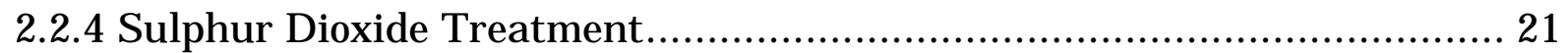

2.3 Analytical Techniques............................................................................ 22

2.3.1 Stress-Induced Chemiluminescence (SCL) ……................................... 22

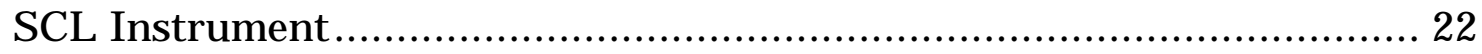

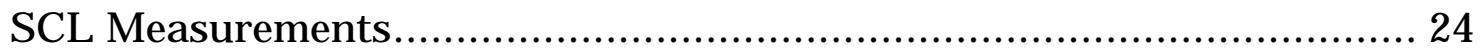

2.3.2 Conventional Chemiluminescence (CL) .......................................... 25

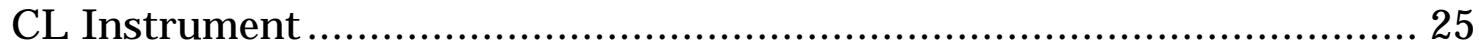

CL Measurements in Oxidative Atmosphere ......................................... 25 
CL Measurements in Inert Atmosphere............................................ 25

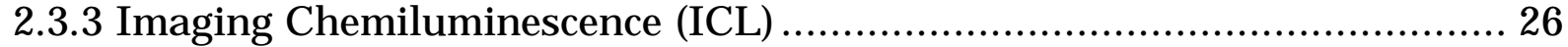

ICL Instrument................................................................. 26

ICL Measurements in Oxidative Atmosphere .................................... 26

ICL Measurements in Inert Atmosphere .......................................... 26

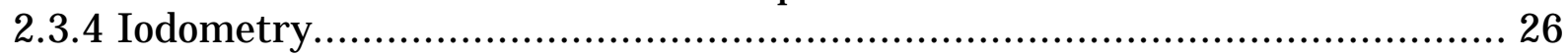

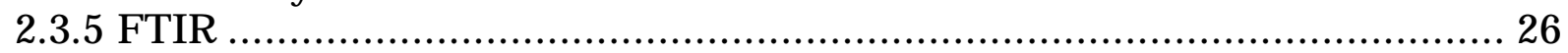

2.3.6 Ultaviolet Spectroscopy .......................................................... 27

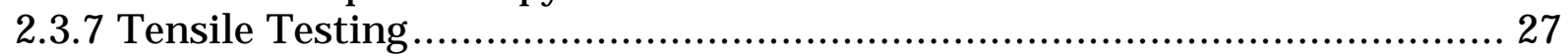

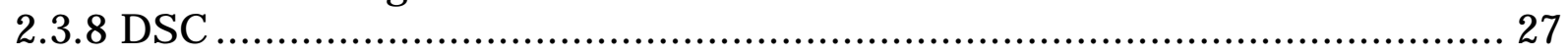

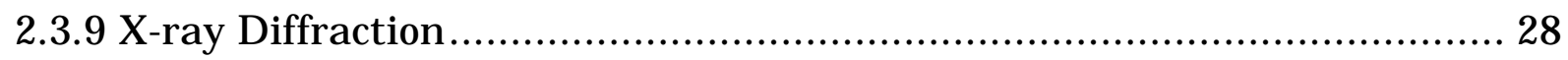

3. RESULTS AND DISCUSSION .........................................................30

\subsection{Luminescence Observed during Tensile Testing of Injection Moulded}

Polyamides ................................................................................................................ 30

3.1.2 Geometrical Factors Influencing Luminescence............................. 32

3.1.3 Relation between Luminescence Intensity and Stress Induced Adiabatic

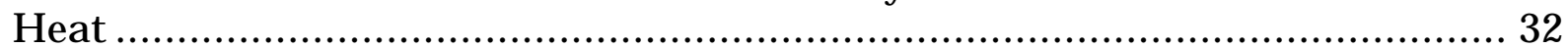

3.1.4 Factors Affecting Luminescence Intensity and Stress Induced Adiabatic

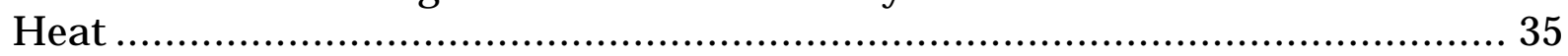

3.1.5 Factors Affecting Luminescence Intensity but not Stress Induced Adiabatic

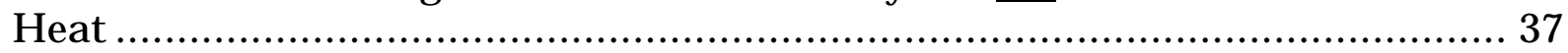

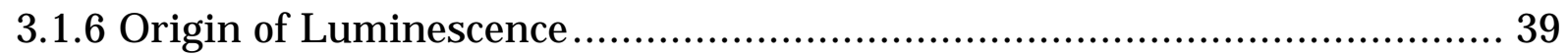

3.2 Luminescence at Fracture ....................................................... 42

3.3 Influence of Thermoluminescence.................................................. 50

3.3.1 Observations of Additional Luminescence During SCL Measurements .... 50

3.3.2 Investigation of the Origin of Additional Luminescence ...................... 50

3.3.3 Stress Induced Luminescence...................................................... 54

3.3.4 General Considerations of the Influence of TL on CL Measurements....... 58

3.4 Oxidation of Polymers During Constant Load.................................. 59

3.4.1 SCL Results ................................................................................ 59

3.4.2 Chemical, Physical and Mechanical Properties of Creep-Aged Specimens . 64

3.4.3 ICL Images of Creep-Aged Specimens ....................................... 71

3.4.4 General Remarks to the Study ................................................... 74

4. CONCLUSIONS .............................................................................6

5. SUGGESTIONS FOR FUTURE WORK.............................................77

6. ACKNOWLEDGEMENTS .............................................................78

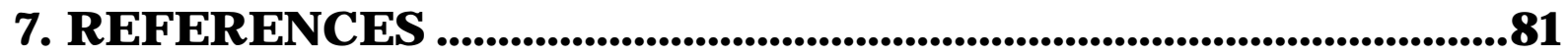

